\title{
Production of Actinium-225 via High Energy Proton Induced Spallation of Thorium-232
}

\author{
Final Technical Report \\ DE-SC0003602
}

\begin{abstract}
Applicant/Institution: NorthStar Medical Radioisotopes, LLC
Street Address: 706 Williamson Street, Suite 2, Madison, WI 53703

Principal Investigator: James T. Harvey

Address: 706 Williamson Street, Suite 2, Madison, WI 53703

Telephone Number: 630-904-4227

Email: jharvey@northstarnm.com

DOE/Office of Science Program Office: Office of Science

DOE/Office of Science Program Manager Contact: Dennis Phillips

National Laboratory Collaborators (funded separately):
\end{abstract}

Argonne National Laboratory - PI: Jerry Nolen (ANL-PHY) and George Vandegrift (ANL-CSE)

Fermi National Accelerator Laboratory - PI: Tom Kroc 


\section{Executive Summary}

The effort described herein to investigate an alternative production route for actinium-225 that does not utilize any DOE legacy materials derived from uranium-233 was proven successful at the proof-of-principle level. Actinium-225 is a potential therapeutic agent for cancer and infectious diseases but research efforts have been hampered by the lack of supply and the high costs of current production methods. The investigation of this new production route targets the elimination of both these issues by providing a potential route that can produce in one day more actinium-225 than the current world's annual output and reduce the costs of the material by as much as a factor of ten. This effort demonstrates the production route is feasible. By demonstrating the potential of the production route, this effort demonstrates supply and costs issues plaguing research and clinical development with actinium-225 can be resolved. Resolution of both supply and costs issues allows clinical research to proceed through clinical trials and potentially produce one or more effective therapies for cancer or infectious diseases that could benefit the public. The effort also demonstrated that other radioisotopes with potential medical significance can be co-produced. 


\section{Comparison of Accomplishments with Goals}

\begin{tabular}{|c|c|c|c|}
\hline Task & Result & Responsibility & Schedule \\
\hline $\begin{array}{l}\text { 1. Reaction Yields } \\
\text { and Radiological } \\
\text { Simulations }\end{array}$ & $\begin{array}{l}\text { MCNPx/CINDER and FLUKA } \\
\text { calculations completed and report } \\
\text { provided to FNAL for review on June } \\
1,2010 . \quad \text { Revised report issued } \\
\text { September } 28,2010 \text { with additional } \\
\text { information requested by FNAL and } \\
\text { ANL and was part of the MOU. }\end{array}$ & $\begin{array}{l}\text { NMR, ANL-PHY, } \\
\text { FNAL }\end{array}$ & Completed \\
\hline \multicolumn{4}{|l|}{$\begin{array}{l}\text { 2. Design \& Test } \\
\text { Target Assembly }\end{array}$} \\
\hline 2a. Design & $\begin{array}{l}\text { Meeting held at FNAL on June } 21 \text {, } \\
2010 \text { to discuss Task } 1 \text { report, } \\
\text { discuss FNAL operations requested } \\
\text { information on proposed irradiation, } \\
\text { and first discussion on target holder } \\
\text { concepts. Walk through of proposed } \\
\text { irradiation area occurred on July } 29 \text {, } \\
2010 \text {. }\end{array}$ & $\begin{array}{l}\text { NMR, ANL-PHY, } \\
\text { FNAL }\end{array}$ & Completed \\
\hline 2b. Fabricate/Acquire & $\begin{array}{l}\text { ANL-PHY has prepared drawings for } \\
\text { the target holder and target holder } \\
\text { stand to be used for the irradiation. } \\
\text { Drawings were part of the MOU. }\end{array}$ & $\begin{array}{l}\text { NMR, ANL-PHY, } \\
\text { FNAL }\end{array}$ & Completed \\
\hline 2c. Install \& Test & $\begin{array}{l}\text { Target and target holder ready for } \\
\text { installation and irradiation. }\end{array}$ & $\begin{array}{l}\text { NMR, ANL-PHY, } \\
\text { FNAL }\end{array}$ & Completed \\
\hline 3. Irradiations & $\begin{array}{l}\text { Irradiation completed on June } 7 \text {, } \\
2011 . \text { Total proton count was } \\
9.36 \mathrm{E} 16 \text {. }\end{array}$ & FNAL & Completed \\
\hline \multicolumn{4}{|l|}{$\begin{array}{l}\text { 4. Chemical } \\
\text { Separations and } \\
\text { Product Evaluation }\end{array}$} \\
\hline $\begin{array}{l}\text { 4A. Chemical } \\
\text { Separations }\end{array}$ & $\begin{array}{l}\text { Target was delivered to ANL week of } \\
\text { June } 13^{\text {th }} \text { Gamma spectra taken } \\
\text { week of June } 20^{\text {th }} \text {. Chemical } \\
\text { separations started first week of July. }\end{array}$ & NMR, ANL-CSE & Completed \\
\hline $\begin{array}{l}\text { 4B. Product } \\
\text { Evaluation }\end{array}$ & Evaluated actinium- 225 product & NMR, ANL-CSE & Completed \\
\hline $\begin{array}{l}\text { 5. mAb Labeling and } \\
\text { Evaluation }\end{array}$ & $\begin{array}{l}\text { Task not performed due to failure of } \\
\text { the Ac } 225 \text { to arrive from ORNL in } \\
\text { time as result of order processing } \\
\text { difficulties at ANL. }\end{array}$ & NMR & Not Done \\
\hline $\begin{array}{l}\text { 6. Project Technical } \\
\text { Report }\end{array}$ & Submitted & NMR & Completed \\
\hline
\end{tabular}




\section{Project Objectives}

\section{Background}

The science of cancer research is currently expanding its use of alpha particle emitting radioisotopes. Coupled with the discovery and proliferation of molecular species that seek out and attach to tumors, new therapy and diagnostics are being developed to enhance the treatment of cancer and other diseases. Some of these molecules have the ability to be conjugated with a radioisotope whereby the radioactivity can be delivered directly to the cells to be treated. Some of today's therapies involve high-energy beta emitters. Research is showing promise that an even more effective therapy can be developed with alpha emitters - with far less side effects and patient discomfort. This latest technology is commonly referred to as Alpha Immunotherapy (AIT) or Targeted Alpha Therapy (TAT). Scientists are looking for ways to minimize side effects by using radioisotopes that produce alpha radiation, which has the benefit of a short destructive path and minimizes damage to adjacent healthy tissue. Depending on the isotope, another desirable feature is that the carrier molecules have far more success of reaching the tumor sites without being destroyed in transit. Many common cancer-fighting drugs today use beta emitters, which are comparatively hundreds of times more destructive to surrounding good tissue.

Related to the market excitement of expanding the source of one such alpha emitter (bismuth-213), a 2005 press release has stated that with respect to availability and promise of actinium-225 (the parent isotope of bismuth-213),

"In clinical trials, bismuth-213 has been used in a mode of cancer treatment called alpha immunotherapy (AIT), which researchers believe could lead to development of a socalled "magic bullet" for cancer treatment. The therapy involves the combination of alpha particle-emitting radionuclides -- in this case, bismuth-213 -- with monoclonal antibodies or peptides that occur naturally in the human body. In the NIH research, the bismuth-213 is combined with one such monoclonal antibody, and then injected into a cancer patient. The antibodies recognize and specifically bond to malignant cancer cells. When the bismuth-213 decays, it imparts alpha particles into the cancerous cells with low risk of damaging the surrounding healthy cells."

"Clinical results to date have looked very promising, but lack of availability of the isotope actinium-225 and the present high cost for that which is available has greatly limited the research," said Dr. Barbara Y. Croft, of the National Cancer Institute."

Currently, research with bismuth-213, and its parent actinium-225, includes clinical trials for therapies for acute myeloid leukemia (AML). Scientist at the Albert Einstein College of Medicine described their work at a recent the American Association for the

\footnotetext{
${ }^{1}$ Isonics Begins Supplying Rare Cancer-Fighting Isotope to National Institutes of Health, Wednesday January 5, 2005, Isonics Corp., http://www.isonics.com
} 
Advancement of Science (AAAS) Annual Meeting work in infectious diseases including HIV. $^{2}$ Other results have been published demonstrating the potential application of bismuth-213 as a therapeutic for prostate, gastric, breast, pancreatic, and ovarian cancer along with Hodgkin's lymphoma, and bone marrow transplant.

Actinium-225/Bismuth-213 is a parent/daughter radioisotope pair that is highly sought after because of the potential for treating numerous diseases and its ability to be chemically compatible with many known and widely used carrier molecules (such as monoclonal antibodies and proteins/peptides).

The current worldwide supply of actinium-225 can be summarized as follows:

ORNL: Currently produces the bulk of the supply of actinium-225 from a single $150 \mathrm{mCi}$ source of actinium-225's parent, thorium-229 that is milked $\sim 6$ times per year.

ITU: ITU has a small amount of thorium-229 supplied by ORNL a number of years ago and produces $\sim 350 \mathrm{mCi}$ of actinium-225 annually. ITU does not market or sell this actinium-225 but provides it only to their "collaborators".

Russia: There have been various attempts to ship small amounts (few $\mathrm{mCi}$ ) of actinium225 from Russia but the actual sources are largely unknown and highly sporadic in availability.

Several routes have been proposed for potential actinium-225 supply resolution. The most immediate way for supply to be expanded is to expand production at ORNL from the current thorium-229 material. While this material is limited, and an increase in production is likely limited to at best a $2 \mathrm{X}$ increase in the amount of actinium-225 to market, this would be a small but nevertheless useful expansion of the actinium-225 supply for the near term. This single source though, even if production is increased, cannot meet the real longer-term (>2yrs hence) needs for actinium-225.

Unfortunately, all remaining DOE controlled thorium-229 is currently part of the uranium-233 stocks held at either INL or ORNL. About $45 \%$ of the available Th229 is tied up in the LWBR fuel pellets. NorthStar has successfully demonstrated through a CRADA at INL that the technology exist to extract actinium-225 from this source on a routine basis. Unfortunately, DOE has proceeded with disposal of this source at NTS. Sections of the core began shipping in 2008 and a portion of the drummed material has also been dispositioned for disposal. The permanent loss of this source represents the permanent loss of about $45,000 \mathrm{mCi}$ of annual actinium-225 production.

The remaining thorium-229 is part of the high enrichment uranium-233 housed at ORNL in building 3019. Recovery of this source of thorium-229 would allow for production of

\footnotetext{
${ }^{2}$ Ekaterina Dadachova, Topical Lecture, American Association for the Advancement of Science, Annual Meeting, February 2009
} 
about $60,000 \mathrm{mCi}^{3}$ of actinium-225 annually. NorthStar, in conjunction with INL, has proposed to recover a small portion of this thorium-229 using about $1 \%$ of the uranium233 stock, an amount that would produce, in addition to the current production, about $3,600 \mathrm{mCi}$ of actinium-225 annually ${ }^{4}$. NorthStar has developed methodology that would allow for processing this small sample $(\sim 15 \mathrm{Kg})$ within a years time frame and return it to the down-blending contractor for scheduled disposition and has discussed the project with both INL and ORNL personnel. Moving forward though is complicated by Congressional action in 2005 that removed DOE's flexibility to consider alternative uses, however temporary, of this uranium-233. Thus, NorthStar awaits approval from DOE-EM to discuss this project with ORNL/INL and the DOE contractor for the building 3019 downblending project. Demonstration of NorthStar's technology at this scale is consistent with the IG report relative to having a "demonstrated or proven" process to recover the thorium-229 safely and without impact on the down-blending effort. If relief from the Congressional actions of 2005 cannot be obtained and down-blending proceeds as scheduled, the permanent loss of this source represents the permanent loss of up to $60,000 \mathrm{mCi}$ of annual actinium-225 production.

The following figure 5 stresses the importance of actinium-225 supply expansion and clearly indicates that loss of access to DOE controlled thorium-229 sources means supply expansion can only occur with new production technologies. It also clearly shows that even with access to DOE thorium-229 sources, the approval of multiple treatments using actinium-225, or its daughter bismuth-213, could require alternative production methodologies regardless.

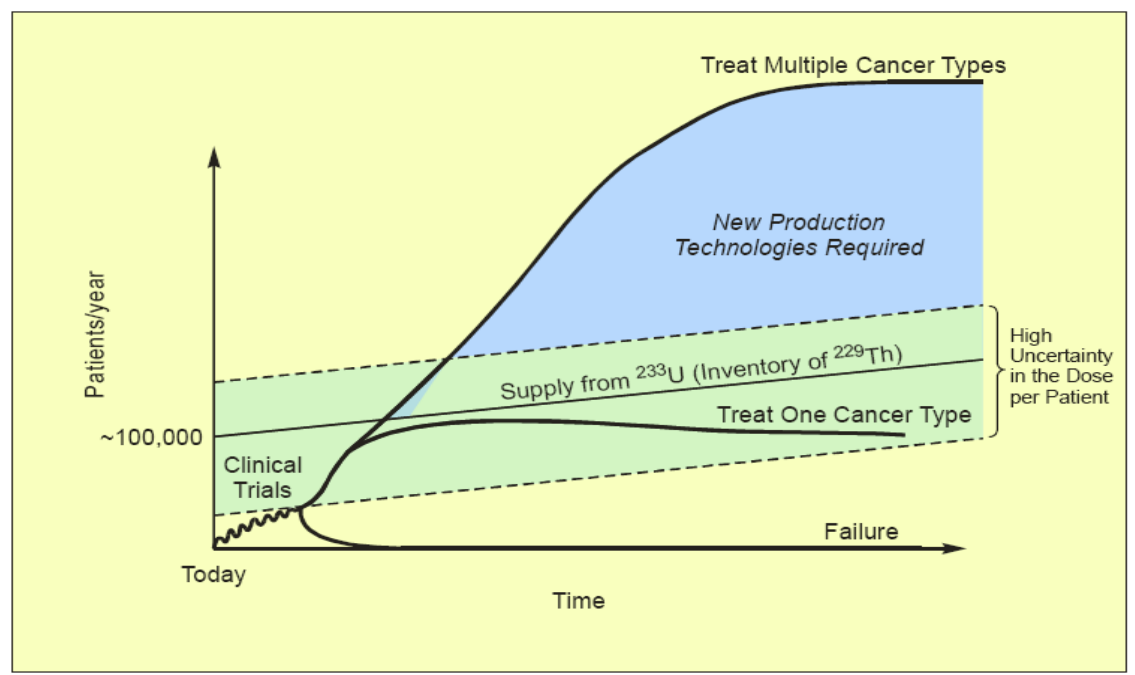

Figure 1: Relative need of actinium-225 with time

\footnotetext{
${ }^{3}$ The range of numbers of patients that can be treated with the full recovery of all thorium-229 in building 3019 is highly dependent on disease modality and whether the treatment isotope is actinium-225 or bismuth-213. That range could be as little as 10,000 to more than 100,000 annually.

${ }^{4}$ This amount is sufficient to meet near term research needs and allow one or more clinical trials to proceed to potential FDA approval if successful. Current supply will not allow this to happen.

${ }^{5}$ Forsberg, C.W., Uses for U233, Briefing for USDOE, March 22, 2000.
} 
New processes for supply expansion have not been fully developed, currently have only been demonstrated on a minute scale, and currently do not produce any commercially available quantities. Further, all alternative processes being considered rely on either an accelerator approach (producing radium-225 or actinium-225 directly) or a high-flux reactor to produce thorium-229 and all require use of radium-226 as the target material (the reactor approach could potentially use thorium-228 as target material). Those approaches are:

Using a cyclotron:

Using an electron accelerator:

Using a reactor:
$\operatorname{Ra} 226(p, 2 n) A c 225$

$\operatorname{Ra} 226(\gamma, \mathrm{n}) \operatorname{Ra} 225 \rightarrow \operatorname{Ac} 225$

$\operatorname{Ra} 226(x n, x \beta \gamma) \operatorname{Th} 229$

or

$\operatorname{Th} 228(\mathrm{n}, \gamma) \operatorname{Th} 229$

Use of radium-226 or thorium-228 in each of these alternative approaches comes complete with a plethora of nuclear and safety issues complicating its use. Without availability of DOE sources to produce actinium-225, the use of actinium-225 and/or bismuth-213 as a potential treatment could result in the inability to treat any meaningful quantities of patients unless an alternative production route can be established. We provide in this effort a new and unique route to actinium-225 production that does not require:

- Access to DOE uranium-233 materials, thus working around the "access issue created by Congress in 2005 ,

- Use of radium-226, thus eliminating the nuclear and health and safety challenges of using radium-226 in a high-flux reactor, and

- Use of thorium-228, thus eliminating the nuclear and health and safety challenges of using thorium-228 in a high flux reactor.

The route proposed herein utilizes high energy protons to produce actinium-225 via spallation of a thorium-232 target. The resulting irradiated target is processed using chemistry developed as part of NorthStar's CRADA at INL to extract micro quantities of actinium-225 from macro quantities of thorium. NorthStar has teamed with the Physics Division of Argonne National Laboratory and with the Fermi National Accelerator Laboratory, each of whom were funded directly by the Office of Science for their respective tasks.

The effort described herein was designed to provide a "proof of principal" of the proposed route as a starting point for future efforts to bring this new, abundant source of actinium-225 to the medical community at a supply level that no longer restricts its use and at a cost competitive price that no longer prohibits its use. The full Task listing is provided in Appendix A. The project task matrix summary is presented as follows: 


\section{Task Matrix}

\begin{tabular}{|c|c|c|c|c|}
\hline Task & Result & Responsibility & $\begin{array}{c}\text { Critical } \\
\text { Path }\end{array}$ & Schedule \\
\hline $\begin{array}{l}\text { 1. Reaction Yields } \\
\text { and Radiological } \\
\text { Simulations }\end{array}$ & $\begin{array}{l}\text { MCNPx/CINDER and } \\
\text { FLUKA calculations } \\
\text { completed and report } \\
\text { provided to FNAL for } \\
\text { review on June } 1,2010 . \\
\text { Revised report issued } \\
\text { September } 28,2010 \text { with } \\
\text { additional information } \\
\text { requested by FNAL and } \\
\text { ANL and was part of the } \\
\text { MOU. }\end{array}$ & $\begin{array}{l}\text { NMR, ANL- } \\
\text { PHY, FNAL }\end{array}$ & No & Completed \\
\hline \multicolumn{5}{|l|}{$\begin{array}{l}\text { 2. Design \& Test } \\
\text { Target Assembly }\end{array}$} \\
\hline 2a. Design & $\begin{array}{l}\text { Meeting held at FNAL } \\
\text { on June 21, } 2010 \text { to } \\
\text { discuss Task } 1 \text { report, } \\
\text { discuss FNAL operations } \\
\text { requested information on } \\
\text { proposed irradiation, and } \\
\text { first discussion on target } \\
\text { holder concepts. Walk } \\
\text { through of proposed } \\
\text { irradiation area occurred } \\
\text { on July 29, } 2010 \text {. }\end{array}$ & $\begin{array}{l}\text { NMR, ANL- } \\
\text { PHY, FNAL }\end{array}$ & No & Completed \\
\hline $\begin{array}{c}2 \mathrm{~b} . \\
\text { Fabricate/Acquire }\end{array}$ & $\begin{array}{l}\text { ANL-PHY has prepared } \\
\text { drawings for the target } \\
\text { holder and target holder } \\
\text { stand to be used for the } \\
\text { irradiation. Drawings } \\
\text { were part of the MOU. }\end{array}$ & $\begin{array}{l}\text { NMR, ANL- } \\
\text { PHY, FNAL }\end{array}$ & No & Completed \\
\hline 2c. Install \& Test & $\begin{array}{l}\text { Target and target holder } \\
\text { ready for installation and } \\
\text { irradiation. }\end{array}$ & $\begin{array}{l}\text { NMR, ANL- } \\
\text { PHY, FNAL }\end{array}$ & No & Completed \\
\hline 3. Irradiations & 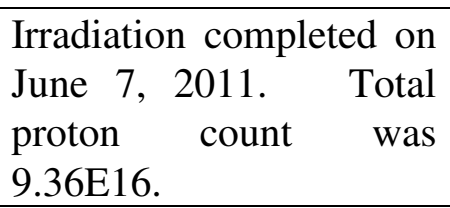 & FNAL & Yes & Completed \\
\hline
\end{tabular}




\begin{tabular}{|c|c|c|c|c|}
\hline $\begin{array}{l}\text { 4. Chemical } \\
\text { Separations and } \\
\text { Product Evaluation }\end{array}$ & & & & \\
\hline $\begin{array}{l}\text { 4A. Chemical } \\
\text { Separations }\end{array}$ & $\begin{array}{l}\text { Target was delivered to } \\
\text { ANL week of June } 13^{\text {th }} \text {. } \\
\text { Gamma spectra taken } \\
\text { week of June } 20^{\text {th }} \text {. } \\
\text { Chemical separations to } \\
\text { start first week of July. }\end{array}$ & $\begin{array}{l}\text { NMR, ANL- } \\
\text { CSE }\end{array}$ & No & Completed \\
\hline $\begin{array}{l}\text { 4B. Product } \\
\text { Evaluation }\end{array}$ & $\begin{array}{l}\text { Evaluated actinium-225 } \\
\text { product }\end{array}$ & $\begin{array}{l}\text { NMR, ANL- } \\
\text { CSE }\end{array}$ & No & Completed \\
\hline $\begin{array}{l}\text { 5. mAb Labeling } \\
\text { and Evaluation }\end{array}$ & $\begin{array}{l}\text { Task not performed due } \\
\text { to failure of the Ac } 225 \text { to } \\
\text { arrive from ORNL in } \\
\text { time as result of order } \\
\text { processing difficulties at } \\
\text { ANL. }\end{array}$ & NMR & No & Not Done \\
\hline $\begin{array}{l}\text { 6. Project } \\
\text { Technical Report }\end{array}$ & Submitted & NMR & No & Completed \\
\hline
\end{tabular}

\section{Results and Discussion}

\section{Description of Spallation Process}

As part of previous R\&D efforts carried out at Argonne National Laboratory recently in support of the proposed US FRIB facility, it was shown that a very effective production mechanism for actinium-225 is spallation of thorium-232 by high energy proton beams. These studies, carried out by Jerry Nolen and I.C. Gomes, used the Los Alamos CEM nuclear model within the MCNPX simulation code. The high yields are predicted for proton beam energies of $200 \mathrm{MeV}$ and above. For a given proton beam power the yields for a given target thickness, $\sim 50 \mathrm{~g} / \mathrm{cm} 2$, are highest at $200 \mathrm{MeV}$. For a given beam current they increase slightly with energy to about $400 \mathrm{MeV}$ and then decrease slightly for beam energies in the several $\mathrm{GeV}$ regime. Spallation of heavy elements is a common reaction mechanism for the production of short-lived isotopes for nuclear physics research; this is the mechanism used for so-called ISOL-type radioactive beam facilities, such as ISOLDE at CERN and ISAC at TRIUMF. This mechanism is not commonly used for the production of relatively long-lived medical isotopes such as actinium-225, but is being proposed in this effort as a potential solution to the supply issue surrounding actinium-225 in a manner that does not require the use of DOE uranium-233 stocks.

The effective production cross section extracted from preliminary simulations is about 20 $\mathrm{mb}$ at $200 \mathrm{MeV}$. Experimental measurements give a cross section of $14 \mathrm{t} / \mathrm{-} 3 \mathrm{mb}$ 
measured at $340 \mathrm{MeV}^{6}$. This result is probably due to secondary production reactions in the relatively thick target of these preliminary simulations. More detailed simulations accounting for all such effects were carried out during the planning stages of the proposed irradiations at FNAL.

\section{Description of the Irradiation}

The irradiation of the sample took place in front of the dump for FNAL's $8 \mathrm{GeV}$ booster synchrotron. The $400 \mathrm{MeV}$ irradiation position under consideration was ruled out early in the effort as this location is in-vacuum and not preferred by FNAL personnel. Figure 2 is an aerial view of FNAL with an overlay of the FNAL accelerator chain. The booster beam dump location is marked on the figure.

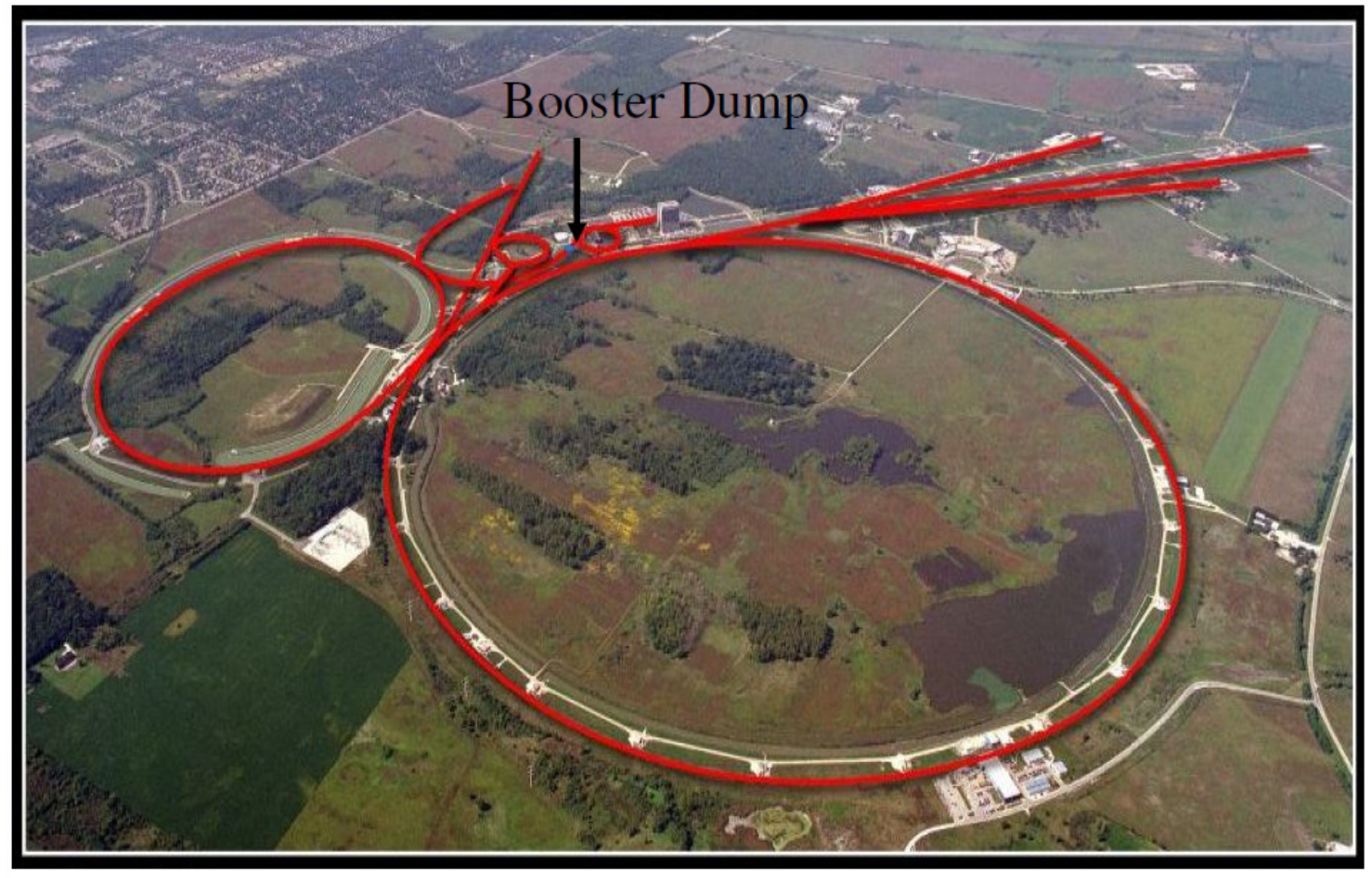

Figure 2: Fermi National Accelerator Laboratory aerial view

This provided an in-air location for the sample that was easily accessible. Dedicated beam could be directed to the sample at an even rate. Additional beam was also received but was just a few percent of the dedicated beam. The desired beam needed was a minimum of $8 \times 10^{16}$ protons delivered over a period of 2 to 7 days. The total number of protons actually delivered was $9.77 \times 10^{16}$ over 4 days plus a 1.5 day cool-down.

The proton beam at FNAL is pulsed and all beam accelerated has a specific purpose. Each pulse is tagged with an event type and all events are loaded into a $10 \mathrm{MHz}$ clock which controls the timing of the beam throughout the accelerator complex. This event

\footnotetext{
${ }^{6}$ M. Linder and R.N. Osborne, Phys. Rev. 103 (1956) 378
} 
type (denoted by a two digit hexadecimal number) specifies the path of the beam, the synchronization of the various accelerators along that path, and the ultimate destination of the beam.

The primary event used for the irradiation was event 17, a booster study pulse. Other events that end at the booster dump are events, 13, 15, 16, and 1C. The presence of these events was necessary for high energy physics operations and was unavoidable. However, their presence during the irradiation period was benign and they did not significantly affect the cool-down period. Their total contribution was about $4 \%$ of the total protons delivered.

A wire scanner upstream of the end of the dump beamline provided profiles of the beam (Figures $3 \& 4$ ). There was also discoloration on the covering of the opening to the dump. The dimensions of the discoloration are consistent with the profiles from the wire scanner. This strongly indicated that the beam size and positioning is steady. These were then used to determine the size of the sample and the positioning of the sample holder. The sample was sized to the standard deviation of the beam width and height and therefore did not intercept the entire beam. Analysis of the copper cladding provided a measure of the actual number of protons that struck the target.

The sample was placed in front of the dump on June 1, 2011 and irradiation commenced at noon. Event 17 provided beam at a steady rate of approximately $2.5 \times 10^{16}$ protons per day until the dedicated beam was terminated at $8 \mathrm{AM}$ on June 5. The sample remained in place until 13:30 on June 7 when an access was made to remove the sample. During the two day cool-down period at the end of dedicated irradiations, less than $2 \%$ additional beam was delivered to the sample. This irradiation used $\sim 10 \%$ of the total protons for $\sim 4$ days with the remaining $\sim 90 \%$ being used for basic high energy physics research at FNAL. Table 1 lists the protons delivered to the sample each day.

Table 1: Protons striking the sample by day and event type

\begin{tabular}{|c|c|c|c|c|c|c|}
\hline Date & Event 13 & Event 15 & Event 16 & Event 17 & Event 1C & Total \\
\hline June 1 & $8.79 \mathrm{E}+12$ & $2.73 \mathrm{E}+14$ & $3.45 \mathrm{E}+12$ & $1.05 \mathrm{E}+16$ & - & $1.07 \mathrm{E}+16$ \\
\hline June 2 & $1.38 \mathrm{E}+14$ & $5.39 \mathrm{E}+14$ & $9.84 \mathrm{E}+12$ & $2.24 \mathrm{E}+16$ & $2.86 \mathrm{E}+13$ & $3.39 \mathrm{E}+16$ \\
\hline June 3 & $1.98 \mathrm{E}+14$ & $2.09 \mathrm{E}+14$ & $6.36 \mathrm{E}+12$ & $2.56 \mathrm{E}+16$ & $2.20 \mathrm{E}+14$ & $6.01 \mathrm{E}+16$ \\
\hline June 4 & $1.97 \mathrm{E}+14$ & $5.40 \mathrm{E}+14$ & $1.13 \mathrm{E}+13$ & $2.56 \mathrm{E}+16$ & - & $8.64 \mathrm{E}+16$ \\
\hline June 5 5 AM & $5.24 \mathrm{E}+13$ & - & $5.74 \mathrm{E}+12$ & $9.60 \mathrm{E}+15$ & - & $9.60 \mathrm{E}+16$ \\
\hline June 5 $>8$ AM & $1.24 \mathrm{E}+14$ & $2.95 \mathrm{E}+14$ & $4.52 \mathrm{E}+12$ & - & - & $9.64 \mathrm{E}+16$ \\
\hline June 6 & $1.65 \mathrm{E}+14$ & $6.73 \mathrm{E}+14$ & $8.84 \mathrm{E}+12$ & - & - & $9.73 \mathrm{E}+16$ \\
\hline June 7 & $1.15 \mathrm{E}+14$ & $3.32 \mathrm{E}+14$ & $6.01 \mathrm{E}+12$ & - & - & $9.77 \mathrm{E}+16$ \\
\hline Totals & $1.00 \mathrm{E}+15$ & $2.86 \mathrm{E}+15$ & $5.66 \mathrm{E}+13$ & $9.36 \mathrm{E}+16$ & $2.49 \mathrm{E}+14$ & \\
\hline
\end{tabular}




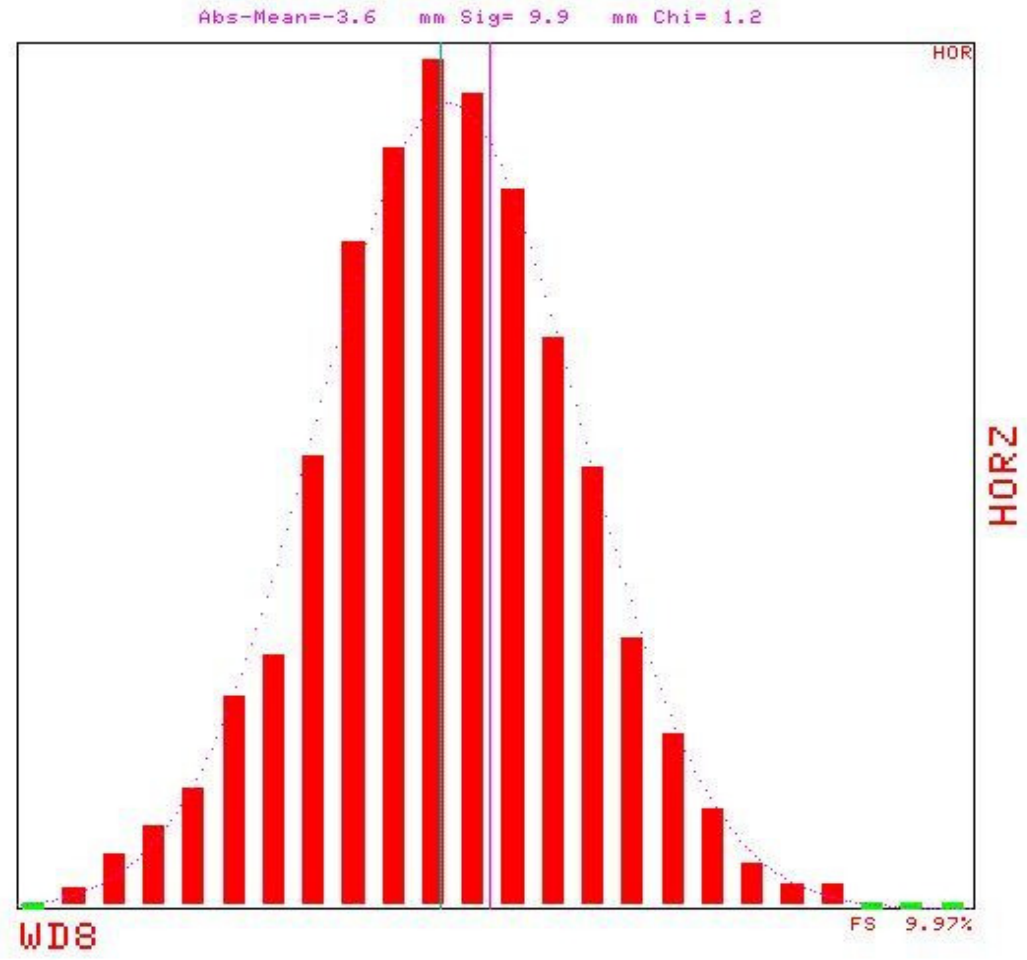

Figure 3: Horizontal beam profile with a sigma of $1 \mathrm{~cm}$.

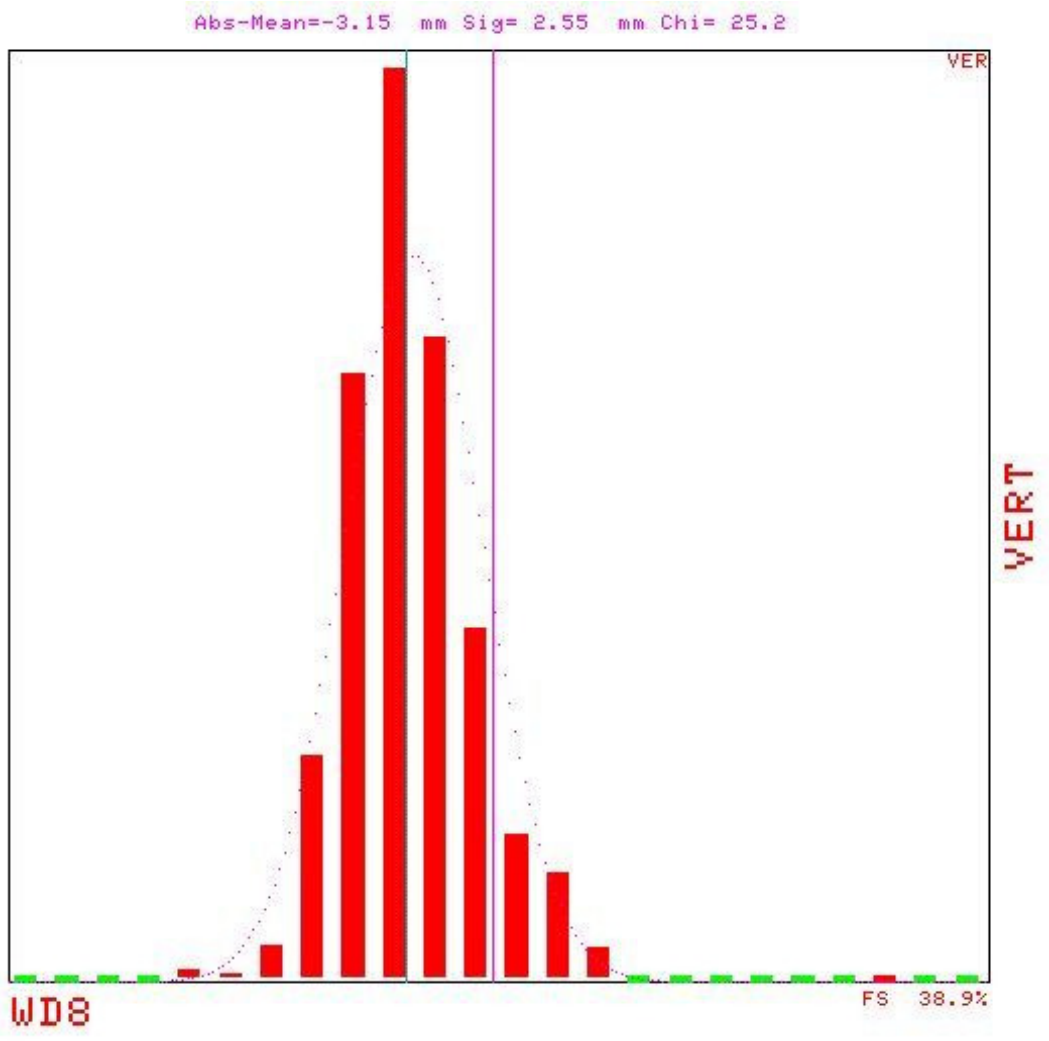

Figure 4: Vertical beam profile with a sigma of $0.25 \mathrm{~cm}$. 
After the sample was removed from the dump area, it was stored at FNAL until it had cooled to the point that it could be shipped in a shielded shipping container. It was then delivered to Argonne for chemistry work.

\section{$\underline{\text { Summary of Modeling Effort }}$}

During the design phase of the thorium irradiation experiment, a number of calculations were performed to support the design and approval of the irradiation to be performed in front of the FNAL dump of the $8 \mathrm{GeV}$ booster synchrotron. The calculations included examination of target heating. The effort incorporated estimated production rate of the main isotopes of interest (mainly actinium-225, actinium-226, and actinium-227), estimated irradiated target fraction of DOE STD-1027-92 CAT-3 threshold, gamma-ray activity for several cooling down periods of time, and alpha particles activity in the target, as well as activation of the air and surrounding structures of the irradiation position, including particles flux and current analysis for the main particles produced in the target and beam stop structure. The heating report addressed concerns about melting down the target with the 168 Watts beam power and the only 1 Watt deposited in the target. These calculations were used as a basis for the target design and FNAL Health Physics approval of the experiment. Appendix B contains the full details of these calculations, prepared by I.C. Gomes (consultant to NorthStar for this project), presented as part of a Memorandum of Understanding (MOU) prepared for the effort. The MOU summarizes with backup details the proposed plan to aid in various approvals needed to execute the project.

The basic design called for a thorium target $2 \times 1 \times 1 \mathrm{~cm}^{3}(2 \mathrm{~cm}$ wide, $1 \mathrm{~cm}$ tall, and $1 \mathrm{~cm}$ thick). During fabrication of the target a copper enclosure was added and for convenience and simplicity of fabrication and handling of the available thorium sheets, the thorium region of the target was fabricated with dimensions of $0.9 \times 0.4 \times 0.5 \mathrm{in}^{3}(2.286 \times 1.016 \times 1.27$ $\mathrm{cm}^{3}$ ) resulting in a total volume of thorium of $\sim 2.95 \mathrm{~cm}^{3}$. The copper cover that wrapped the thorium was $0.05 "(0.127 \mathrm{~cm})$ thick. The overall outer dimensions of the target with enclosure were $1.0 \times 0.5 \times 0.6 \mathrm{in}^{3}\left(2.54 \times 1.27 \times 1.52 \mathrm{~cm}^{3}\right)$, except that the copper plate in the back had a tab making the back copper plate dimensions $1.0 \times 0.75 \times 0.05 \mathrm{in}^{3}$ $\left(2.54 \times 1.90 \times 0.127 \mathrm{~cm}^{3}\right)$. Figure 5 is a picture of the target assembly.

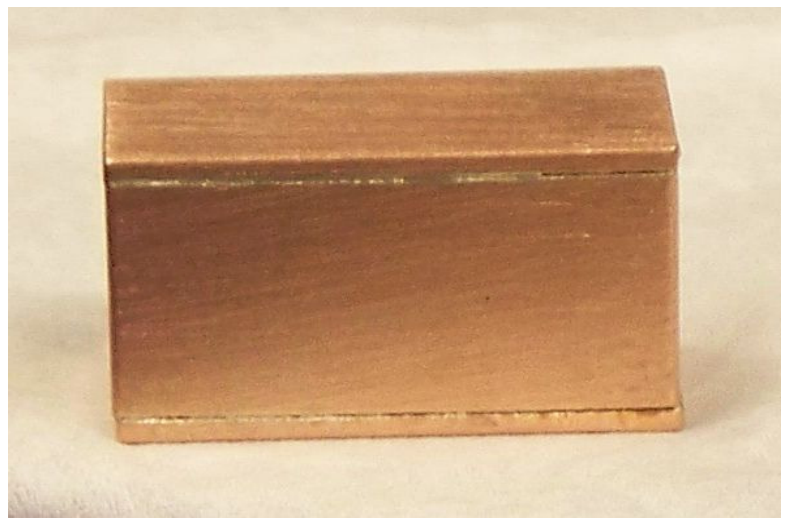

Figure 5: Target assembly - copper housing with thorium target inside 
Figure 6 shows the target holder mounted in front of the booster beam dump.

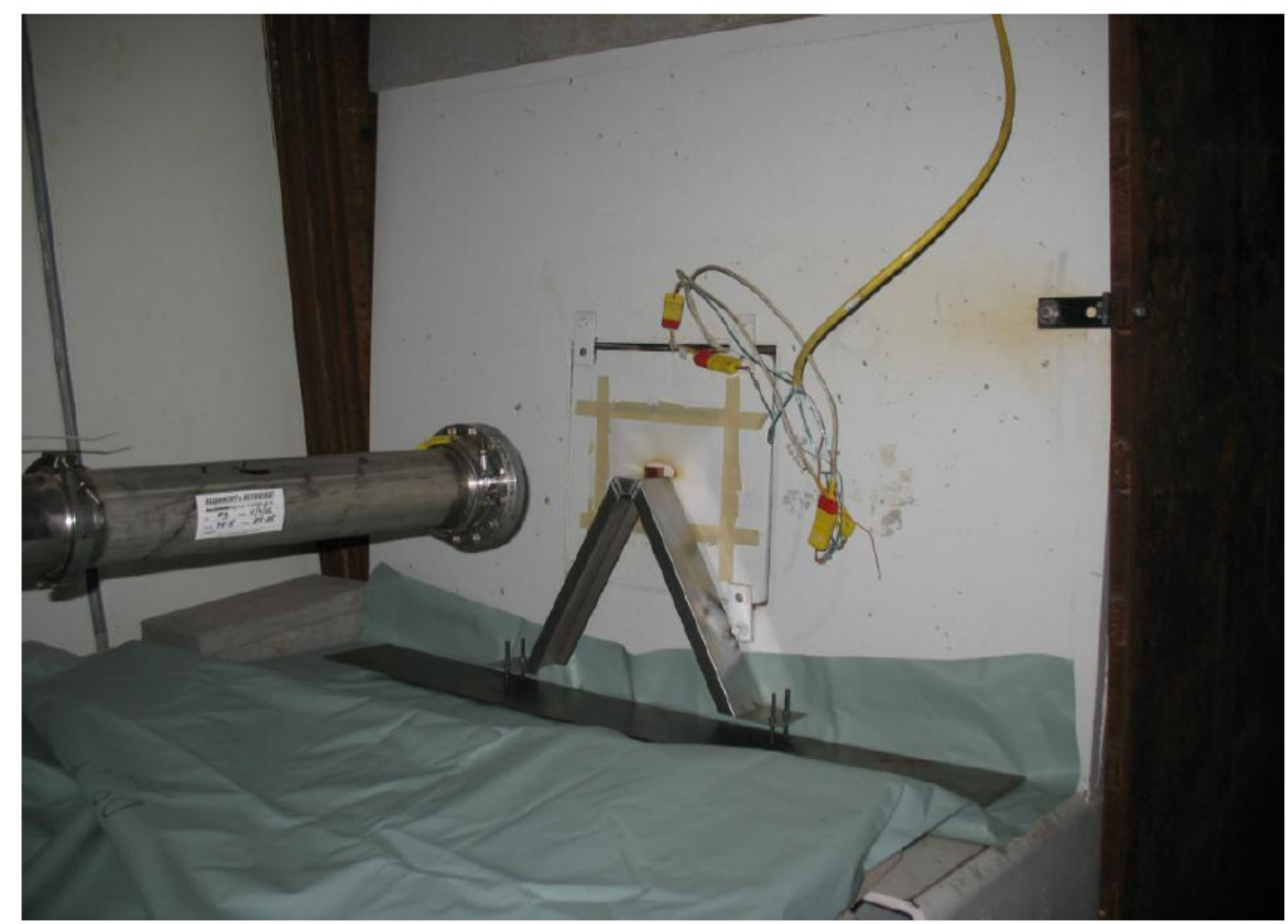

Figure 6: Target holder mounted in front to the $8 \mathrm{GeV}$ beam dump of the booster

The target was irradiated for several days with a nearly constant averaged proton rate and one and a half days with a much reduced proton rate, called cool-down period. The total number of protons actually delivered to the target was $9.77 \times 10^{16}$ protons. The positioning of the beam and beam profile was subject to a post-irradiation analysis of the activation of the front plate and its findings are presented later in this section.

This calculation presents a comparison of the estimated production rate of the isotopes of interest compared with actual measurements of their activity during the handling of the irradiated target in the chemical separation process. Also, an analysis of the activity of the front copper plate of the target to obtain the activity of several spallation products based on direct reading of the gamma-ray spectrum, published cross sections, and calculated values was performed.

\section{ANALYSIS OF THE BEAM PROFILE ON THE FRONT PLATE}

The determination of the beam profile on the front plate during irradiation is important to define the number of protons that hit the plate and as a consequence allowing the calculation of the production cross section of the isotopes of interest, mainly actinium225. 
The irradiation position of the experiment was in front of the dump for FNAL $8 \mathrm{GeV}$ booster synchrotron, as such, it is not a location where the beam positioning and beam profile is closely monitored. During the design activities of the experiment it was decided that the beam profile and beam positioning were to be confirmed by reading the activation of the front copper plate with a gamma collimator, which would allow to read the gamma rays through a small aperture in a tungsten block. The tungsten block was first conceived to shield the gamma-rays coming from other positions in the plate and allowing only the gamma-rays emitted within the collimator line of sight to reach the detector. This allows mapping the gamma spectrum throughout the plate.

The beam profile given by FNAL, based on their previous measurements and supported by the discoloration of the cover at the entrance of beam stop channel, can be approximated by a Gaussian with sigma equals to $1 \mathrm{~cm}$. for the horizontal direction and $0.25 \mathrm{~cm}$. for the vertical direction. Using this beam profile it is expected, based on MCNPX calculations, that $65.3 \%$ of the protons would hit a $1 \times 2 \mathrm{~cm}^{2}$ plate placed in the entrance of the beam-stop channel. The calculations performed in support of the design and approval of the experiment was based on these target dimensions and beam profile. The irradiated target had dimensions, for the area facing the beam in the thorium region of $0.9 \times 0.4 \mathrm{in}^{2}\left(2.286 \times 1.016 \mathrm{~cm}^{2}\right)$.

A new set of calculations was prepared using the dimensions and composition of the irradiated target. As it was described above, in the fabricated and irradiated target, the thorium region had dimensions of $0.9 \times 0.4 \times 0.5 \mathrm{in}^{3}\left(2.286 \times 1.016 \times 1.27 \mathrm{~cm}^{3}\right)$ resulting in a total volume of thorium of $\sim 2.95 \mathrm{~cm}^{3}$. This can be compared with the $2.0 \mathrm{~cm}^{3}$ of the original design of the target. The copper cover that wrapped the thorium was 0.05 in $(0.127 \mathrm{~cm})$ thick. The overall outer dimensions of the target, with enclosure, were 1.0x0.5x0.6 in $\mathrm{in}^{3}\left(2.54 \times 1.27 \times 1.52 \mathrm{~cm}^{3}\right)$, except that the copper plate in the back had a tab making the back copper plate dimensions $1.0 \mathrm{x} 0.75 \mathrm{x} 0.05 \mathrm{in}^{3}\left(2.54 \mathrm{x} 1.90 \mathrm{x} 0.127 \mathrm{~cm}^{3}\right)$.

The previous results when scaled up to the volume of the new target seemed to be a little in the high side; it was then decided to first perform the analysis of the beam profile on the front plate. Several measurements were taken at different points on the front plate. The primary approach was to scan the plate in one direction, let's say in the horizontal one, and finds the maximum activity in that direction; then scan the direction perpendicular from where the point of maximum activity was found and finally re-scan the first direction at position of the maximum in the previous direction. The readings obtained are shown in Figure 7; the values presented are the number of counts for the same period of time and they were read at the positions presented in the figure. Figure 8 presents the horizontal normalized (to the maximum number of counts) Gaussian fitting of the beam profile as it was input in the MCNPX source (solid line) compared with the data read at a few positions along the horizontal line at $-0.2 \mathrm{~cm}$ from the center of the plate. The FWHM for this Gaussian was assumed to be $2.4 \mathrm{~cm}$ what can be compare with $2.355 \mathrm{~cm}($ sigma $=1 \mathrm{~cm})$ provided by FNAL. The center of the horizontal distribution was found to be at $-0.5 \mathrm{~cm}$. Figure 9 presents the vertical normalized (to the maximum number of counts) Gaussian fitting of the beam profile as it was input in the MCNPX 
source (solid line) compared with the data read at a few positions along the vertical line at $-0.5 \mathrm{~cm}$ from the center of the plate. The FWHM for this Gaussian was assumed to be $0.6 \mathrm{~cm}$ what can be compare with $0.589 \mathrm{~cm}($ sigma $=0.25 \mathrm{~cm})$ provided by FNAL. The center of the vertical distribution was found to be at $-0.2 \mathrm{~cm}$.

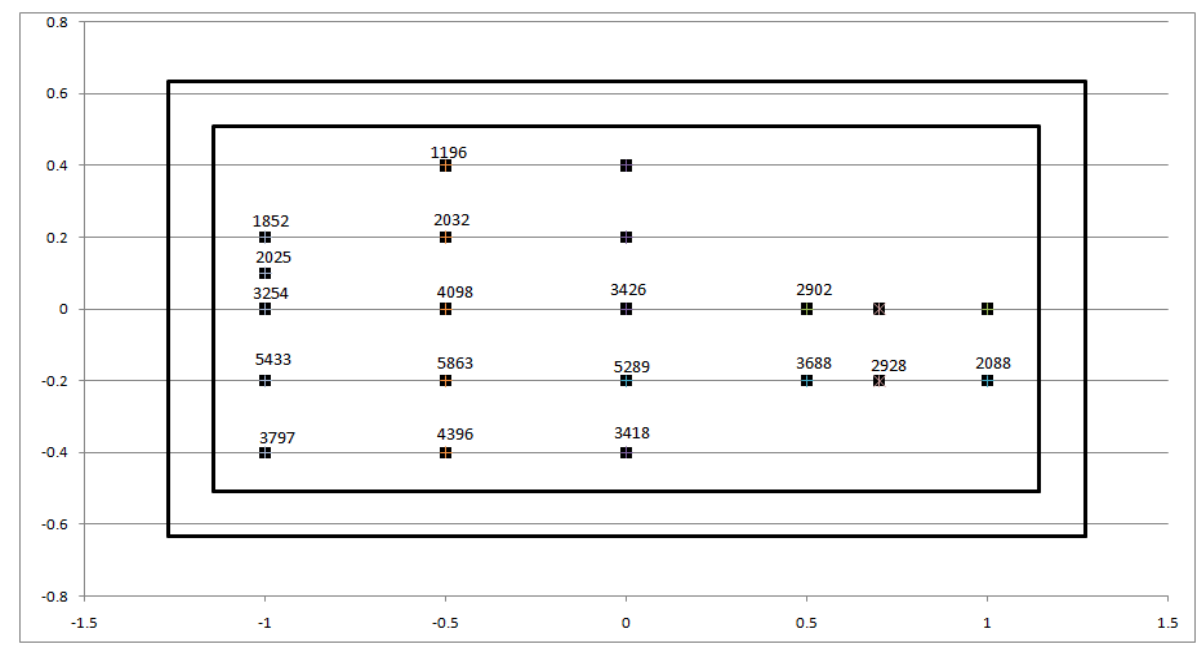

Figure 7: Number of counts read on the front plate at several positions.

Based on the data the Gaussian distributions for the $\mathrm{x}$ and $\mathrm{y}$ directions of the beam profile input to the MCNPX source term were as follows:

X-direction: $\mathrm{FWHM}=2.4 \mathrm{~cm}$, center of the distribution $=-0.5 \mathrm{~cm}$

Y-direction: $F W H M=0.6 \mathrm{~cm}$, center of the distribution $=-0.2 \mathrm{~cm}$.

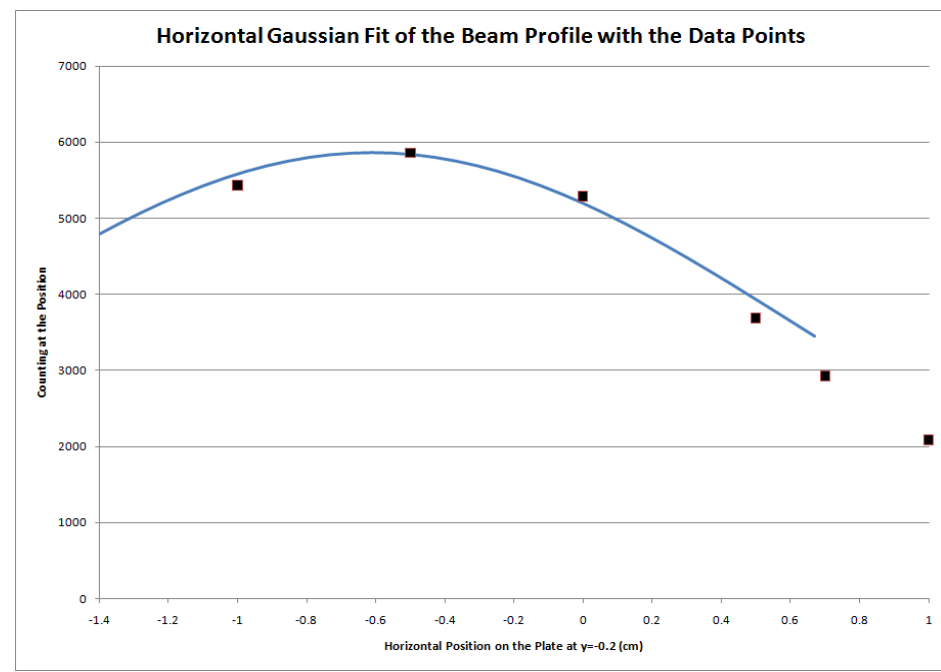

Figure 8: Gaussian fitting of the counting read (solid line) along the horizontal direction at the line position $0.2 \mathrm{~cm}$ below the center plate in the vertical direction. The center of the distribution is at $-0.5 \mathrm{~cm}$ from the center of the plate in the horizontal direction. The counting readings are represented by the points in the graph. 


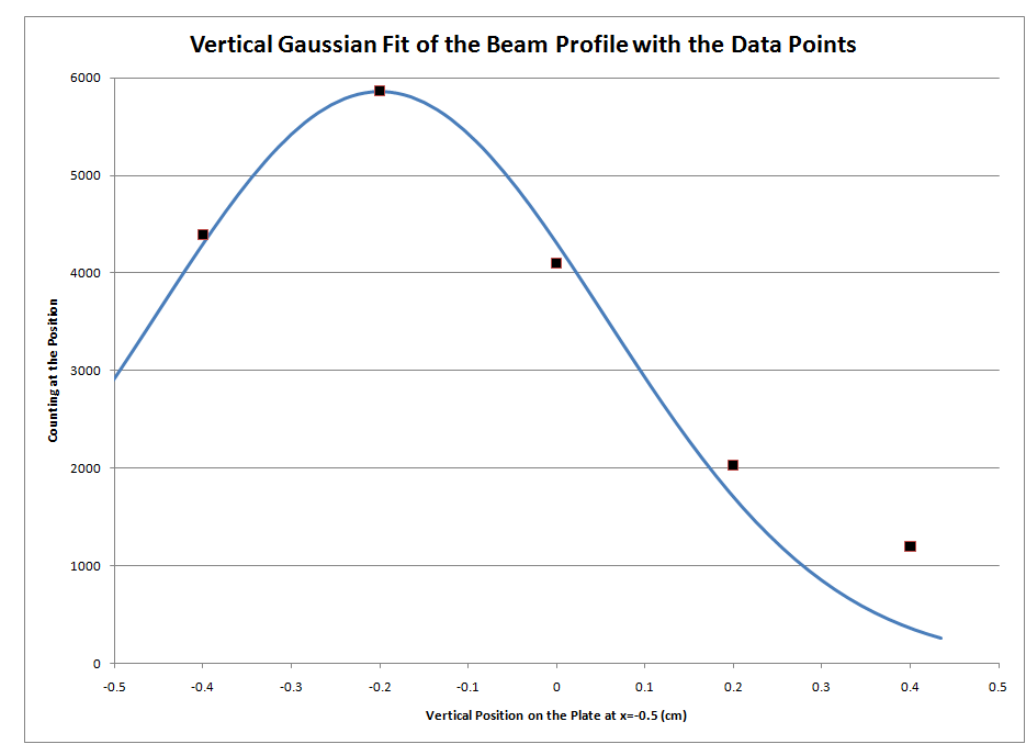

Figure 9: Gaussian fitting of the counting read (solid line) along the vertical direction at the line position $0.5 \mathrm{~cm}$ to the left of the center plate in the horizontal direction. The center of the distribution is at $-0.2 \mathrm{~cm}$ from the center of the plate in the vertical direction.

The counting readings are represented by the points in the graph.

Approximately $70 \%$ of the available protons struck the copper target holder with $\sim 60 \%$ striking the thorium target.

\section{ANALYSIS OF THE ACTIVATION IN THE FRONT PLATE}

The beam profile on the front plate, as indicated before, is an important parameter to define the number of protons hitting the target during the experiment. The analysis of the activation of the front plate is also an important element to support the adopted beam profile and confirm both, the calculated activation using computer codes and nuclear models, and to compare with published spallation cross section for the production of some long-lived isotopes.

The front plate of the target was made of copper and it was bombarded by $8 \mathrm{GeV}$ proton beam. The activation of the front plate will be due to the interactions of beam particles and any other secondary particle created within the front plate and in other regions of the target which are directed back to the front plate. An available publication ${ }^{7}$ that contains cross section measurements for a thin stack of foils bombarded by $8 \mathrm{GeV}$ protons was used for sake of comparing the activation of the front plate with the expected activation using the measured cross sections. The first problem detected with the publication was that its cross sections were measured for a stack of foils as such they do not constitute a

\footnotetext{
${ }^{7}$ P. Kozma and J. Kliman, "Spallation of Copper by 9 GeV/c Protons and Deuterons”, J. Phys. B 38 p. $1317-1327$ (1988)
} 
reaction cross section for a so called "thin target" but they added on some secondary interactions of secondary particles produced in the stack of foils. Table 2 presents the materials and thicknesses of the foils in the stack from the publication referenced. The second problem is that the publication does not indicate which foils were read to extract the published cross sections.

Table 2: Materials and thicknesses on the stack of foils irradiated

\begin{tabular}{|c|c|c|}
\hline Material & $\begin{array}{l}\text { Thickness } \\
(\mathrm{mg} / \mathrm{cm} 2)\end{array}$ & Thickness $(\mathrm{cm})$ \\
\hline Aluminum & 5.8 & 0.0022 \\
\hline Aluminum & 20.3 & 0.0075 \\
\hline Aluminum & 5.7 & 0.0021 \\
\hline Mylar & 17.5 & 0.0125 \\
\hline Mylar & 17.4 & 0.0124 \\
\hline Copper & 88.3 & 0.0099 \\
\hline Copper & 923.3 & 0.1033 \\
\hline Copper & 917.5 & 0.1026 \\
\hline Copper & 85.1 & 0.0095 \\
\hline Mylar & 17.5 & 0.0125 \\
\hline $\begin{array}{c}\text { Mylar } \\
\text { Total }\end{array}$ & 17.3 & 0.0124 \\
\hline Thickness & & 0.2869 \\
\hline
\end{tabular}

In order to verify the influence of the secondary particles on the response of the foils, as a stack, to the irradiation the MCNPX code was used to simulate the irradiation of the stack. The calculations were carried out for two reasons, the first to have an assessment of the magnitude, predicted by MCNPX, of the impact of having a stack of foils, and second to allow an initial assessment of the nuclear models of MCNPX in predicting the production "cross sections." The publication only provides production "cross section" for a selected number of isotopes from the spallation of the copper by the $8 \mathrm{GeV}$ protons. Note that the calculated and published values are not in reality production cross sections, but an approximate value which is target geometry dependent and could be seen, roughly, as a thick target cross section. Table 3 presents the results obtained with MCNPX and the published cross sections for the isotopes produced by the copper spallation. It should be pointed out that the publication does not indicate which foil was used for making the measurement for each of the published cross section. In the headings of the columns occasionally there are two isotopes listed, the isotope listed in the first line is the one for which the production cross section is given and the isotope listed in the second line is a parent isotope that has a relatively short half-life when compared with the daughter and it is assumed that it has fully decay to the daughter in the MCNPX results presented. The last line of the table presents the published results along with the estimated error bar for the measurement. As it can be seen MCNPX tends to underestimate some values of the cross section and overestimate others, but in general there is agreement between the two 
sets. Also, it can be seen that, in general, there is an increase of about $10 \%$ in the "cross section" predicted by MCNPX as one considers the foils deeper in the stack.

Table 3: Calculated and published cross sections for selected isotopes from the spallation of copper by $8 \mathrm{GeV}$ protons.

\section{CROSS SECTIONS (mbarns)}

$\begin{array}{lllllllllll}\text { Material } & \begin{array}{l}\text { Thickness } \\ (\mathrm{mg} / \mathrm{cm} 2)\end{array} & \text { Sc-46 } & \begin{array}{l}\text { V-48 } \\ \text { Cr-48 }\end{array} & \begin{array}{l}\text { Cr-51 } \\ \text { Mn-51 }\end{array} & \text { Mn-54 } & \text { Fe-59 } & \text { Co-56 } & \text { Co-57 } & \text { Co-58 } & \text { Co-60 } \\ \mathrm{Cu} & 88.3 & 5.23 & 8.85 & 15.05 & 15.25 & 1.14 & 5.85 & 18.91 & 19.55 & 7.21 \\ \mathrm{Cu} & 923.3 & 5.40 & 9.43 & 16.07 & 16.65 & 1.25 & 6.43 & 20.62 & 21.53 & 8.04 \\ \mathrm{Cu} & 917.5 & 5.58 & 9.78 & 16.68 & 17.57 & 1.27 & 6.88 & 22.26 & 23.09 & 8.56 \\ \mathrm{Cu} & 85.1 & 5.72 & 10.10 & 16.49 & 17.72 & 1.26 & 6.69 & 22.28 & 22.86 & 8.48 \\ & & & & & & & & & & \\ \text { Published } & & 6.22 \pm & 13.11 \pm & 18.02 \pm & 13.36 \pm & 1.23 \pm & 7.12 \pm & 17.72 \pm & 23.53 \pm & 10.12 \pm \\ \text { X-Sec } & & 0.21 & 0.37 & 1.38 & 0.56 & 0.22 & 0.30 & 1.64 & 0.77 & 0.53\end{array}$

The next step in the analysis of the activation of the front plate of the target is to compare the measured activity of some isotopes and compare with the calculated activity at the day of the measurement. In order to do that, the calculated isotope production by MCNPX was input in the CINDER code and time evolution of the inventory was calculated. The activity was computed at several times during irradiation and after shutdown, and in particular 84 days after shutdown when the reading of the front plate took place. The calculations were performed taking into account the irradiation scenario provided by FNAL. The irradiation scenario is shown in Table 1. The accumulated total number of protons is presented in the last column.

Table 4 presents the results from the MCNPX calculated and measured activity of the front plate. The front plate after it was cut from the target had its thickness reduced from $0.127 \mathrm{~cm}$ to $0.109 \mathrm{~cm}$ and the table calculated values are adjusted for this weight difference in the plate. The values are given for the activity 84 days after the end of the irradiation. It can be seen that there is not a perfect agreement between the values but in general the calculated and measured activities are within a relatively narrow range. The measured values are estimated to have a $\pm 10 \%$ uncertainty. The calculated values are based on nuclear models and the deviations from measured values are intrinsic to the nuclear model, which can adjusted as more experimental data is made available. The statistical uncertainty of the Monte Carlo calculated values is very low.

Table 4: Calculated and measured activity $(\mu \mathrm{Ci})$ of a few long-lived isotopes generated by the spallation of the copper front-plate. The calculated values are corrected to $1.09 \mathrm{~mm}$ thickness.

$\begin{array}{lcccccccccc} & \text { Be-7 } & \text { Sc-46 } & \text { V-48 } & \text { Cr-51 } & \text { Mn-54 } & \text { Fe-59 } & \text { Co-56 } & \text { Co-57 } & \text { Co-58 } & \text { Co-60 } \\ \text { Calculated } & 6.83 & 4.00 & 1.12 & 7.61 & 7.76 & 1.13 & 5.77 & 9.96 & 20.2 & 1.26 \\ \text { Measured } & - & - & - & - & - & - & 3.87 & 7.90 & 15.3 & 1.10\end{array}$


The calculated production of the isotopes of interest can be used to calculate a production "cross section" for the geometry of the target. These "cross section" values should be roughly in agreement with the published "cross sections" for the stack of foils presented in Table 2. Table 5 displays the calculated production "cross section" for the copper front plate when irradiated as part of the thorium target, as described previously. As it can be seen by comparing Table 2 and Table 5 that the production "cross section" is somehow dependent on the radiation environment produced by the target, but the values are relatively consistent and the calculations can predict within a narrow error band the spallation production of products in a wide range of charge and mass.

Table 5: Production "cross section” extracted from the MCNPX calculated production rate for the spallation products in the copper front plate of the target.

$\begin{array}{lllllllllll} & \text { Be-7 } & \text { Sc-46 } & \text { V-48 } & \text { Cr-51 } & \text { Mn-54 } & \text { Fe-59 } & \text { Co-56 } & \text { Co-57 } & \text { Co-58 } & \text { Co-60 } \\ \begin{array}{l}\text { Production } \\ \text { X-sec (mb) }\end{array} & 9.70 & 5.58 & 8.78 & 16.6 & 22.2 & 1.67 & 7.67 & 24.2 & 27.8 & 14.0 \\ & & & & & & & & & & \\ \text { Published } & & 6.22 \pm & 13.11 \pm & 18.02 \pm & 13.36 \pm & 1.23 \pm & 7.12 \pm & 17.72 \pm & 23.53 \pm & 10.12 \pm \\ \text { X-Sec } & & 0.21 & 0.37 & 1.38 & 0.56 & 0.22 & 0.30 & 1.64 & 0.77 & 0.53\end{array}$

\section{ANALYSIS OF THE THORIUM SPALLATION PRODUCTS}

The main objective of the irradiation experiment was to demonstrate the production of actinium-225 by the spallation of a thorium target. In addition to actinium-225, other products are presented in the irradiated thorium target but this analysis will be restricted to a small number of isotopes. The MCNPX/CINDER calculated values for the actual irradiation scenario is shown in Table 6. The activity of the irradiated thorium, after separated from the copper enclosure, was measured at several phases of the chemical separation process and adjusted to the EOI (end of irradiation) time (assumed to be June $5^{\text {th }} 2011$ at 8:00 AM). The reported activity is corrected to the EOI when intense beam irradiation ceased. It can be seen that the results compare relatively well the estimated production by MCNPX/CINDER of the isotopes of interest in the FNAL irradiation experiment.

Table 6: MCNPX/CINDER calculated activity (Ci) for selected isotopes.

$\begin{array}{llllll} & \text { Ac-225 } & \text { Ac-227 } & \text { Ra-225 } & \text { Th-227 } & \text { Ra-223 } \\ \mathrm{T}_{1 / 2} \text { (days) } & 10.0 & 7952 & 14.9 & 18.7 & 11.4 \\ \text { Calculated Activity } & 2.51 \mathrm{E}-03 & 3.53 \mathrm{E}-06 & 5.71 \mathrm{E}-04 & 8.62 \mathrm{E}-04 & 1.22 \mathrm{E}-03\end{array}$




\section{Chemical Separation of Actinium from Thorium Target}

Post irradiation, the thorium-232 target will contain a plethora of radioisotopes as a result of the spallation reaction and thus will require a robust chemical separation to isolate the actinium isotopes. After a sufficient cool-down period of about 10-days, the residual target activity will be reduced significantly and is expected to be handled in a shielded glove box. The only actinium isotopes present will be actinium-225 and actinium-227 in an activity ratio expected to be about 1000:1. The 1.2-day actinium-226 will be decayed at least 3 orders of magnitude by processing time.

NorthStar has developed the necessary chemical separations that have been proven to provide outstanding purification of actinium from large quantities of thorium. As part of a demonstration process at ORNL, a separation scheme was developed to purify actinium-225 from up to $50 \mathrm{~g}$ of thorium. The flow sheet for that process is depicted in Figures 10-14. As shown, the process is a 5 step separation that produces in the end an actinium product of high purity in a small volume of about $5 \mathrm{~mL}$. The UTEVA and DGA resins and cartridges referred to on the flow sheets are standard resin material marketed commercially by Eichrom Technologies of Darien, IL. AGMP-1 is a standard analytical grade macro-porous anion exchange resin commercially available. Since the total activity of the target is currently unknown, provision is made for the chemical separations to be performed at ANL by personnel in the Chemical Sciences and Engineering (CSE) Division.

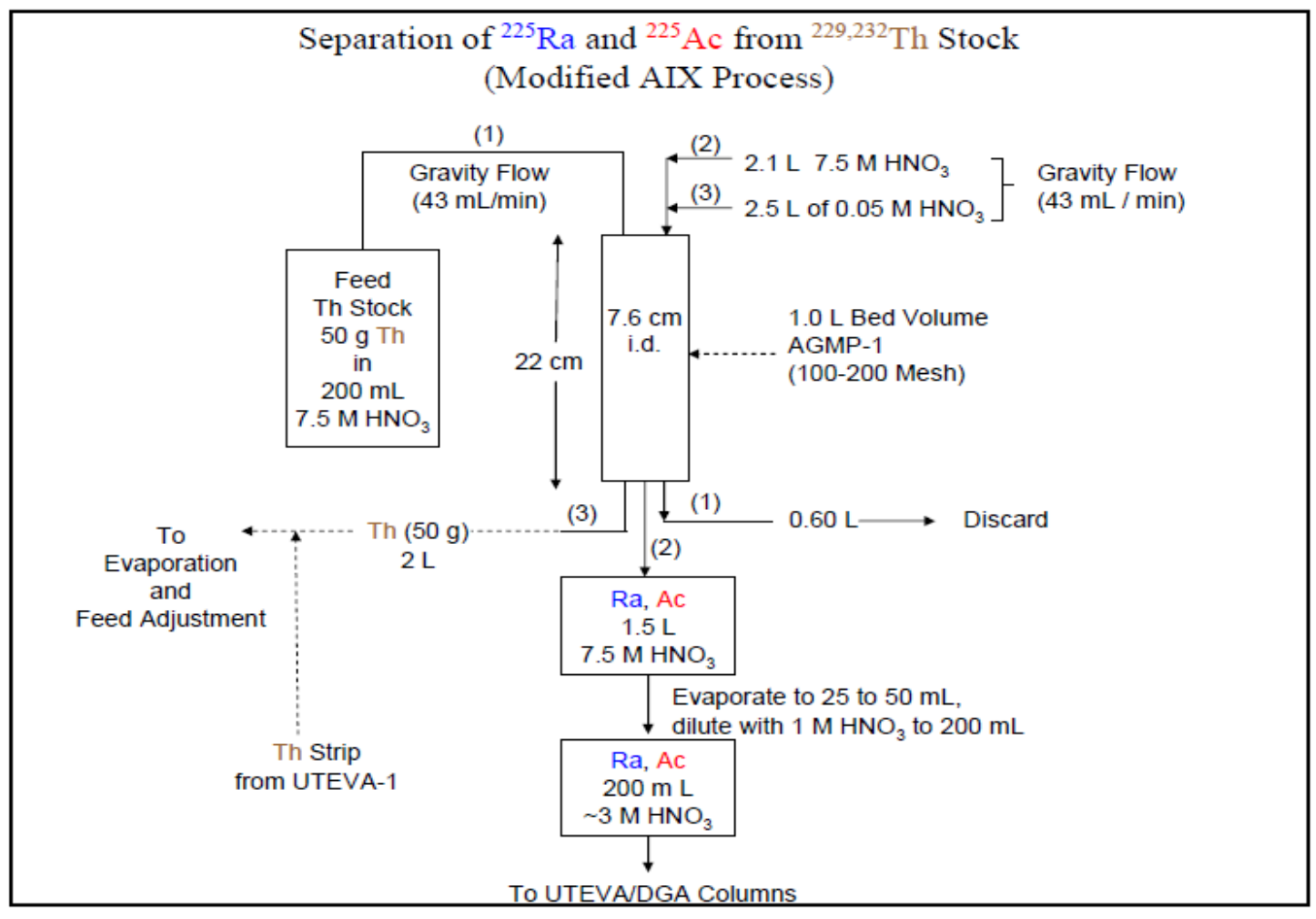

Figure 10: AIX bulk thorium separation step 
Alternatively, one can employ a liquid-liquid first step as shown in Figure 10a and Figure $10 b$.

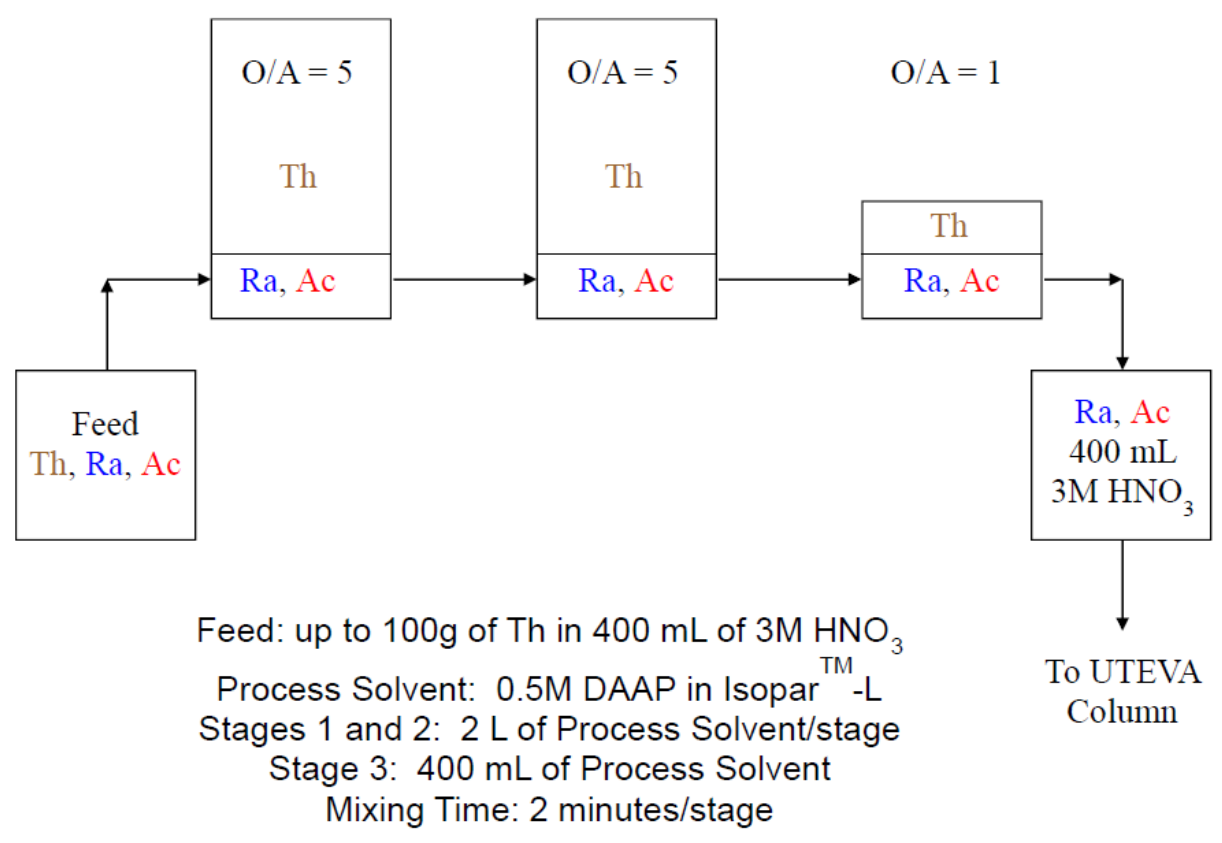

Figure 10a: Liquid-liquid first step to remove bulk thorium

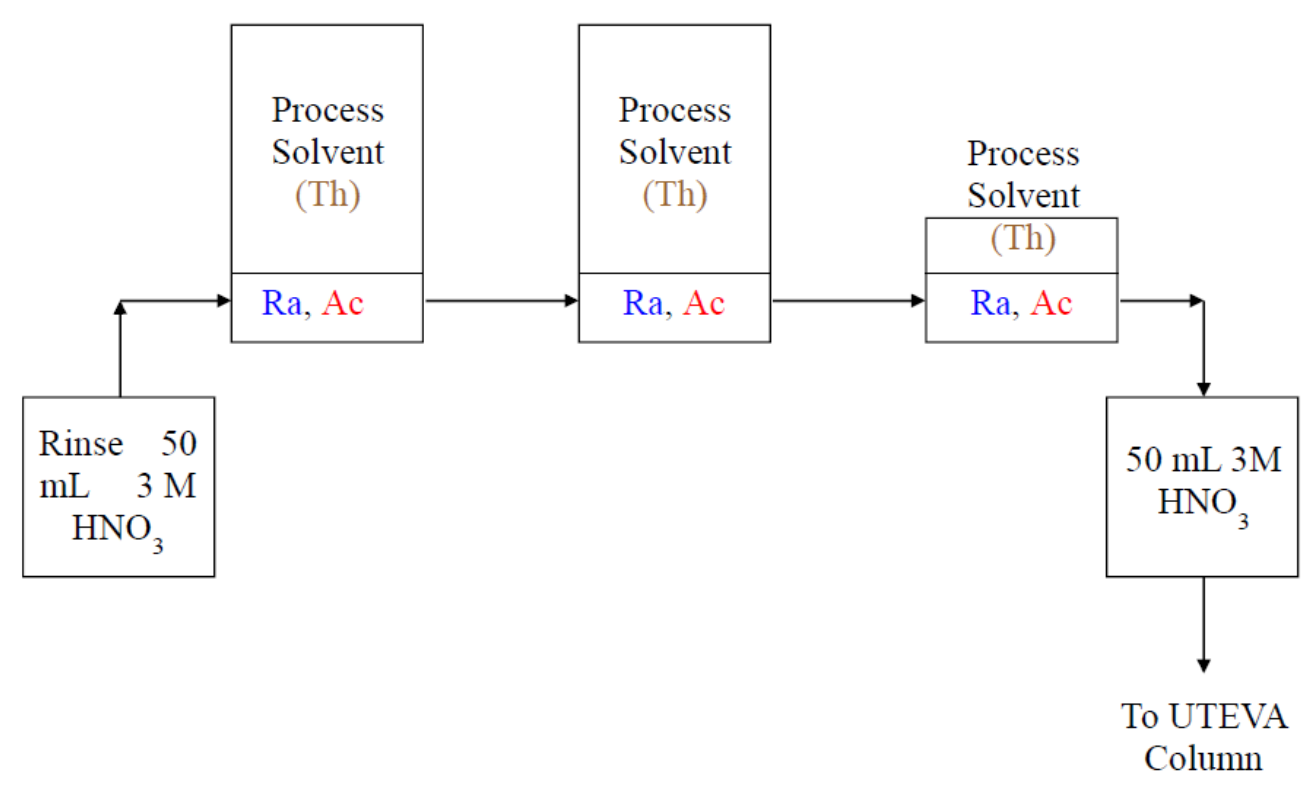

Figure 10b: Back extraction step 


\section{Separation of Ra and Ac from Trace Th}

(Columns are preconditioned with $1 \mathrm{BV} 3 \mathrm{M} \mathrm{HNO}_{3}$ )

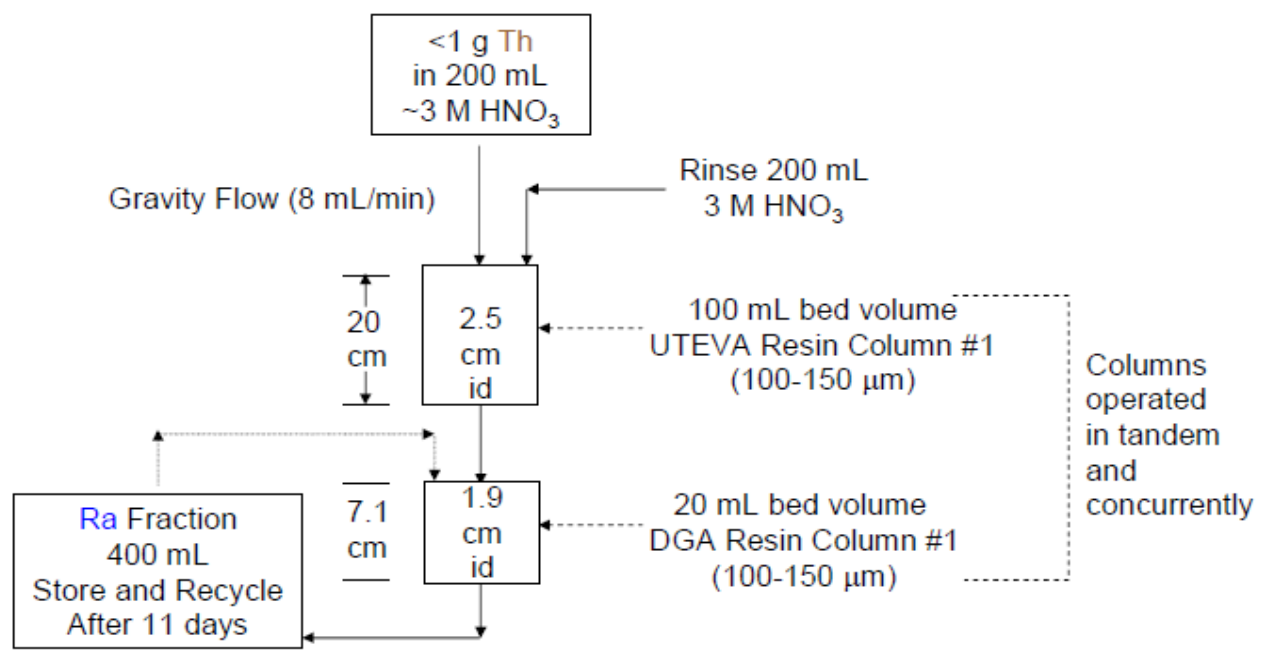

Figure 11: Initial isolation of actinium fraction with secondary thorium separation

\section{Separated UTEVA and DGA Columns}
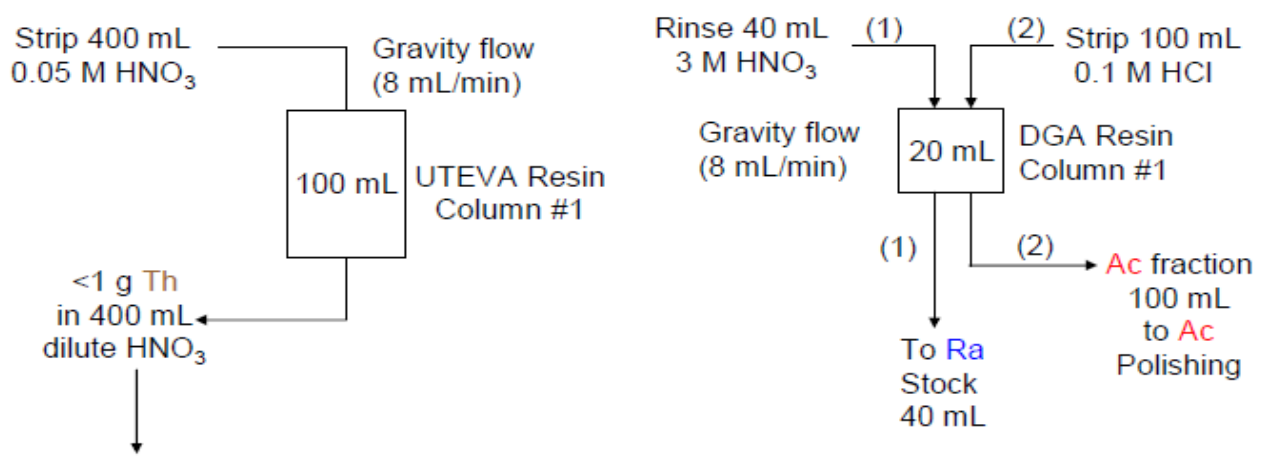

To filtration and evaporation

Figure 12: Recovery of initial actinium fraction and residual thorium 


\section{Ac Polishing Flowchart}

(Columns are preconditioned with $1 \mathrm{BV} 3 \mathrm{M} \mathrm{HNO}_{3}$ )

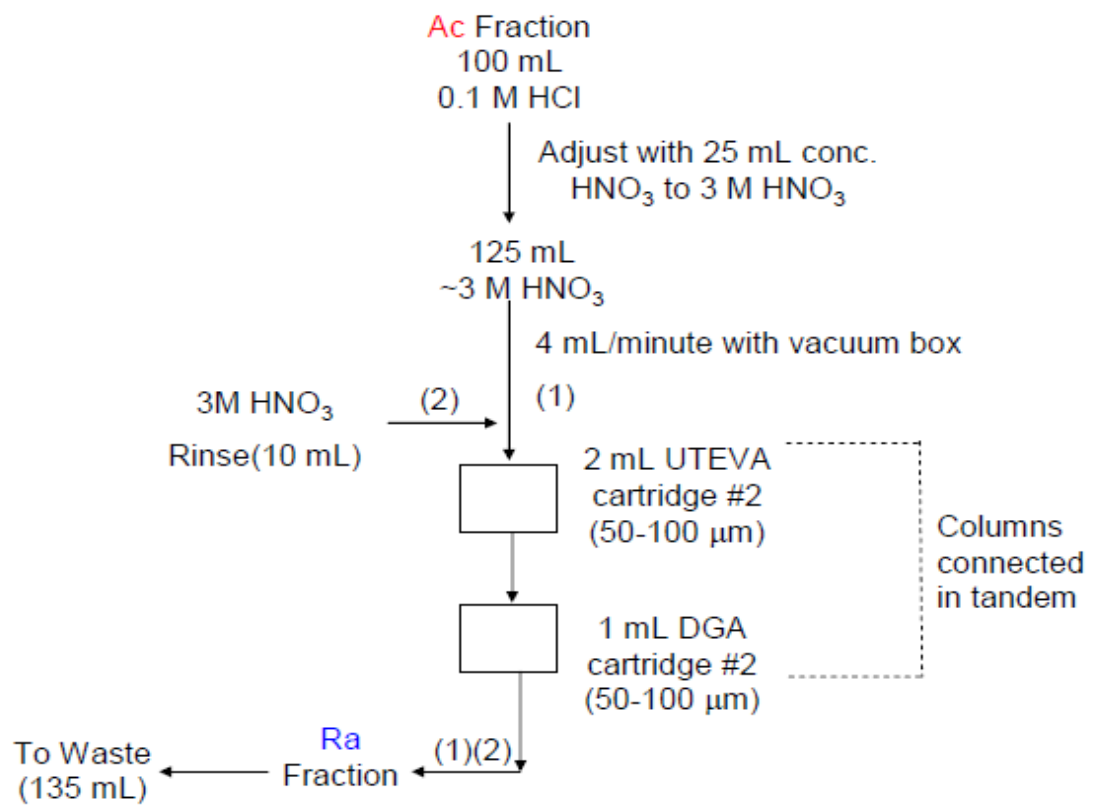

Figure 13: Step1 of final actinium purification

\section{Disconnected UTEVA and DGA Cartridges}

\section{(Discard UTEVA Cartridge)}

Flow rate $1 \mathrm{~mL} / \mathrm{min}$ with vacuum box

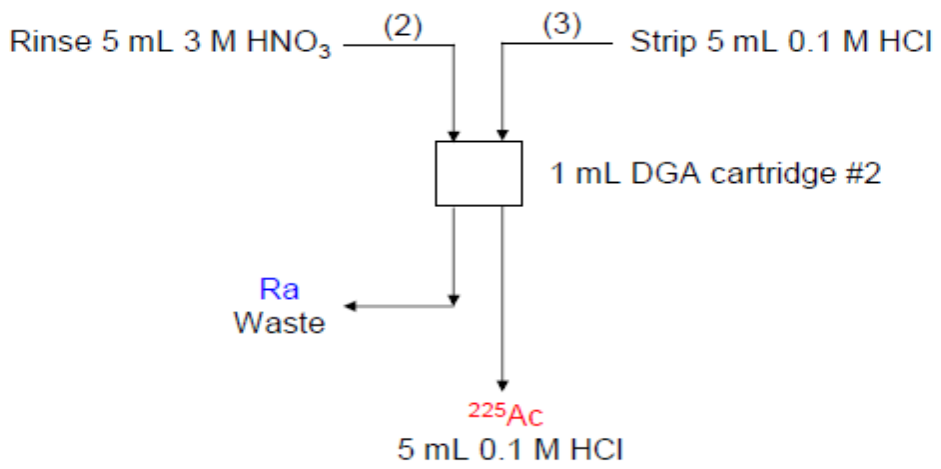

Figure 14: Final actinium product 
During the course of product evaluation, lanthanide radionuclides were detected in the actinium final product. These are from the fission products also produced in the high energy proton irradiation of the thorium target. For future work, an added clean-up step must be added prior to the final polishing (Figure 14). That added step is shown in Figure 15. It is clear from the conditions shown, the lanthanide fission products can effectively be removed from the actinium final product.

Due to the size of the target and in anticipation of future efforts that may involve similar or even larger targets, the liquid-liquid separation process was chosen for the bulk separation (Figures 10a \& 10b). Once the separation was completed, analysis of the resulting fractions was begun. Figure 16 shows the gamma spectra of the dissolved thorium target, the organic phase and the aqueous phase after the bulk separation step was completed. One can clearly see in Figure 16 that the bulk separation acted as intended. In comparing the organic and aqueous phases to the original dissolved material, the thorium and protactinium are in the organic phase as intended while the radium, actinium and daughters have stayed in the aqueous phase, again as intended.

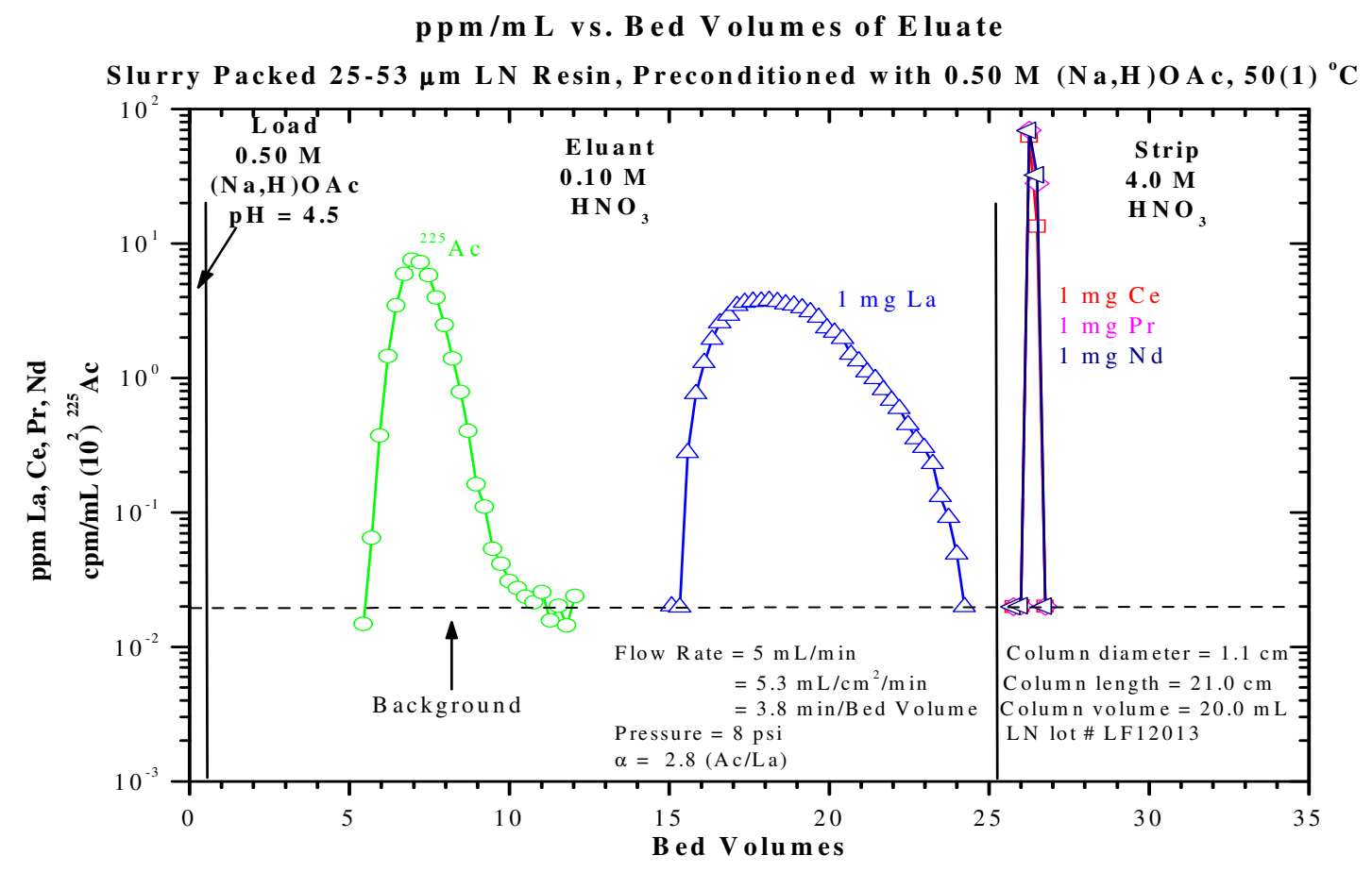

Figure 15: Added step for removal of lanthanide fission products 


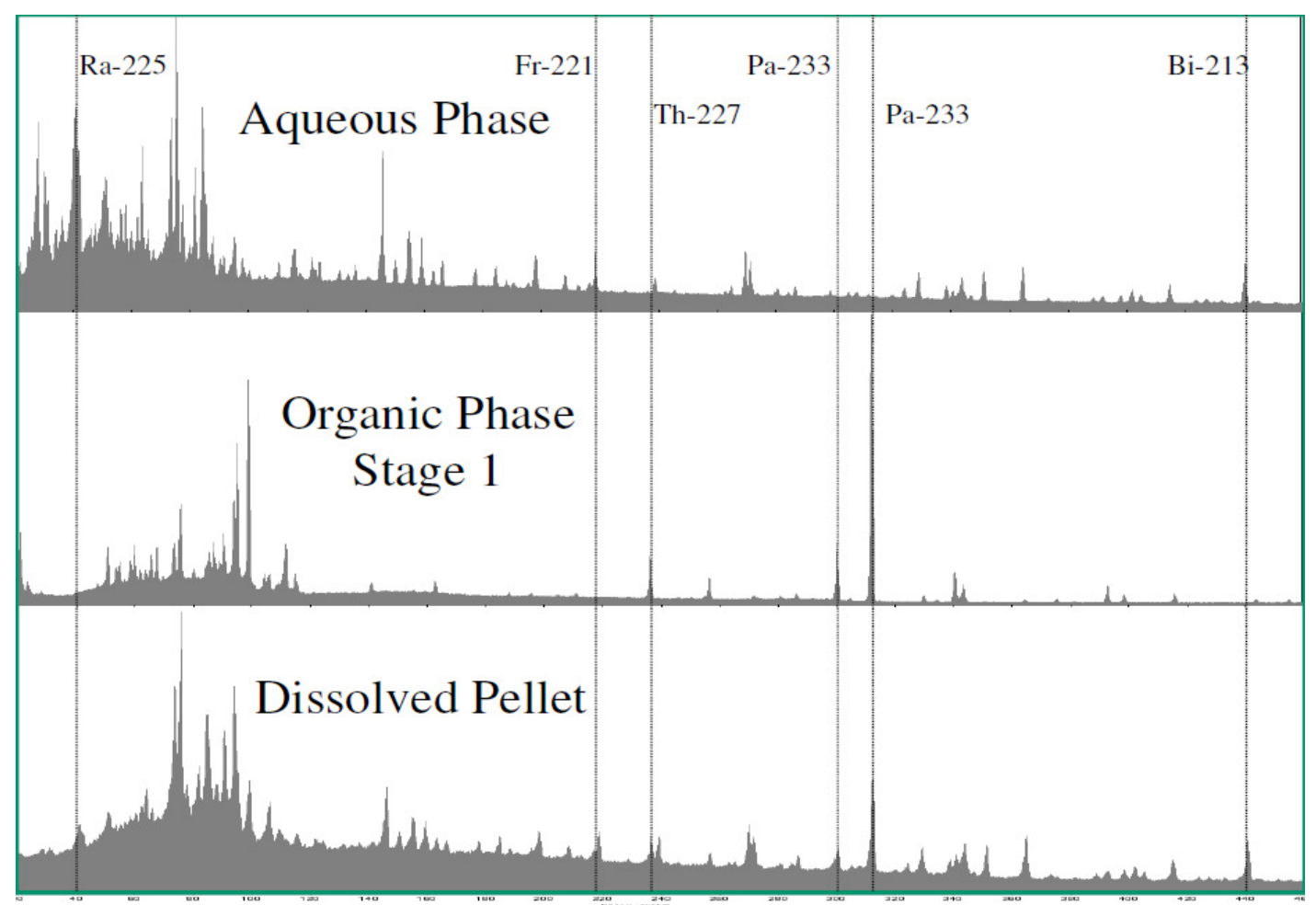

Figure 16: Gamma spectra of the dissolved target, organic phase and aqueous phase

Figure 17 is an alpha spectrum comparing the dissolved target solution with the aqueous feed to the first UTEVA/DGA column set (marked IX feed). Here one can see the aqueous feed is mostly devoid of thorium. The purpose of the first UTEVA/DGA column set is to scavenge the remaining thorium and provide the initial capture of the actinium product. This separation also serves as the primary actinium/radium separation. The radium fraction can be used to milk "second chance" actinium-225.

Of importance to note at this point is that the directly produced actinium-225 contains a small fraction of actinium-227 $(<0.5 \%$ in this case). This effort was not designed to address if this small fraction of actinium-227 would interfere with the use of actinium225 directly as a therapeutic agent. It does not interfere with the use of this actinium-225 to generate bismuth-213 for therapeutic use. Regardless, the separation and setting aside the radium-225 fraction as shown in Figure 13 allows for the recovery of "second chance" actinium-225 that is devoid of actinium-227.

Figure 18 depicts the separation of the aqueous phase feed to the initial UTEVA/DG resin separation to the final product. The alpha spectra presented clearly shows the actinium product contains no thorium and no radium, only actinium plus actinium daughters. As noted above, lanthanide fission products were observed in the gamma spectra but as none are alpha emitters, they do not appear in this slide. The insertion of the separation shown in Figure 13 above is necessary for future production of actinium-225 via this method to remove these unwanted radionuclides. 


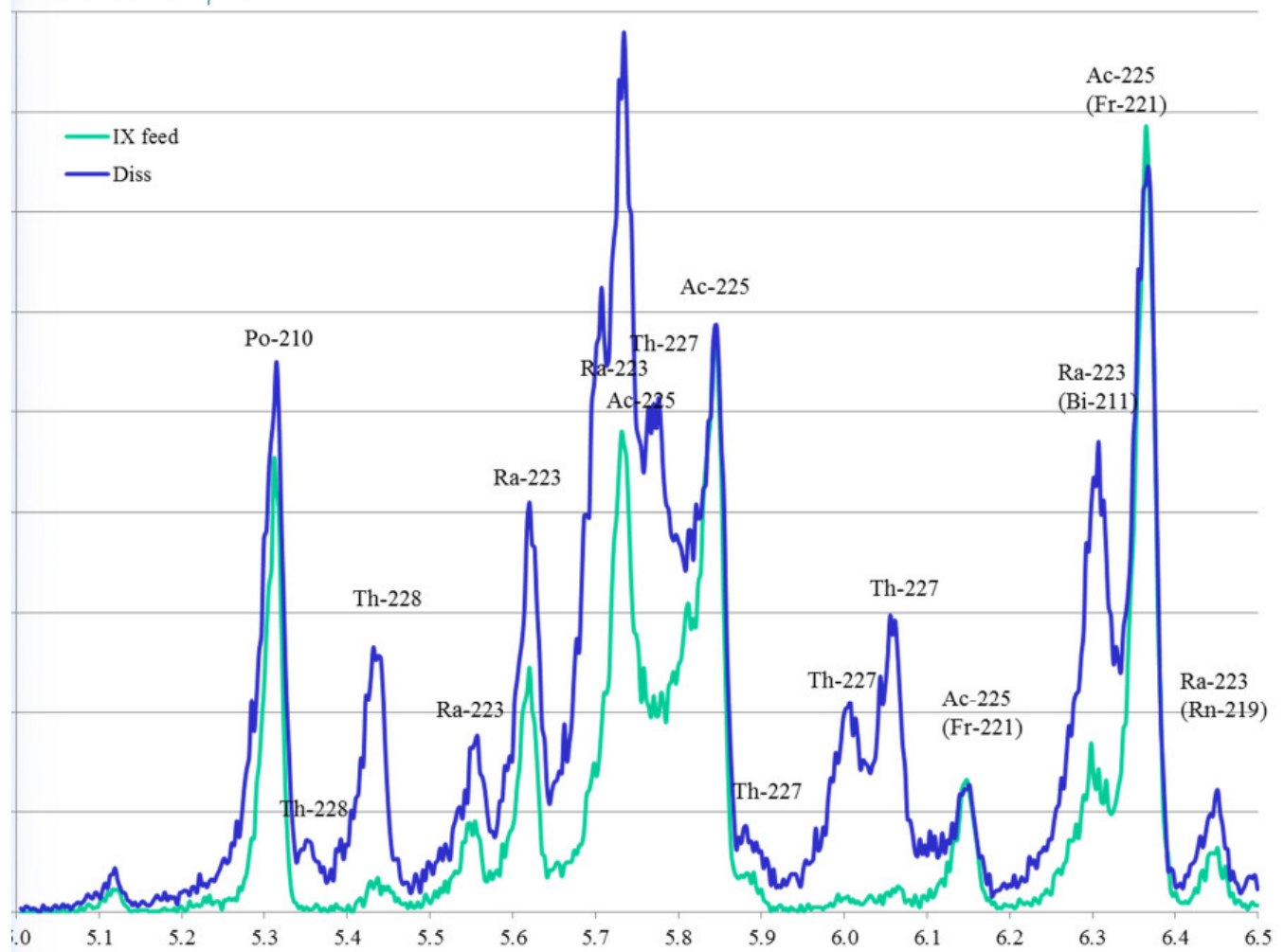

Figure 17: Initial alpha spectra comparing aqueous feed with dissolved target solution

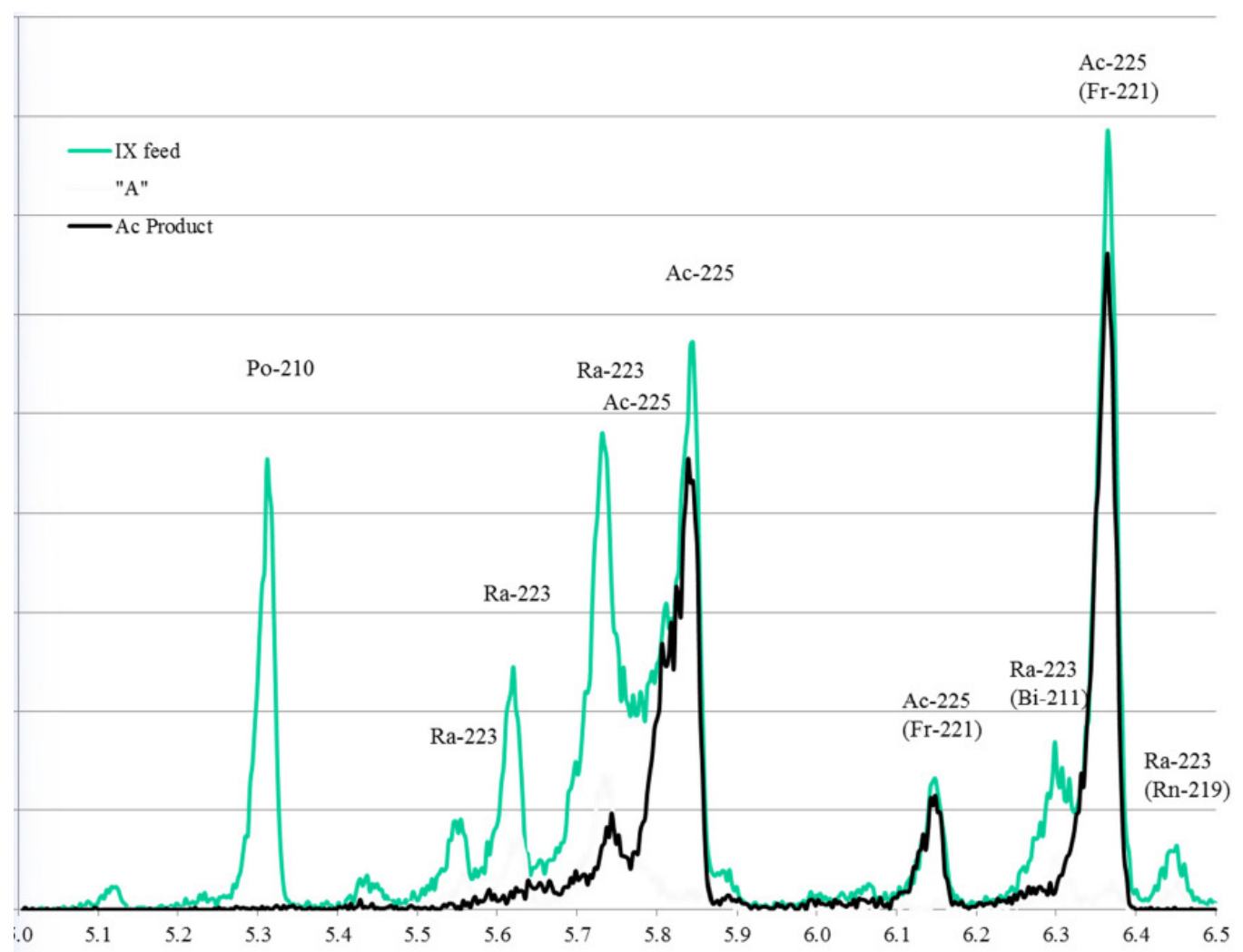

Figure 18: Comparison of the aqueous feed to the final actinium product 
Table 7 presents the results of the production of five primary radioisotopes of interest. The presented data is the average of the analysis performed by two different laboratories at ANL and at the PG Research Foundation. While slightly lower across the board than the calculated values, the agreement with the predicted activities is good and clearly shows that the calculations can be used to predict yields from the process. This demonstrated predictive ability increases the probability of success as the process is scaled up to the next level described in the Future Effort section below.

Table 7: Activities of actinium and related radioisotopes in millicuries

$$
\text { Ac-225 Ac-227 Ra-225 Th-227 Ra-223 }
$$

$\begin{array}{lccccc}\text { Calculated Activity } & 2.51 & 0.004 & 0.57 & 0.86 & 1.22 \\ \text { Measured }( \pm 1 \sigma \text { TPU) } & 2.08 \pm 0.20 & 0.003 \pm 0.001 & 0.49 \pm 0.11 & 0.86 \pm 0.11 & 0.77 \pm 0.09\end{array}$

Using the measured activities, we have estimated the measured cross sections for the reactions of primary interest. Table 8 presents those cross sections with a comparison to recently published cross section from Los Alamos from their efforts at $800 \mathrm{MeV}{ }^{8}$ Table 8 presents the comparison of the measured production cross section with the MCNPX calculated "thick target production cross section", for the same isotopes presented in Table 7. The MCNPX "thick target production cross section" was calculated for the whole target taking into account all secondary interactions. The purpose of presenting the "thick target production cross section", for the particular target configuration of the FNAL irradiation experiment, is to have another way to provide an order of magnitude check of both, the MCNPX and a simple back of envelope approach capabilities to predict the production rate in a thorium irradiated target. Note that the Los Alamos cross section values are for an $800 \mathrm{MeV}$ proton beam and the FNAL irradiation experiment was performed with an $8 \mathrm{GeV}$ proton beam. As it can be seen the cross section for actinium225 agrees well while the others follow a known pattern due to the difference of energy in the proton beam. It is known that the total spallation cross section saturates around 1 $\mathrm{GeV}$ and that the higher energy beam tends to produce, relatively, more products with atomic number and mass number away from the target material. On the other hand the products with atomic and mass number closer to the target material have their production reduced for the higher energy beam. It is not the objective of this report to validate the cross section but the results indicate that they agree reasonably well. It can be seen that using MCNPX to simulate a target irradiation is a valid tool to design an experiment.

Table 8: Comparison of calculated and measured cross sections for selected isotopes

$\begin{array}{lccccc} & \text { Ra-223 } & \text { Ra-225 } & \text { Ac-225 } & \text { Ac-227 } & \text { Th-227 } \\ \text { Calculated x-sec } & 7.09 & 4.89 & 16.0 & 13.6 & 9.84 \\ \text { LANL } & 5.0 \pm 0.6 & 3.0 \pm 0.3 & 13.5 \pm 0.7 & 20.8 \pm 3.1 & 12.0 \pm 1.0 \\ \text { This Work }( \pm 1 \sigma \text { TPU }) & 4.5 \pm 0.5 & 4.2 \pm 0.9 & 13.3 \pm 1.3 & 10.2 \pm 3.4 & 9.8 \pm 1.3\end{array}$

\footnotetext{
${ }^{8}$ Meiring Nortier, presentation at the "7th Target Alpha Therapy (TAT) Symposium”, July 17-19, 2011 Berlin, Germany
} 
One task (Task 5: Monoclonal Antibody (mAb) labeling and evaluation) was not performed during the course of this effort. It was planned to take bismuth-213 generated from actinium-225 produced by the spallation process and label it to MUC1 (or similar) antibody with comparison to similarly labeled bismuth-213 derived from actinium-225 purchased from ORNL. Unfortunately, due to an order processing error at ANL, the purchased actinium-225 arrived almost 90-dyas late and after the end of the project time period. Funds for this task were returned to the Office of Science.

\section{Summary}

The effort described herein to investigate an alternative production route for actinium-225 that does not utilize any DOE legacy materials derived from uranium-233 was proven successful at the proof-of-principal level. Actinium-225 is a potential therapeutic agent for cancer and infectious diseases but research efforts have been hampered by the lack of supply and the high costs of current production methods. The investigation of this new production route targets the elimination of both these issues by providing a potential route that can produce in one day more actinium-225 than the current world's annual output and reduce the costs of the material by as much as a factor of ten. This effort demonstrates the production route is feasible. By demonstrating the potential of the production route, this effort demonstrates supply and costs issues plaguing research and clinical development with actinium-225 can be resolved. Resolution of both supply and costs issues allows clinical research to proceed through clinical trials and potentially produce one or more effective therapies for cancer or infectious diseases that could benefit the public. The effort also demonstrated that other potentially significant medical radioisotopes that can be used in targeted alpha therapy can be co-produced such as radium-223, thorium-227 (parent of radium-223), and radium-225 (parent of actinium225). A host of other fission product radioisotopes, whose value determination was not part of this effort, are also co-produced.

\section{Future Efforts}

NorthStar will propose to the Office of Science a follow-on study during CY2012 to take this effort to the next level. That effort will propose to further develop this production route by producing clinically relevant amounts of actinium-225 ( 100mCi) per irradiation. Three irradiations will be proposed. Actinium-225 produced during each irradiation will then be delivered to at least four (4) clinical partners NorthStar has already signed-on for evaluation of the actinium-225 produced by this route relative to the clinical research each clinical partner already has underway utilizing actinium-225. The thrust of the proposed effort is not only to scale-up production to clinically relevant levels but to also prove the produced actinium-225 will perform acceptably for clinical researchers. 


\section{Products Developed}

\section{Conference Presentations:}

Alternate Method for Production of Ac225 - High Energy Proton Spallation of Thorium, presented at the 7th TAT Symposium, July 17-19, 2011, Berlin, Germany and at the $57^{\text {th }}$ Annual Radiobioassay and Radiochemical Measurements Conference, October 31November 4, 2011, Sandestin, FL 


\section{APPENDIX A}

\section{Task Summary and SOW}

Task 1: Reaction yields and radiological simulations (3 months)

Simulations will be carried out for a detailed 3D model of the production areas for the $400 \mathrm{MeV}$ and $8 \mathrm{GeV}$ beams including the effects of thorium targets at various locations and thicknesses relative to the beam dumps. These simulations, using MCNPX and Cinder, will serve as the basis for radiological planning in terms of safety envelopes, the overall actinium-225 yields, and the inventory of impurity isotopes as a function of time after the irradiations during a cool-off period. Simulations will provide necessary information for input to Task 2 Go-No Go milestones.

Task 2: Design \& Test Target Assembly (6 months; concurrent start with Task 1)

Task 2a: Design

Mechanical design of sample holders and vacuum enclosures with provision for rapid sample changing will be carried out after preliminary decisions on the optimal irradiation area are completed.

Task 2b: Fabricate/acquire

The mechanical and vacuum components will be constructed and/or modified from existing components that may be borrowed for the irradiations.

Task 2c: Install \& Test

The apparatus will be installed and checked out at the chosen irradiation area(s).

\section{Task 2 Go-No Go Milestones}

Prior to beginning of irradiations at FNAL, the following Go-No-Go milestones must be satisfactorily met for the $400 \mathrm{MeV}$ irradiation location:

- Design of the experimental cross to fit within the physical constraints of the location,

- That the radiation environment of the location allows the installation of the cross,

- That the radiation environment produced by the irradiation of the sample remains within the radiological safety envelope of the area, and 
- That accelerator operation allows the installation of the cross without jeopardizing the FNAL's primary mission of high energy physics operations.

and/or, the following Go-No Go milestone must be met for use of the $8 \mathrm{GeV}$ irradiation location:

- That the radiation environment produced by the irradiation of the sample remains within the radiological safety envelope of the area.

Task 3: Irradiations (3 months; begins month 4 of Task 2)

Irradiations (up to three) will be done as permitted by the FNAL accelerator operating schedule and as approved by FNAL staff upon satisfactorily meeting irradiation position required milestones given in Task 2 .

Task 4: Chemical separation and product evaluation (3 months; one month post start of Task 3)

Task 4a: separation (1 month each irradiation)

Chemical target processing will be performed post each irradiation after an appropriate target cool down period. The processing scheme to be employed will be as outlined in the flow sheets presented in the body of the proposal. ANL staff will perform initial quality testing and upon their release, a portion of the actinium-225 product will be shipped to NorthStar for final product evaluation.

Task 4b: product evaluation (1 month each irradiation)

For each product purified at ANL and received by NorthStar, the following product quality tests will be performed:

- Alpha spectroscopy of both actinium and bismuth products to ascertain presence of unwanted alpha emitters,

- Gamma spectroscopy of both actinium and bismuth products to ascertain presence of unwanted beta/gamma emitters,

- Decay/half-life studies of both actinium and bismuth products over multiple half-lives, and

- ICP analysis of the actinium and bismuth products for metals content.

Product quality testing will be performed relative to a sample of actinium-225 obtained from ORNL, considered the current standard of actinium-225 in the US. 
Task 5: mAb labeling and evaluation (1 month; concurrent with Task 4b)

In addition to Task 4 product quality test, labeling of a mAb will be performed for bismuth-213 generated from the actinium-225 parent for both the actinium-225 from ORNL and the actinium-225 produced by this effort.

Task 6: Project Technical Report (1 month)

In addition to a monthly progress summary, a final technical report will be prepared for DOE distribution detailing results of all Tasks outlined above. 


\title{
APPENDIX B
}

\section{Memorandum of Understanding for the NorthStar Medical Radioisotopes Thorium Irradiation Project}

\author{
February 2, 2011
}

\section{Introduction}

This memorandum is intended solely for the purpose of providing a work allocation for Fermi National Accelerator Laboratory and the participating institutions. It reflects an arrangement that is currently satisfactory to the parties involved. It is recognized, however, that changing circumstances of the evolving research program may necessitate revisions. The parties agree to negotiate amendments to reflect such revisions.

This Memorandum of Understanding applies to the use of the FNAL Booster Dump to study the yields of actinium-225, actinium-226, and actinium-227 production by the bombarding of a thorium target by an $8 \mathrm{GeV}$ proton beam. The tests will be carried out as a collaborative effort of FNAL, Argonne National Laboratory, I.C. Gomes Consulting \& Investment, Inc., and NorthStar Medical Radioisotopes.

\section{Personnel and Institutions}

James Harvey (NorthStar)

Jerry Nolen (Argonne-PHY)

George Vandegrift (Argonne-CSE)

Thomas Kroc (FNAL)

\section{Experimental Area, Beams, and Schedule Considerations}

Location

The tests will take place in the MI-8 line immediately upstream of the Booster Dump. The target will be located in the air gap between the end of the beam line and the face of the dump. The target will be a $2 \mathrm{~cm} \times 1 \mathrm{~cm} \times 1 \mathrm{~cm}$ piece of thorium- 232 housed in a sealed copper housing. The target holder mount will be an open, tubular frame structure primarily made of aluminum that will hold the target in place immediately in front of the beam dump. Both target holder and target holder mount are pictured in drawings in Attachment 1. 


\section{Beam}

Type of Beam Needed: $8 \mathrm{GeV}$ proton beam

Total Beam Needed: minimum $8 \times 10^{16}$ protons over a period of $2-7$ days

Beam Size Needed: approx. $1.5 \mathrm{~cm}(\mathrm{H})$ x $1 \mathrm{~cm}(\mathrm{~V})$

\section{Experimental Conditions}

The proposed target will be a $2 \mathrm{~cm} \times 1 \mathrm{~cm} \times 1 \mathrm{~cm}$ target made of metallic thorium- 232 . The target will be inside a copper case of dimensions just large enough to accept the target. The purpose of the copper case is to retain any alpha particle recoil from the thorium-232 and to provide a mechanism to assess the total number of protons striking the target through a number of known copper $(\mathrm{p}, \mathrm{x})$ reactions for which the cross sections are available at $8 \mathrm{GeV}$. The beam can be delivered by adding an appropriate number of "17" (Booster studies) events to the timeline in order to achieve the needed intensity. The total number of protons desired is, $5 \times 10^{14} \mathrm{p} / \mathrm{hr}$ for 7 days $\approx 8 \times 10^{16}$, represents approximately $1 \%$ of the annual limit of $6.8 \times 10^{18}$ stated in TM-2340. Note: excursions from the average pulse rate cause temperature increase of the target. A quantitative estimate of the tolerable excursions has been examined. The conclusion of thermal considerations (thorium target plus copper target holder) is:

- Examples of acceptable run scenarios:

○ 10 turns $\left(4.5 \times 10^{12}\right.$ protons per pulse $)$ at $0.1 \mathrm{~Hz}$ for approximately 2 days

- 1 turn $\left(4.5 \times 10^{11}\right.$ protons per pulse $)$ at $0.3 \mathrm{~Hz}$ for 7 days

○ 10 turns at $0.03 \mathrm{~Hz}$ for 7 days

- The first scenario delivers an average power of less than 5 watts to the sample plus the copper enclosure. This power can be dissipated by free air convection and thermal radiation. All other scenarios dissipate less power.

- Full power beam $(4.5 \mathrm{E} 12$ at $1 \mathrm{~Hz})$ can be safely tolerated for up to $10 \mathrm{sec}$ without overheating the sample (temp rise would be $<200^{\circ} \mathrm{C}$ in $10 \mathrm{~s}$ at full power), and

- The safe operating temperature of the copper enclosure will be up to $400^{\circ} \mathrm{C}$ as determined by the melting point of the hard solder.

See Attachment 2 for the complete thermal analysis.

The estimated activities of the primary radioisotopes of interest at the end of irradiation (EOI) assuming a 7 day steady irradiation to achieve the desired number of total protons is:

$\begin{array}{lll}\text { Ac225 } & 329 \text { microcuries } & \text { 10-day half-life } \\ \text { Ac226 } & 616 \text { microcuries } & \text { 1.2-day half-life } \\ \text { Ac227 } & <1 \text { microcurie } & \text { 22-year half-life }\end{array}$


By time of shipment, the bulk of the actinium-226 will be decayed, along with all other radioisotopes produced with a half-life of 1 day or less.

The estimated activities 10 days post EOI are:

$\begin{array}{lll}\text { Ac225 } & 188 \text { microcuries } & \text { 10-day half-life } \\ \text { Ac226 } & 7 \text { microcuries } & \text { 1.2-day half-life } \\ \text { Ac227 } & <1 \text { microcurie } & \text { 22-year half-life } \\ \text { Total alpha } & 2290 \text { microcuries } & \end{array}$

The estimated activities 30 days post EOI are:

$\begin{array}{lll}\text { Ac225 } & 63 \text { microcuries } & \text { 10-day half-life } \\ \text { Ac226 } & <0.01 \text { microcuries } & \text { 1.2-day half-life } \\ \text { Ac227 } & <1 \text { microcurie } & \text { 22-year half-life } \\ \text { Total alpha } & 989 \text { microcuries } & \end{array}$

A complete report of the theoretical yield calculations is provided in Attachment 3.

The anticipated irradiation schedule is as follows:

- The sample and its holder are placed in position during a booster access.

- The timing of this access will be determined by normal accelerator operational needs. The placement of the sample will be parasitic.

- The sample is irradiated for $2-7$ days.

$\circ$ During this time, additional beam can be sent to the booster dump as dictated by operational needs. Note that full intensity pulse streams at $1 \mathrm{~Hz}$ rate must be limited to $10 \mathrm{~s}$ (10 pulses) to avoid overheating the sample. It takes about $100 \mathrm{~s}$ for the sample to cool down following such a pulse stream. A log of all pulses (clock time and intensity) needs to be recorded for normalization of the irradiation/activation of the sample.

- Personnel associated with this project will monitor the sample irradiation rate and may request modifications to the rep rate to compensate.

- We ask for assistance from booster and operational personnel in initial steering of the beam to the dump. Once beam is established, project personnel will be responsible for monitoring the beam and the accumulated protons.

- At the end of irradiation, an access will be requested at the next convenient time dictated by accelerator operations. Hopefully, within 7 - 10 days.

- During this time, beam may still be directed to the dump if necessary for accelerator operations. However, we ask that this be minimized or avoided if possible.

- Project personnel will continue to monitor any additional protons on the sample. 
- Note that following the accumulation of 8E16 protons, the sample can be removed with tongs in $\sim 1$ minute and the target support stand moved to the side out of the beam also in $<1$ minute

- During the access, the sample and holder will be removed. The sample will be placed in its shipping container.

- If necessary, the container with the sample will be moved to a safe location determined by FNAL ES\&H to allow it to cool to safe shipping limits.

\section{Handling of Irradiated Materials}

The estimated unshielded dose from the target, aluminum target stand, and copper case at 1 meter at EOI is $\sim 600 \mathrm{mR} / \mathrm{hr}$ while the estimated unshielded dose from the target, aluminum target stand, and copper case at 1 meter 1 day post EOI is $\sim 85 \mathrm{mR} / \mathrm{hr}$. The estimate dose 10-days post EOI on the surface of the shipping container (target plus copper target holder) is $\sim 43 \mathrm{mR} / \mathrm{hr}$. At 30 -days post EOI on the surface of the shipping container (target plus copper target holder) is $\sim 12 \mathrm{mR} / \mathrm{hr}$. Actual experimental conditions will determine what these doses will be at any point post EOI.

ANL-CSE personnel will receive the target shipped from FNAL and upon receipt, will remove the target from the shipping container and place in a shielded hood for processing. The first step will be to remove the thorium-232 target from the copper case reserving the case for further studies via gamma spectroscopy. The thorium-232 target will be dissolved and will undergo chemical separation for a number of radioisotopes of interest, primary of which will be the actinium isotopes (Ac-225, Ac-226, and Ac-227) and actinium-225 parent radium-225. Other radioisotopes of medical interest will also be separated if such can be identified in gamma counting an aliquot of the dissolved primary solution.

\section{Schedule}

The project schedule by Task is:

\section{Task 1: Reaction simulations (3 months; 2QTRCY2010)}

Simulations, using MCNPX and Cinder, will serve as the basis for radiological planning in terms of safety envelopes, the overall actinium yields, and total inventory gamma activity.

Task 2: Design \& Test Target Assembly (6 months; late 2QTRCY2010 through 4QTRCY2010)

\section{Task 2a: Design}

Mechanical design of sample holders with provision for rapid sample changing will be carried out after preliminary decisions on the optimal irradiation area are completed. 
Task 2b: Fabricate/acquire

The sample and holder will be provided by the project.

Task 2c: Install \& Test

The apparatus will be installed and checked out at the chosen irradiation area. FNAL may be asked to provide some shimming materials for positioning the holder. Installation will be conducted with the assistance of FNAL Booster and ES\&H personnel.

\section{Task 2 Go-No Go Milestones (1QTRCY2011)}

- Need approval to proceed with first irradiation by end of 1QTRCY2011.

\section{Task 3: Irradiations (1QTRCY2011 or early 2QTRCY2011)}

Irradiations (one currently planned) will be done as permitted by the FNAL accelerator operating schedule and as approved by FNAL staff upon satisfactorily meeting irradiation position required milestones given in Task 2. Each irradiation requires independent FNAL approval.

Task 4: Chemical separation and product evaluation (3 months; beginning with first irradiation)

Task 4a: separation (1 month each irradiation)

Chemical target processing will be performed post each irradiation after an appropriate target cool down period. The processing scheme to be employed will be as outlined in the flow sheets presented in the body of the proposal. ANL-CSE staff will perform initial quality testing and upon their release, a portion of the actinium-225 product will be shipped to NorthStar for final product evaluation.

Task 4b: product evaluation (1 month each irradiation)

For each product purified at ANL-CSE and received by NorthStar, the following product quality tests will be performed:

- Alpha spectroscopy of both actinium and bismuth products to ascertain presence of unwanted alpha emitters,

- Gamma spectroscopy of both actinium and bismuth products to ascertain presence of unwanted beta/gamma emitters,

- Decay/half-life studies of both actinium and bismuth products over multiple half-lives, and 
- Inductively Coupled Plasma (ICP) analysis of the actinium and bismuth products for metals content.

Product quality testing will be performed relative to a sample of actinium-225 obtained from ORNL, considered the current standard of actinium-225 in the US.

Task 5: Monoclonal Antibody (mAb) labeling and evaluation (1 month; concurrent with $\underline{\text { Task } 4 \mathrm{~b})}$

In addition to Task 4 product quality test, labeling of a mAb will be performed for bismuth-213 generated from the actinium-225 parent for both the actinium-225 from ORNL and the actinium-225 produced by this effort.

Task 6: Project Technical Report (1 month; late 2QTRCY2011)

In addition to a quarterly progress summary, a final technical report will be prepared for DOE distribution detailing results of all Tasks outlined above.

\section{Responsibilities by Institution - Non FNAL}

Personnel from the participating institutions will provide the target material and fixtures for supporting the target at the appropriate position in the beam.

NorthStar has proposed and will provide, upon approval, an appropriate DOT/IATA container for the transportation of the irradiated target to ANL-CSE Division for chemical analysis. Details of the transport container proposed transport container can be found at:

The container (type 001-724 shipping system) is the following:

http://www.biodex.com/radio/pet/pet_724feat.htm

The Certificate can be found at:

http://www.biodex.com/radio/pet/reports/001724_compliance.pdf

Shipping will be done via FedEx ground at the point that the surface dose readings of the shipping container holding the target fall within DOT YELLOW-II limits $(<50 \mathrm{mrem} / \mathrm{hr}$ all points on the surface of the shipping container). Currently, based on the expected

activities of the target and copper case, shipping cannot occur before the $10^{\text {th }}$ day post EOI. Actual experimental conditions will determine when the shipment can take place. It should be noted that delays in shipping will not impact the primary chemical analyses planned as there is sufficient activity of actinium-225 produced to provide more than adequate activities for studies planned as long as the target can be shipped within a month of EOI. 
Argonne will coordinate with FNAL ES\&H to ensure that transportation of the irradiated target complies with DOE STD-1027-92 CAT-3. Attachment 4 provides an analysis of the radioisotopes present as a fraction of the limits given in the standard in the thorium target, aluminum target stand, and copper target holder at EOI and 10-days post EOI.

Shipping and handling contacts are:

ANL: Andrew P. Bracken, (630) 252-7388, abracken@anl.gov

FNAL: Billy Arnold, (630) 840-3741, billy_arnold@fnal.gov

NMR: James Harvey, (630) 904-4227, jharvey@ northstarnm.com

\section{Responsibilities by Institution - FNAL}

FNAL Accelerator Division

The accelerator division provides access time for the installation of the target and its supporting structure. It will then supply beam to the target noted in Section 3 above. After the irradiation is complete, another access will be provided within seven days of the end of irradiation for the retrieval of the target. Target will be placed in the shipping container and set aside until the shipment can be made in accordance with FNAL, DOE, and DOT regulations.

FNAL ES\&H Section

NEPA and other safety reviews. Coordination of shipment of irradiated target.

\section{Summary of Costs}

$\begin{array}{llll}\text { Source of Funds [\$K] } & \text { Equipment } & \text { Operating } & \begin{array}{l}\text { Personnel } \\ \text { (person weeks) }\end{array} \\ \text { Accelerator Division } & \$ 0 \mathrm{~K} & \$ 0 \mathrm{~K} & 1 \\ \text { ES\&H Section } & \$ 0 \mathrm{~K} & \$ 0 \mathrm{~K} & 1 \\ \text { Totals FNAL } & \$ 0 \mathrm{~K} & \$ 0 \mathrm{~K} & 2\end{array}$




\section{SIGNATURES:}

/ / 2011

James Harvey, NorthStar Medical Radioisotopes

/ $\quad / 2011$

Jerry Nolen, Argonne National Laboratory

/ / 2011

George Vandegrift, Argonne National Laboratory

/ / 2011

Thomas Kroc, FNAL

/ $\quad / 2011$

Roger Dixon, Accelerator Division, FNAL

/ / 2011

Nancy Grossman, ES\&H Section, FNAL

/ / 2011

Stuart Henderson, Associate Director for Accelerators, FNAL 
Attachment 1

Target Holder and Target Stand Drawings 


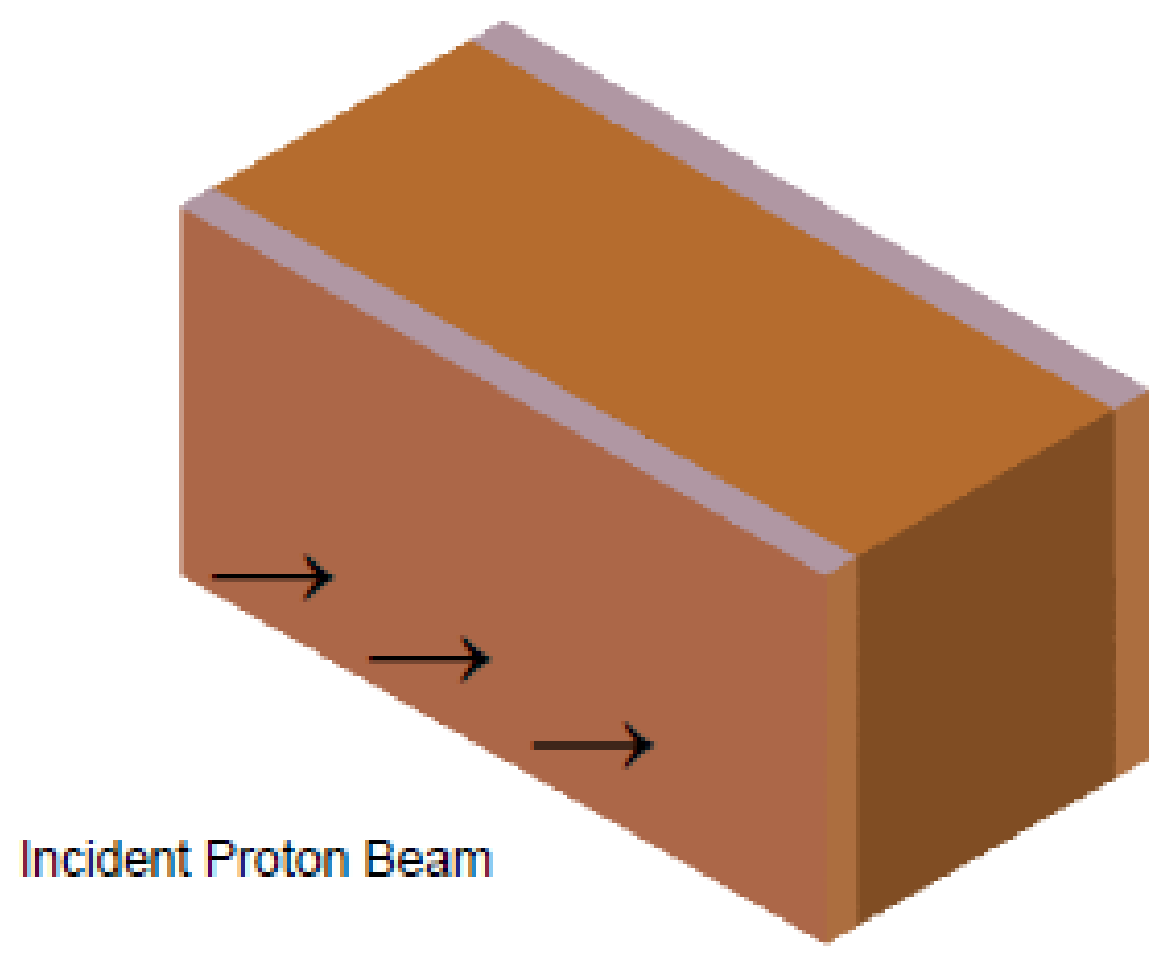

Copper Target Holder $(2 \mathrm{~cm} \times 1 \mathrm{~cm} \times 1 \mathrm{~cm})$ 


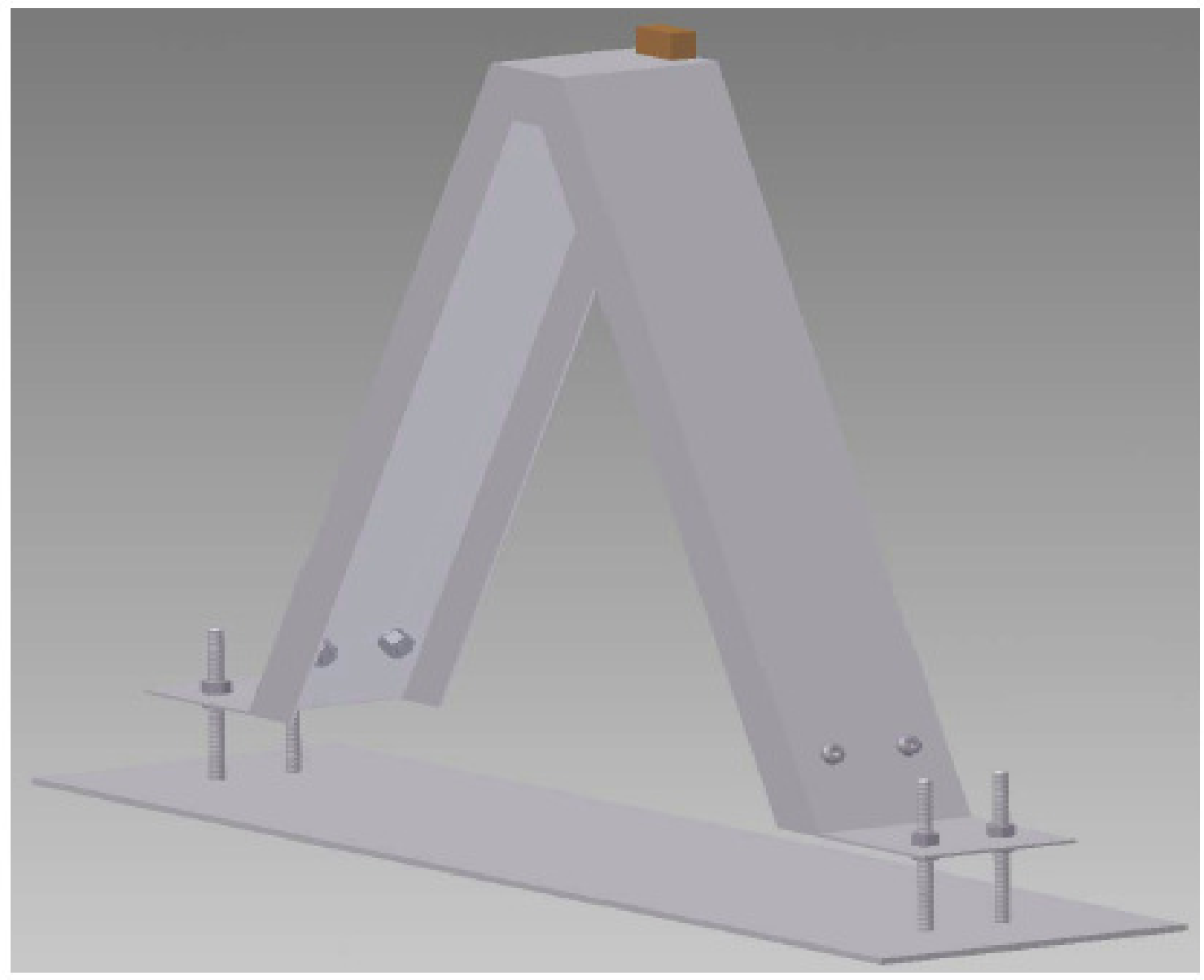

Aluminum Target Holder Stand 
Attachment 2

Target Temperature Excursion Analysis 
Target temperature rise per pulse and equilibrium max temperature at full booster beam current

$2 \mathrm{~cm} 3$ thorium target

Booster max p per pulse (10 turn accumulation):

Protons required to achieve 100 micro-Ci per $\mathrm{cm} 3$ :

Beam rate options:

density of thorium: $11.7 \mathrm{~g} / \mathrm{cm} 3$

volume of thorium sample: $2 \mathrm{~cm} 3$

mass of thorium samples

energy of protons: $8 \mathrm{GeV}$

beam power at full current

power deposited in sample (based on Itacil's thermal simulations with MCNPX)

Stefan-Boltzmann constant

watts radiated

$16.129 \mathrm{~cm} 2$

0.3 emissivity

air cooling, free convection

$0.001 \mathrm{~W} / \mathrm{cm} 2-\mathrm{K}$

$16.129 \mathrm{~cm} 2$

Delta-T per full intensity pulse

number of pulses to raise temperarue $400 \mathrm{C}$ with no cooling assumed values

$5.00 \mathrm{E}+12$ full current protons per pulse of booster

$8.00 \mathrm{E}+16$ about $1 \%$ of annual beam dump dose limit

$\begin{array}{llll}1.60 \mathrm{E}+04 \text { seconds } & 4.44 \mathrm{E}+00 \text { hours } & 1.85 \mathrm{E}-01 \text { days } & \\ 1.60 \mathrm{E}+05 & 4.44 \mathrm{E}+01 & 1.85 \mathrm{E}+00 & \sim 2 \text { days @ } 1 \text { pulse per } 10 \mathrm{sec} \\ 1.60 \mathrm{E}+06 & 4.44 \mathrm{E}+02 & 1.85 \mathrm{E}+01 & \\ & & \\ 0.12 \mathrm{~J} / \mathrm{g}-\mathrm{K} & & \\ 11.7 \mathrm{~g} / \mathrm{cm} 3 & \\ 2 \mathrm{~cm} 3 & \\ & \\ & \\ & \\ & \end{array}$

$6.67 \mathrm{E}+00 \mathrm{~kW}$

$\begin{array}{lrl}< & 40.0 \text { Watts } & \text { at full beam power } \\ < & 4.0 \text { Watts } & \text { at } 10 \% \text { power }\end{array}$

$5.67 \mathrm{E}-12 \mathrm{~W} / \mathrm{cm} 2-\mathrm{K} 4$

5.628232 Watts

6.4516 Watts

$14.2 \mathrm{~K}$

28.1 less than $30 \mathrm{~s}$ at full current

(temp rise would be $<200 \mathrm{C}$ in $10 \mathrm{~s}$ at full power

Conclusion:

Full power beam can be safely tolerated for up to $10 \mathrm{~s}$ without overheating the sample

days (until a total dose of $8 \mathrm{E} 16$ protons)

A viable run scenario is up to $5 \mathrm{E} 12$ protons per pulse once every $10 \mathrm{~s}$ or less for about 2 This scenario delivers an average power of less than 4 watts to the sample

This power can be dissipated by free air convection and thermal radiation 


\section{Effect of copper housing}

density of copper: $8.9 \mathrm{~g} / \mathrm{cm} 3$

total thickness of copper front and back:

energy loss of protons in copper at $8 \mathrm{GeV}$

fraction of energy loss

using same fraction of beam power as for thorium per $\mathrm{g} / \mathrm{cm} 2$ gives power in windows:

thickness of copper sides

estimate of percent of beam hitting sides

total power deposited by halo in the sides

total power deposited in the copper

volume of copper $\left(0.5^{\prime \prime} \times 0.5^{\prime \prime} \times 1.0^{\prime \prime}\right.$ with $0.05^{\prime \prime}$ wall thickness

total mass of copper

specific heat of copper: $0.385 \mathrm{~J} / \mathrm{g}-\mathrm{K}$

Delta-T of copper per full intensity pulse

number of pulses to raise copper temperature $400 \mathrm{C}$ with no cooling assumed (assume no heat transfer from Th in short time)
$8.9 \mathrm{~g} / \mathrm{cm} 3$

$25 \mathrm{~mm}$

$2.225 \mathrm{~g} / \mathrm{cm} 2$

$1.52 \mathrm{MeV} / \mathrm{g} / \mathrm{cm} 2$

0.00019 fraction per $\mathrm{g} / \mathrm{cm} 2$

\subsection{4 watts at $10 \%$ beam power}

$12.7 \mathrm{~mm}$

$11.303 \mathrm{~g} / \mathrm{cm} 2$

$5 \%$

0.193214 watts at $10 \%$ beam power

0.953897 watts at $10 \%$ beam power

$0.589934 \mathrm{~cm} 3$

$5.250415 \mathrm{~g}$

$0.385 \mathrm{~J} / \mathrm{g}-\mathrm{K}$

$\sim 3 x$ that of Th per $g$

$4.7 \mathrm{~K}$

$84.8 \quad$ less than $80 \mathrm{~s}$ at full current

Conclusion:
[Notl power beam can be safely tolerated for up to $10 \mathrm{~s}$ without overheating the sample
specific heats and masses of the thorium and copper, and the number of Joules of energy deposited per pulse. Following a stream of pulses
at $1 \mathrm{~Hz}$ it takes about $100 \mathrm{sec}$ for the sample temperature to return to equilibrium.]
A viable run scenario is up to $5 \mathrm{E} 12$ protons per pulse once every $10 \mathrm{~s}$ or less for about 2 days (until a total dose of $8 \mathrm{E} 16$ protons)
This scenario delivers an average power of less than 5 watts to the sample + copper enclosure
This power can be dissipated by free air convection and thermal radiation
The safe operating temperature of the copper enclosure will be up to $400 \mathrm{C}$ as determined by the melting point of the hard solder.


Attachment 3

Report of Theoretical Calculations 


\section{Final Report}

\section{Calculations in Support of the Grant \\ Production of Actinium-225 via High Energy Proton Induced Spallation of Thorium-232}

\section{I.C.Gomes Consulting \& Investment Inc.}

September 21, 2010 


\section{PART I - Activation Analysis of the Target}

\section{Introduction}

Calculations were performed to assess the expected activity of ${ }^{225} \mathrm{Ac}$ and other radioactivity produced in a sample irradiated at a position near the beam stop of the booster beam line at FNAL. This irradiation position was selected based on the accessibility criterion allowing a very simple placement of the sample against the front wall of the beam stop. The beam profile at this position is related to the beam intensity which depends on the number of turns that takes to fill the booster. Despite all beam profiles being already included in the model and calculations performed only the case for 10 turns in the booster is presented in this report. This is made to avoid excessive number of results and also because all profiles are relatively similar with the same total number of protons per second hitting the target.

The case reported is for a thorium target placed in front of the concrete box which encases the steel beam stop. Calculations performed at the FNAL indicated that the beam stop can only take about 20 minutes of the $8 \mathrm{GeV}$ proton beam of the booster beam line at a rate of $6.0 \times 10^{13}$ protons per second before the steel beam stop melts. Considering that the placement of the thorium target will have almost no influence on the power intensity reaching the beam stop, this limitation is expect to be maintained during irradiation. However limitation regarding the activity level in the target for transportation after irradiation is also an important parameter to be taken in consideration. The irradiation scenario selected was to have the target irradiated for a full week, 24 hours per day with a proton intensity of $1.32 \mathrm{e}+11$ protons per second, representing a total number of protons on the target of $8.0 \times 10^{16}$.

\section{General Assumptions}

The beam intensity was considered to be $1.32 \times 10^{11}$ protons per second representing $8.0 \times 10^{16}$ protons during the total one week of irradiation. The beam energy is assumed to be 8 $\mathrm{GeV}$. The beam operates at $1 \mathrm{~Hz}$ with a pulse length of $1.56 \mu \mathrm{sec}$.

Considering the nature of the irradiation the calculations where performed in steady state mode, not in pulsed mode because it has no impact on the activation or temperature distribution of the target. The length of irradiation was assumed to be a full week with 24 hours per day irradiation. Based on the hypothesis that the steel beam stop will melt with $6 . \times 10^{13}$ protons per second in 20 minutes results a total number of protons of $7.2 \times 10^{16}$; however it was assumed to be very safe to irradiate the target by roughly the same number of protons but during a much long period of time, namely one week. The assumption of melting the beam stop with $7.2 \times 10^{16}$ protons in 20 minutes is very conservative and it does not consider any heat transfer from the beam stop and surroundings. Then, the irradiation scenario selected is expected to face no problem in being accepted by the safety review committee at FNAL.

Then based on the points outlined above, the full irradiation scenario was assumed to be one week of irradiation at $1.32 \times 10^{11}$ protons per second and a cooling time of 10 days before transporting the irradiated target from the FNAL to Argonne National Laboratory. The geometric configuration of the target was assumed to be a thorium block with external dimensions of $1 \times 2 \times 1 \mathrm{~cm}^{3}$, being $1-\mathrm{cm}$ thick in the beam direction. The range of an $8 \mathrm{GeV}$ proton in a full 
density thorium is about $5.72 \mathrm{~m}$, indicating that only a small amount of the beam energy will be deposited in the thorium target.

In the beam and radiation transport simulations carried out with the MCNPX, the beam stop is also represented in the geometry despite having relatively small influence on the activation results for the target.

\section{Results}

Table 1 presents the results for a single Thorium target with dimensions $2 \mathrm{~cm} \mathrm{x} 1 \mathrm{~cm} \mathrm{x}$ $1 \mathrm{~cm}$ placed in front of the entrance of the beam stop inside the concrete block. Table 1 gives, for the irradiation scenario considered the activity $(\mathrm{Ci})$ of the three actinium isotopes of interest (225, 226, and 227) at the end of the irradiation and 10 days after shutdown. The volume of the target is $2 \mathrm{~cm}^{3}$ and the density of the thorium is $11.67 \mathrm{~g} / \mathrm{cm}^{3}$. As it can be seen, the activity of the ${ }^{225} \mathrm{Ac}$ does reduce by about a factor of 2 during its half-life (10 days) but it is not exactly $50 \%$ due to the additional feeding from the decay of ${ }^{225} \mathrm{Ra}$.

Table 1. Activity (Ci) of the actinium isotopes at the end of the irradiation, 10 and 30 days after shutdown, in a Thorium target with dimensions $2 \times 1 \times 1 \mathrm{~cm}^{3}$ irradiated during 7 days with $8 \mathrm{GeV}$ protons at a rate of $1.32 \times 10^{11}$ protons/sec.

\begin{tabular}{|c|c|c|c|}
\hline & After 7 days of Irradiation & 10 days after the EOI & 30 days after the EOI \\
\hline${ }^{225} \mathrm{Ac}$ & $3.29 \times 10^{-4}$ & $1.88 \times 10^{-4}$ & $6.33 \times 10^{-5}$ \\
\hline${ }^{226} \mathrm{Ac}$ & $6.16 \times 10^{-4}$ & $1.99 \times 10^{-6}$ & $1.32 \times 10^{-9}$ \\
\hline${ }^{227} \mathrm{Ac}$ & $7.09 \times 10^{-7}$ & $7.08 \times 10^{-7}$ & $7.07 \times 10^{-7}$ \\
\hline
\end{tabular}

Table 2 presents the total gamma (gamma/ $\left.\mathrm{cm}^{3}-\mathrm{sec}\right)$ in the target geometric configuration and irradiation profile considered. The gamma activity represents the gamma-ray generated informingly distributed inside the sample at just after shutdown, 10, and 30 days after the end of the irradiation. The gamma ray spectrum is given in a multi-group energy structure and the values are the number of gamma-rays generated in the target per cubic centimeter per second within the energy interval of the respective row. As it can be noticed, the high energy gamma-ray component decays much faster than the low energy component what is beneficial in terms of shielding. However, special care should be taken in calculating the dose equivalent for the transportation package because high gamma-rays are still present after 10 or 30 days from the end of irradiation.

Table 2. Estimated multi-group gamma ray activity $\left(\gamma / \mathrm{cm}^{3}-\mathrm{sec}\right)$ in target at the time just after, 10, and 30 days after shutdown. Note that the target is $2 \mathrm{~cm}^{3}$.

\begin{tabular}{|c|c|c|c|c|}
\hline Emin & Emax & $\begin{array}{c}\text { After 7 days of } \\
\text { Irradiation }\end{array}$ & 10 days after the EOI & 30 days after the EOI \\
\hline $0.00 \mathrm{E}+00$ & $1.00 \mathrm{E}-02$ & $1.61 \mathrm{E}+09$ & $7.58 \mathrm{E}+07$ & $2.77 \mathrm{E}+07$ \\
\hline $1.00 \mathrm{E}-02$ & $3.00 \mathrm{E}-02$ & $1.42 \mathrm{E}+09$ & $4.74 \mathrm{E}+07$ & $1.86 \mathrm{E}+07$ \\
\hline $3.00 \mathrm{E}-02$ & $6.00 \mathrm{E}-02$ & $4.15 \mathrm{E}+09$ & $2.10 \mathrm{E}+08$ & $7.99 \mathrm{E}+07$ \\
\hline $6.00 \mathrm{E}-02$ & $1.00 \mathrm{E}-01$ & $1.09 \mathrm{E}+09$ & $5.18 \mathrm{E}+07$ & $2.26 \mathrm{E}+07$ \\
\hline $1.00 \mathrm{E}-01$ & $2.00 \mathrm{E}-01$ & $1.86 \mathrm{E}+09$ & $5.84 \mathrm{E}+07$ & $3.09 \mathrm{E}+07$ \\
\hline
\end{tabular}




\begin{tabular}{|c|c|c|c|c|}
\hline $2.00 \mathrm{E}-01$ & $3.00 \mathrm{E}-01$ & $1.48 \mathrm{E}+09$ & $2.37 \mathrm{E}+07$ & $6.38 \mathrm{E}+06$ \\
\hline $3.00 \mathrm{E}-01$ & $5.00 \mathrm{E}-01$ & $2.15 \mathrm{E}+09$ & $4.59 \mathrm{E}+07$ & $1.90 \mathrm{E}+07$ \\
\hline $5.00 \mathrm{E}-01$ & $5.25 \mathrm{E}-01$ & $1.32 \mathrm{E}+09$ & $1.42 \mathrm{E}+07$ & $5.59 \mathrm{E}+06$ \\
\hline $5.25 \mathrm{E}-01$ & $7.50 \mathrm{E}-01$ & $1.94 \mathrm{E}+09$ & $4.63 \mathrm{E}+07$ & $1.12 \mathrm{E}+07$ \\
\hline $7.50 \mathrm{E}-01$ & $1.00 \mathrm{E}+00$ & $1.76 \mathrm{E}+09$ & $4.77 \mathrm{E}+07$ & $1.24 \mathrm{E}+07$ \\
\hline $1.00 \mathrm{E}+00$ & $1.33 \mathrm{E}+00$ & $1.39 \mathrm{E}+09$ & $1.81 \mathrm{E}+07$ & $2.94 \mathrm{E}+06$ \\
\hline $1.33 \mathrm{E}+00$ & $1.66 \mathrm{E}+00$ & $1.04 \mathrm{E}+09$ & $1.27 \mathrm{E}+07$ & $1.78 \mathrm{E}+06$ \\
\hline $1.66 \mathrm{E}+00$ & $2.00 \mathrm{E}+00$ & $4.29 \mathrm{E}+08$ & $3.26 \mathrm{E}+06$ & $1.96 \mathrm{E}+05$ \\
\hline $2.00 \mathrm{E}+00$ & $2.50 \mathrm{E}+00$ & $4.66 \mathrm{E}+08$ & $4.57 \mathrm{E}+06$ & $3.25 \mathrm{E}+05$ \\
\hline $2.50 \mathrm{E}+00$ & $3.00 \mathrm{E}+00$ & $2.60 \mathrm{E}+08$ & $1.95 \mathrm{E}+06$ & $2.66 \mathrm{E}+03$ \\
\hline $3.00 \mathrm{E}+00$ & $4.00 \mathrm{E}+00$ & $1.74 \mathrm{E}+08$ & $2.42 \mathrm{E}+05$ & $1.18 \mathrm{E}+00$ \\
\hline $4.00 \mathrm{E}+00$ & $5.00 \mathrm{E}+00$ & $4.26 \mathrm{E}+07$ & $1.18 \mathrm{E}+01$ & $1.80 \mathrm{E}-03$ \\
\hline $5.00 \mathrm{E}+00$ & $6.00 \mathrm{E}+00$ & $1.30 \mathrm{E}+07$ & $3.49 \mathrm{E}-03$ & $4.74 \mathrm{E}-13$ \\
\hline $6.00 \mathrm{E}+00$ & $7.00 \mathrm{E}+00$ & $2.73 \mathrm{E}+06$ & $4.73 \mathrm{E}-13$ & $9.07 \mathrm{E}-14$ \\
\hline $7.00 \mathrm{E}+00$ & $8.00 \mathrm{E}+00$ & $6.85 \mathrm{E}+05$ & $4.45 \mathrm{E}-14$ & $2.12 \mathrm{E}-15$ \\
\hline $8.00 \mathrm{E}+00$ & $9.00 \mathrm{E}+00$ & $2.44 \mathrm{E}+05$ & $9.07 \mathrm{E}-15$ & $6.24 \mathrm{E}-16$ \\
\hline $9.00 \mathrm{E}+00$ & $1.00 \mathrm{E}+01$ & $9.45 \mathrm{E}+04$ & $2.12 \mathrm{E}-15$ & $1.77 \mathrm{E}-17$ \\
\hline $1.00 \mathrm{E}+01$ & $1.20 \mathrm{E}+01$ & $6.47 \mathrm{E}+04$ & $6.23 \mathrm{E}-16$ & $0.00 \mathrm{E}+00$ \\
\hline $1.20 \mathrm{E}+01$ & $1.70 \mathrm{E}+01$ & $1.46 \mathrm{E}+04$ & $1.77 \mathrm{E}-17$ & $2.42 \mathrm{E}+08$ \\
\hline $1.70 \mathrm{E}+01$ & $3.00 \mathrm{E}+01$ & $0.00 \mathrm{E}+00$ & $0.00 \mathrm{E}+00$ & $6.62 \mathrm{E}+08$ \\
\hline
\end{tabular}

Table 3 presents the fraction of DOE STD-1027-92 CAT-3 threshold for the target considered (a small piece of thorium $\left(2 \times 1 \times 1 \mathrm{~cm}^{3}\right)$ is irradiated during 7 days with $1.32 \times 10^{11} \mathrm{p} / \mathrm{s}$ ). This table shows how far from the DOE CAT-3 threshold is the hazard of all radioisotopes produced during irradiation at the time that the irradiation ends, 10, and 30 days after shutdown. The results indicate that for the thorium target will be well below the CAT-3 threshold and it would be possible to irradiate the same target during a full week with a beam roughly 700 times more intense than the one used in the simulation and still be below the CAT-3 threshold. This indicates that the experiment will not even be close to pose any serious radiological hazard to the facility. A complete radioisotope inventory is presented in Attachment 4, including both thorium target contribution and copper target holder contribution.

Table 3. Fraction of DOE STD-1027-92 CAT-3 threshold for a $2 \times 1 \times 1 \mathrm{~cm}^{3}$ irradiated.

\begin{tabular}{|c|c|c|c|}
\hline & After 7 days of Irradiation & 10 days after the EOI & 30 days after the EOI \\
\hline $2 \times 1 \times 1 \mathrm{~cm}^{3}$ Target & $1.42 \times 10^{-03}$ & $5.43 \times 10^{-04}$ & $2.11 \times 10^{-04}$ \\
\hline
\end{tabular}

Table 4 presents the activity of other alpha emitters compared with ${ }^{225}$ Ac for cooling times of 10 and 30 and days after the end of the irradiation. The activity for all actinium isotopes is basically the activity of ${ }^{225} \mathrm{Ac}$ and for the other alpha emitters are basically the metals thorium, and radium, the alkali metal francium, and the radioactive noble gas radon. The activity of the radon is about twice larger than the actinium 10 days after shutdown and 3 times larger at 20 
days after shutdown. All alpha emitters have similar activity and energy; being the overall averaged energy about $6.12 \mathrm{MeV}$.

Table 4. Activity (Ci) of alpha emitters in the irradiated target 10 days after the end of the irradiation.

\begin{tabular}{|c|c|c|}
\hline & Actinium Isotopes & All Alpha Emitters (including Ac) \\
\hline 10 days after EOI & $1.88 \times 10^{-04}$ & $2.29 \times 10^{-03}$ \\
\hline 30 days after EOI & $6.33 \times 10^{-05}$ & $9.89 \times 10^{-04}$ \\
\hline
\end{tabular}

\section{Conclusions}

The irradiation of thorium targets in the booster beam line of the FNAL seems to be highly feasible. The expected activity of ${ }^{225}$ Ac the target with $2 \mathrm{~cm} \times 1 \mathrm{~cm}$ face area is near 0.2 $\mathrm{mCi}$ after 7 days of continuous irradiation with $1.32 \times 10^{11}$ protons/sec and 10 days of cooling time. These values can be even higher if only the peak of the beam profile is used. The results presented were based on MCNPX/CINDER calculations with validation of the FLUKA code; all results agreed within a $20 \%$ range.

The activity calculated indicates that a much more powerful proton beam can be used without making the target to reach the CAT-3 limits. The beam power can be about 700 times higher for the small target $2 \times 1 \times 1 \mathrm{~cm}^{3}$ without reaching the CAT-3 limits. Previous calculations have indicated that for a better use of the beam time a larger target can be used, allowing a much larger production rate of the ${ }^{225} \mathrm{Ac}$. 


\title{
PART II - Activation Analysis of the Surroundings of the Irradiation Position
}

\begin{abstract}
This report has as an objective to assess the activation problem of the thorium target irradiation experiment at FNAL. The results presented are not activation calculation per se, but they provide guidelines to assess any possible impact on the beam stop surroundings due to the irradiation of the target with the low pulse rate $8 \mathrm{GeV}$ proton beam. The average beam intensity is assumed to be $1.32 \times 10^{11}$ protons per second and a full week of irradiation is assumed.
\end{abstract}

\section{Introduction}

The calculation of the activation for beam stop and surroundings is a quite involving task; it requires the modeling of all materials present around the target and the assessment of the activation during normal operation to compare with the impact caused by placing a target in front of the beam stop tunnel. Considering that the impact is most likely to be minimal, if not negligible, a simple assessment of the beam interaction with the target should suffice for predicting the degree of the potential additional activation caused by placing a thorium target in front of the beam stop structure.

This report presents the calculated flux and current of all significant particles produced in the target by impinging an $8 \mathrm{GeV}$ proton beam on one centimeter thick thorium target and the heating produced in the beam stop structure with and without the thorium target.

\section{Particle Flux and Current Analysis}

The flux of particles in a thin slice near the outer surfaces of the target is an indication of the intensity of the flux leaving the target. Furthermore, the angular distribution of the current of particles across the outer surfaces of the target can provide the number of particles leaving and entering the target or the beam stop tunnel at different directions. In the following sub-sections a number of flux plots are presented for a thin layer at the entrance and exit of the target. Those plots provide an idea of the spatial distribution of the particles while the following tables provide the number and direction of the particles at the outer surfaces of the target and at the entrance of the tunnel. The figures present the particle flux distribution in a layer $0.2 \mathrm{~cm}$ thick in the direction of the beam and with a cross sectional area of $32 \mathrm{~cm}^{2}(8 \mathrm{cmx} 4 \mathrm{~cm})$. The target, which corresponds just the central part of the figures, has a cross sectional area of $2 \mathrm{~cm}$ by $1 \mathrm{~cm}$ and a thickness of $1 \mathrm{~cm}$. The layer providing the flux estimation for surface of the target facing the incoming beam is placed at a distance of $4 \mathrm{~cm}$, in the direction contrary of the beam direction. The layer providing the flux estimation for the back surface of the target is at the end of the target and extending around to cover the cross sectional area indicated previously.

It is also important to note that the current and the angular distribution given in the tables are the total number of particles crossing the indicated surface with the angle being taken at the point that the particle crosses the surface. The angles are relative to the normal to the surface and the normal of the surfaces points in the direction of the beam. The entrance surface has a cross sectional area of $2 \mathrm{~cm}^{2}(1 \mathrm{~cm} \mathrm{x} 2 \mathrm{~cm})$ and exit surface of the target has an area of $32 \mathrm{~cm}^{2}(8 \mathrm{~cm} \mathrm{x}$ 
$4 \mathrm{~cm})$ while the surface at the entrance of the tunnel has a surface area of $400 \mathrm{~cm}^{2}(20 \mathrm{~cm} \mathrm{x} 20 \mathrm{~cm})$. Then, the surface in the back of the target takes into account some of the particles scattered back from the beam stop tunnel. The surface at the entrance of the beam stop tunnel is placed inside the beam stop tunnel at $1 \mathrm{~mm}$ from the front surface of the concrete structure that houses the steel beam stop. The following analysis is performed for each particle with any significant production in the target.

\subsection{Neutrons}

Figures 1 and 2 present the neutron flux distribution in a thin slice at the entrance and exit of the target, respectively. As it can be seen, in Figure 2, the neutron flux in the layer on the back of the target is very focused in the central region, indicating a very forward peaked distribution while the neutron flux distribution in Figure 1 is much more spread on the surface and it does not present a very defined beam spot profile as in Figure 2. This indicates that the component of the neutron flux coming back to the room from the beam stop has a very strong presence on the neutron flux spatial distribution in the region represented by the plot.

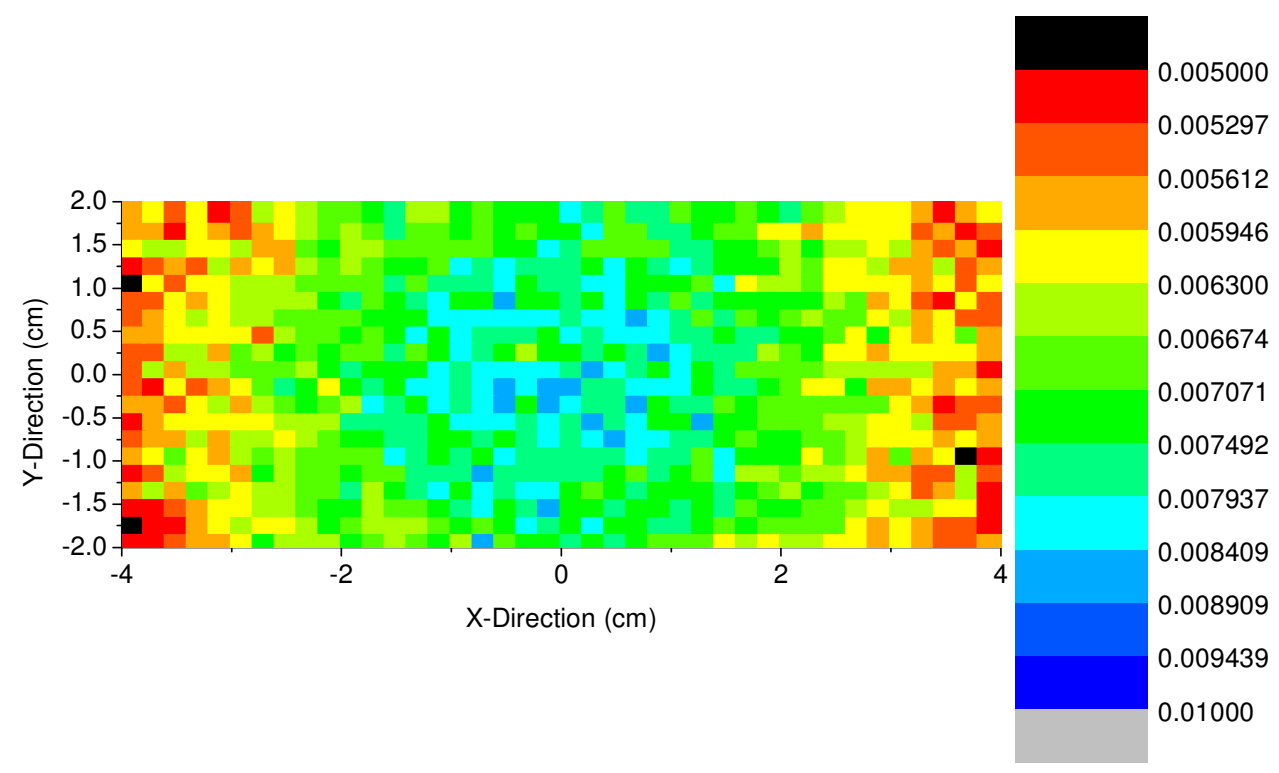

Figure 1. Neutron flux spatial distribution in a layer at the entrance of the target region. The units are neutrons $/ \mathrm{cm}^{2}$-sec normalized for a proton beam intensity of 1.0 proton/sec. 


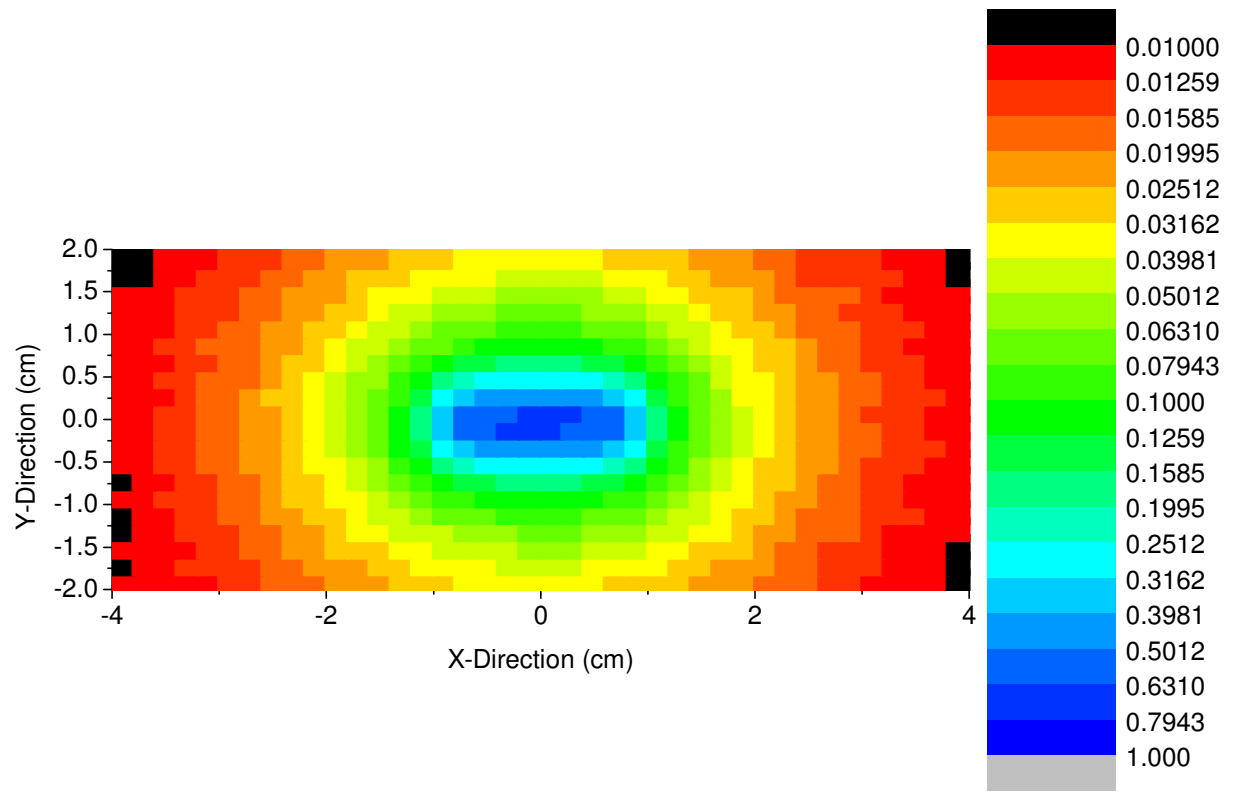

Figure 2. Neutron flux spatial distribution in a layer at the exit of the target region. The units are neutrons $/ \mathrm{cm}^{2}$-sec normalized for a proton beam intensity of 1.0 proton/sec.

Table 1 presents the numeric values of the neutron current through the entrance and exit surfaces of the target and at a surface at the entrance of the beam stop tunnel, for several angular intervals (see a description of the surfaces and angles at the beginning of this section). As it can be seen, with the target present, for each proton that enters the target 0.31 neutrons go into the accelerator hall through the entrance surface of the target, this represents, for a beam intensity of $1.32 \mathrm{e}+11$ protons/ second, $4.09 \mathrm{e}+10$ neutrons/second going into the accelerator hall. Assuming that these neutrons are nearly isotropic this represents a neutron flux of $6.5 \mathrm{e}+05 \mathrm{n} / \mathrm{cm}^{2}-\mathrm{sec}$ at 1 meter from the target and $2.6 \mathrm{e}+04 \mathrm{n} / \mathrm{cm}^{2}-\mathrm{sec}$ at 5 meters from the target. Also in Table 1, one can see that the current coming out of the tunnel when simulating the irradiation scenario without a target is 0.89 neutrons per incident proton beam, indicating a much larger number of neutrons coming out from the tunnel due the beam hitting the walls and steel beam stop inside the tunnel than the ones coming out from the target due the proton beam interaction with the thorium target. It is important to keep in mind that the target front surface has an area of $2 \mathrm{~cm}^{2}$ while the surface at the entrance of the tunnel has an area of $400 \mathrm{~cm}^{2}$. Furthermore, the neutrons coming out of the tunnel with the target has a total number of 0.98 neutrons per proton beam while 0.89 neutrons per proton beam come out of the tunnel without the target present; this indicates that there is only an addition $10 \%$ on the number of neutrons coming out of the tunnel when the target is present and 0.31 neutrons per beam proton from the surface of the target, meaning a total maximum additional neutron number of 0.40 neutrons per proton, or less than $50 \%$ from the number that goes into the accelerator vault without the target. Then the increase in number of neutrons is small and unlikely to produce any significant activation, beyond the one at normal operation, at all. Based on that, one can say that the addition of the target, roughly, will increase the number of 
neutrons in the room by at most 50\%. Table 1 also shows that the neutrons going forward are about 0.72 per proton beam and that the large majority will hit positions deep in the beam stop "tunnel" and will not activate the surface of the concrete.

Table 1. Neutron current angular distribution in the entrance, exit surface of the target and entrance of the beam stop tunnel for the cases with and without target material in the target region. The units are number of neutrons per second and normalized for a proton beam intensity of 1.0 proton/sec.

\begin{tabular}{|c|c|c|c|c|c|c|}
\hline \multicolumn{8}{|c|}{ With the Target Present } \\
\hline Surface & $180^{\circ}$ to $150^{\circ}$ & $150^{\circ}$ to $120^{\circ}$ & $120^{\circ}$ to $90^{\circ}$ & $90^{\circ}$ to $60^{\circ}$ & $60^{\circ}$ to $30^{\circ}$ & $30^{\circ}$ to $0^{\circ}$ \\
\hline Entrance Target & $8.80 \mathrm{E}-02$ & $1.56 \mathrm{E}-01$ & $6.63 \mathrm{E}-02$ & 0.0 & 0.0 & 0.0 \\
\hline Exit Target & $5.75 \mathrm{E}-02$ & $1.77 \mathrm{E}-02$ & $4.52 \mathrm{E}-03$ & $2.61 \mathrm{E}-01$ & $3.15 \mathrm{E}-01$ & $1.47 \mathrm{E}-01$ \\
\hline Tunnel Entrance & $6.50 \mathrm{E}-01$ & $2.24 \mathrm{E}-01$ & $5.64 \mathrm{E}-02$ & $3.46 \mathrm{E}-01$ & $3.15 \mathrm{E}-01$ & $1.47 \mathrm{E}-01$ \\
\hline \multicolumn{7}{|c|}{ Without the Presence of any Target Material } \\
\hline Entrance Target & $3.51 \mathrm{E}-03$ & $9.58 \mathrm{E}-04$ & $1.93 \mathrm{E}-04$ & 0.0 & 0.0 & 0.0 \\
\hline Exit Target & $5.73 \mathrm{E}-02$ & $1.59 \mathrm{E}-02$ & $3.44 \mathrm{E}-03$ & 0.0 & 0.0 & 0.0 \\
\hline Tunnel Entrance & $6.44 \mathrm{E}-01$ & $2.01 \mathrm{E}-01$ & $4.41 \mathrm{E}-02$ & $8.15 \mathrm{E}-05$ & $1.18 \mathrm{E}-05$ & $1.74 \mathrm{E}-06$ \\
\hline
\end{tabular}

\subsection{Protons}

Figures 3 and 4 present the proton flux distribution in a thin slice at the entrance and exit of the target, respectively. As it can be seen the proton flux in both layers is very focused in the central region, indicating that the main component of the proton flux is the beam passing through the target and that the region outside the beam spot (a Gaussian distribution with $\sigma_{\mathrm{x}}=1 \mathrm{~cm}$ and $\sigma_{y}=0.26 \mathrm{~cm}$ ) has a much weaker flux. The slice that is at the entrance of the beam has a much more focused distribution while on the back of the target, the produced protons from nuclear interactions on the target and scattering of the proton beam produce a wider spatial distribution of the protons.

Table 2 presents the numeric values of the proton current through the entrance and exit surfaces of the target and at a surface at the entrance of the beam stop tunnel for several angular intervals (see a description of the surfaces and angles at the beginning of this section). As it can be seen, for each proton that enters the target 0.0133 protons go into the accelerator hall through the front surface of the target, this represents, for a beam intensity of $1.32 \mathrm{e}+11$ protons/second, $1.74 \mathrm{e}+09$ protons/second going into the accelerator hall. Assuming that these protons are nearly isotropic this represents a proton flux of $2.77 \mathrm{e}+04 \mathrm{p} / \mathrm{cm}^{2}-\mathrm{sec}$ at 1 meter from the target and $1.1 \mathrm{e}+03 \mathrm{p} / \mathrm{cm}^{2}-\mathrm{sec}$ at 5 meters from the target. Also, from the table, one can see that the protons entering the accelerator hall by the surface at the entrance of the beam stop tunnel, when the target is present, is only about 0.00137 protons per proton beam and this value compares with 0.00126 protons when the there is no thorium target. Based on that comparatively, one can say that there will be an considerable addition of protons directed to the accelerator hall but the absolute number (about 0.0134 proton per proton beam) of this addition is much smaller than the neutron flux into the accelerator hall as such resulting in a much less activation than the neutron activation. 


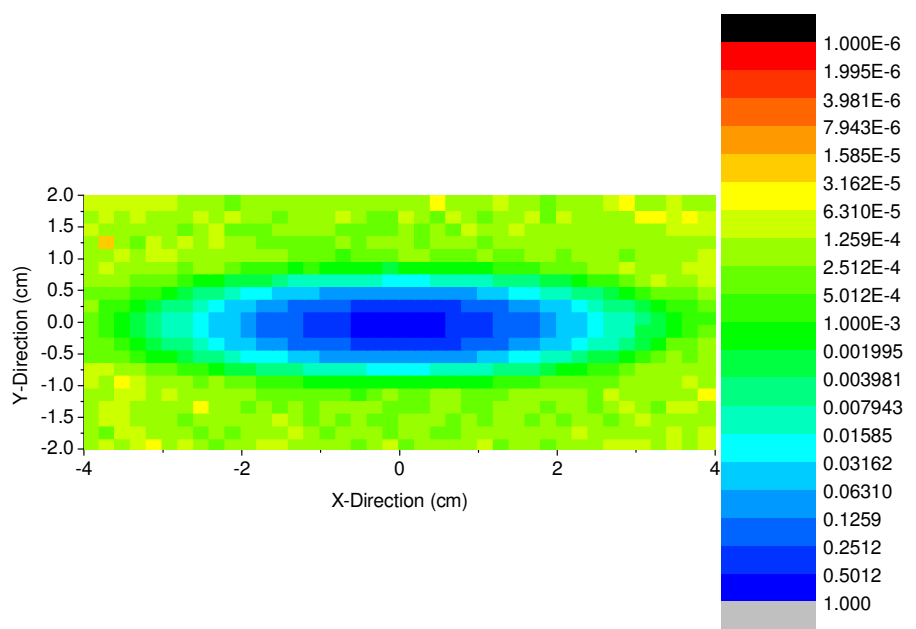

Figure 3. Proton flux spatial distribution in a layer at the entrance of the target region. The units are protons $/ \mathrm{cm}^{2}-\mathrm{sec}$ normalized for a proton beam intensity of 1.0 proton/sec.

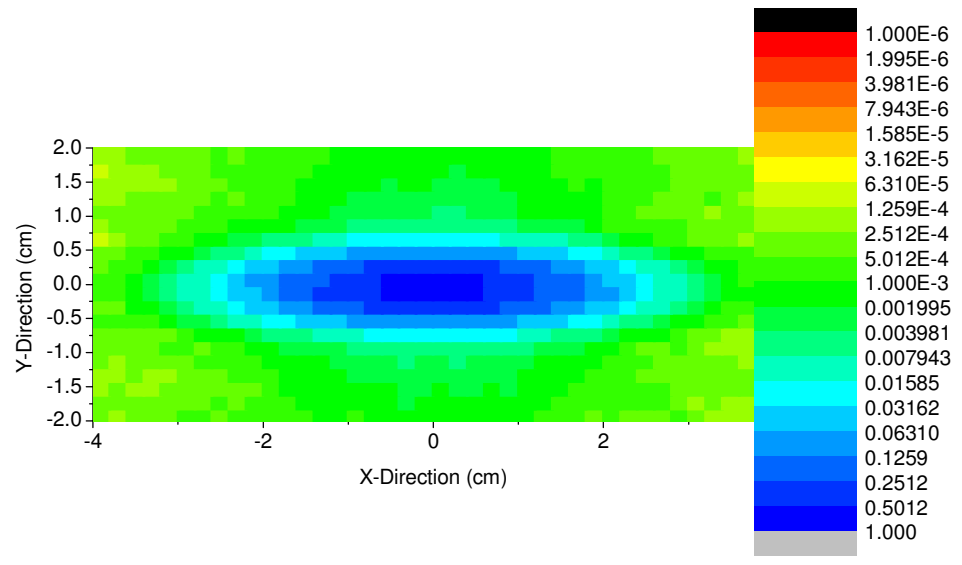

Figure 4. Proton flux spatial distribution in a layer at the entrance of the target region. The units are protons $/ \mathrm{cm}^{2}-\mathrm{sec}$ normalized for a proton beam intensity of 1.0 proton/sec.

Table 2 also shows that the protons hitting the target are only $65 \%$ of the total beam, which is consistent with the Gaussian distribution of the beam profile with a standard deviation of $1 \mathrm{~cm}$ in the $\mathrm{x}$-direction and $0.26 \mathrm{~cm}$ in the y-direction. Table 2 indicates that basically all protons from the beam go to the beam stop tunnel plus a small fraction created by target multiplication of protons. The very large majority of the protons will be in the very forward direction as such they will hit positions deep inside the beam stop "tunnel" and will not activate the surface of the concrete. 
Table 2. Proton current angular distribution in the entrance, exit surface of the target and entrance of the beam stop tunnel for the cases with and without target material in the target region. The units are number of protons per second and normalized for a proton beam intensity of 1.0 proton/sec.

\begin{tabular}{|c|c|c|c|c|c|c|}
\hline \multicolumn{7}{|c|}{ With the Target Present } \\
\hline Surface & $180^{\circ}$ to $150^{\circ}$ & $150^{\circ}$ to $120^{\circ}$ & $120^{\circ}$ to $90^{\circ}$ & $90^{\circ}$ to $60^{\circ}$ & $60^{\circ}$ to $30^{\circ}$ & $30^{\circ}$ to $0^{\circ}$ \\
\hline Entrance Target & $3.59 \mathrm{E}-03$ & $6.65 \mathrm{E}-03$ & $3.04 \mathrm{E}-03$ & 0.0 & 0.0 & $6.53 \mathrm{E}-01$ \\
\hline Exit Target & $1.01 \mathrm{E}-04$ & $5.50 \mathrm{E}-06$ & $3.00 \mathrm{E}-06$ & $1.21 \mathrm{E}-02$ & $2.45 \mathrm{E}-02$ & $1.02 \mathrm{E}+00$ \\
\hline Tunnel Entrance & $1.25 \mathrm{E}-03$ & $9.54 \mathrm{E}-05$ & $2.65 \mathrm{E}-05$ & $1.57 \mathrm{E}-02$ & $2.45 \mathrm{E}-02$ & $1.02 \mathrm{E}+00$ \\
\hline \multicolumn{7}{|c|}{ Without the Presence of any Target Material } \\
\hline Entrance Target & $3.50 \mathrm{E}-06$ & $5.00 \mathrm{E}-07$ & 0.0 & 0.0 & 0.0 & $6.53 \mathrm{E}-01$ \\
\hline Exit Target & $1.00 \mathrm{E}-04$ & $4.00 \mathrm{E}-06$ & $1.00 \mathrm{E}-06$ & 0.0 & 0.0 & $1.00 \mathrm{E}-01$ \\
\hline Tunnel Entrance & $1.20 \mathrm{E}-03$ & $5.55 \mathrm{E}-05$ & $7.00 \mathrm{E}-06$ & 0.0 & 0.0 & $1.00 \mathrm{E}+00$ \\
\hline
\end{tabular}

\subsection{Deuterons}

Figures 5 and 6 present the deuteron flux distribution in a thin slice at the entrance and exit of the target, respectively. As it can be seen the deuteron flux in the layer on the back of the target is much focused in the central region, indicating a very forward peaked distribution, while in the backward direction is much diffused with a much lower intensity.

Table 3 presents the numeric values of the deuterons current through the entrance and exit surfaces of the target and at a surface at the entrance of the beam stop tunnel for several angular intervals (see a description of the surfaces and angles at the beginning of this section). As it can be seen, for each proton that enters the target 4.8e-04 deuterons go into the accelerator hall, this represents, for a beam intensity of $1.32 \mathrm{e}+11$ protons/second, $5.7 \mathrm{e}+07$ deuterons/second going into the accelerator hall. Assuming that these deuterons are nearly isotropic this represents a deuteron flux of $9.11 \mathrm{e}+02 \mathrm{~d} / \mathrm{cm}^{2}-\mathrm{sec}$ at 1 meter from the target and $3.65 \mathrm{e}+01 \mathrm{~d} / \mathrm{cm}^{2}-\mathrm{sec}$ at 5 meters from the target. Also, from the table, one can see that the deuterons entering the accelerator hall by the surface at the entrance of the beam stop tunnel, when the target is present, is only about 4.6e-05 deuterons per proton beam and this value compares with 4.85e-05 deuterons when the there is no thorium target (Note that the results without the target is bigger than with the target, indicating that the statistical uncertainty is larger than the difference of having the target or not). Based on that comparatively, one can say that there will be a considerable addition of deuterons directed to the accelerator hall but the absolute number (about $4.8 \mathrm{e}-04$ deuteron per proton beam) of this addition is much smaller than the neutron flux into the accelerator hall as such resulting in a near negligible activation. 


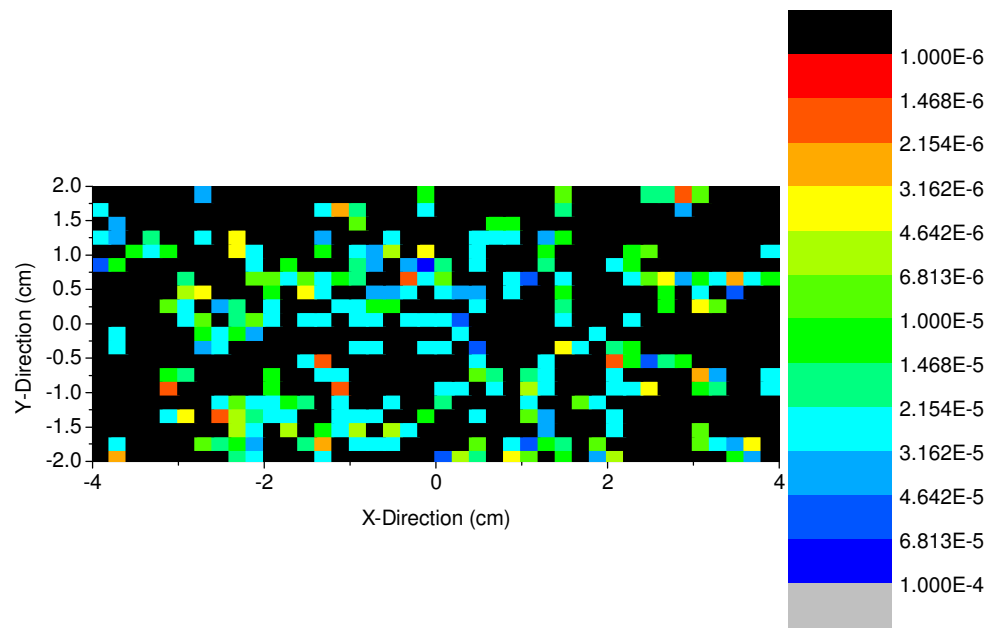

Figure 5. Deuteron flux spatial distribution in a layer at the entrance of the target region. The units are deuterons $/ \mathrm{cm}^{2}$-sec normalized for a proton beam intensity of 1.0 proton $/ \mathrm{sec}$.

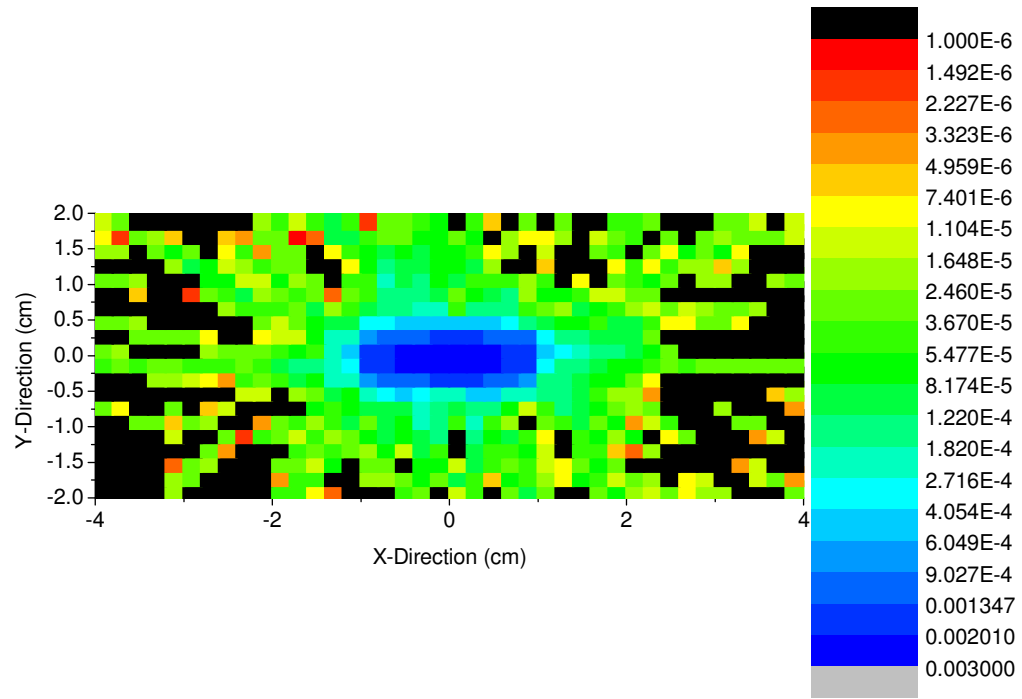

Figure 6. Deuteron flux spatial distribution in a layer at the exit of the target region. The units are deuterons $/ \mathrm{cm}^{2}$-sec normalized for a proton beam intensity of 1.0 proton/sec.

Table 3. Deuteron current angular distribution in the entrance, exit surface of the target and entrance of the beam stop tunnel for the cases with and without target material in the target region. The units are number of deuterons per second and normalized for a proton beam intensity of $1.0 \mathrm{proton} / \mathrm{sec}$.

\begin{tabular}{|c|c|c|c|c|c|c|}
\hline \multicolumn{7}{|c|}{ With the Target Present } \\
\hline Surface & $180^{\circ}$ to $150^{\circ}$ & $150^{\circ}$ to $120^{\circ}$ & $120^{\circ}$ to $90^{\circ}$ & $90^{\circ}$ to $60^{\circ}$ & $60^{\circ}$ to $30^{\circ}$ & $30^{\circ}$ to $0^{\circ}$ \\
\hline Entrance Target & $1.05 \mathrm{E}-04$ & $2.13 \mathrm{E}-04$ & $1.16 \mathrm{E}-04$ & 0.0 & 0.0 & 0.0 \\
\hline
\end{tabular}




\begin{tabular}{|c|c|c|c|c|c|c|}
\hline Exit Target & $3.50 \mathrm{E}-06$ & $2.00 \mathrm{E}-06$ & $5.00 \mathrm{e}-07$ & $3.91 \mathrm{E}-04$ & $6.38 \mathrm{E}-04$ & $3.04 \mathrm{E}-04$ \\
\hline Tunnel Entrance & $3.05 \mathrm{E}-05$ & $1.20 \mathrm{E}-05$ & $3.50 \mathrm{E}-06$ & $4.60 \mathrm{E}-04$ & $6.38 \mathrm{E}-04$ & $3.05 \mathrm{E}-04$ \\
\hline \multicolumn{7}{|c|}{ Without the Presence of any Target Material } \\
\hline Entrance Target & 0.0 & 0.0 & 0.0 & 0.0 & 0.0 & 0.0 \\
\hline Exit Target & $3.00 \mathrm{E}-06$ & $5.00 \mathrm{E}-07$ & $5.00 \mathrm{E}-07$ & 0.0 & 0.0 & 0.0 \\
\hline Tunnel Entrance & $3.55 \mathrm{E}-05$ & $1.15 \mathrm{E}-05$ & $1.50 \mathrm{E}-06$ & 0.0 & 0.0 & 0.0 \\
\hline
\end{tabular}

\subsection{Pions}

Figures 7 and 8 present the pion_+ flux distribution in a thin slice at the entrance and exit of the target, respectively. As it can be seen the pion_+ flux in the layer on the back of the target is much focused in the central region, indicating a very forward peaked distribution, while in the backward direction is much diffused with a much lower intensity.

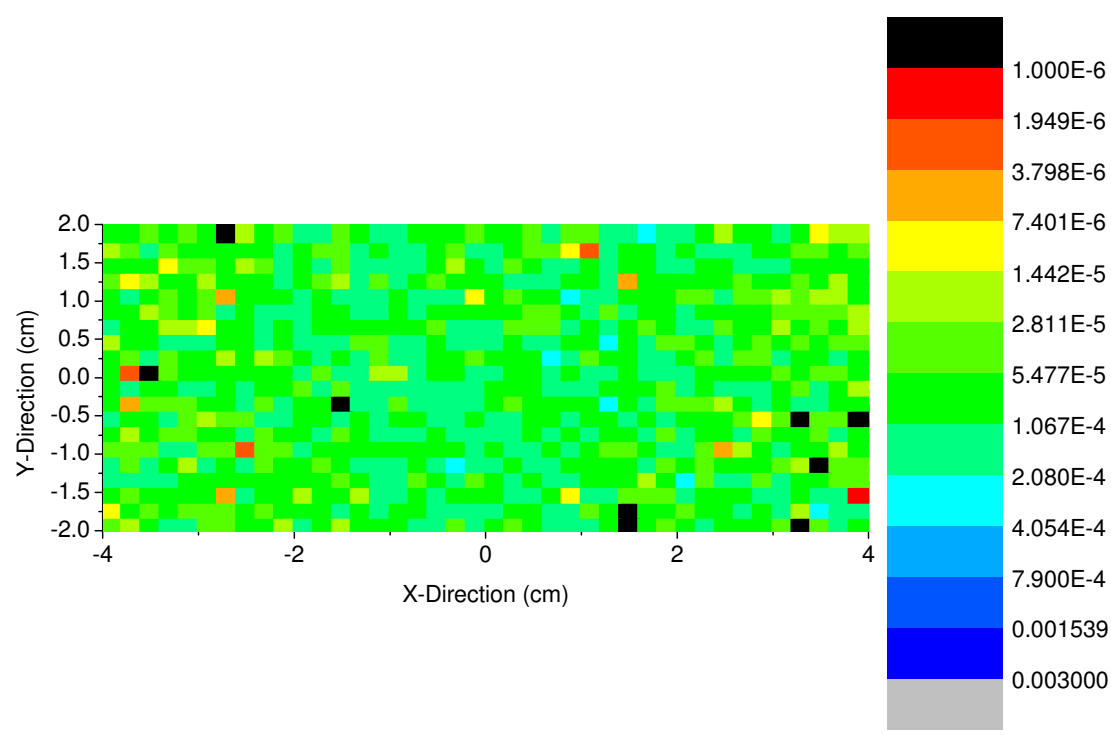

Figure 7. Pion_+ flux spatial distribution in a layer at the entrance of the target region. The units are pions $/ \mathrm{cm}^{2}$-sec normalized for a proton beam intensity of 1.0 proton/sec. 


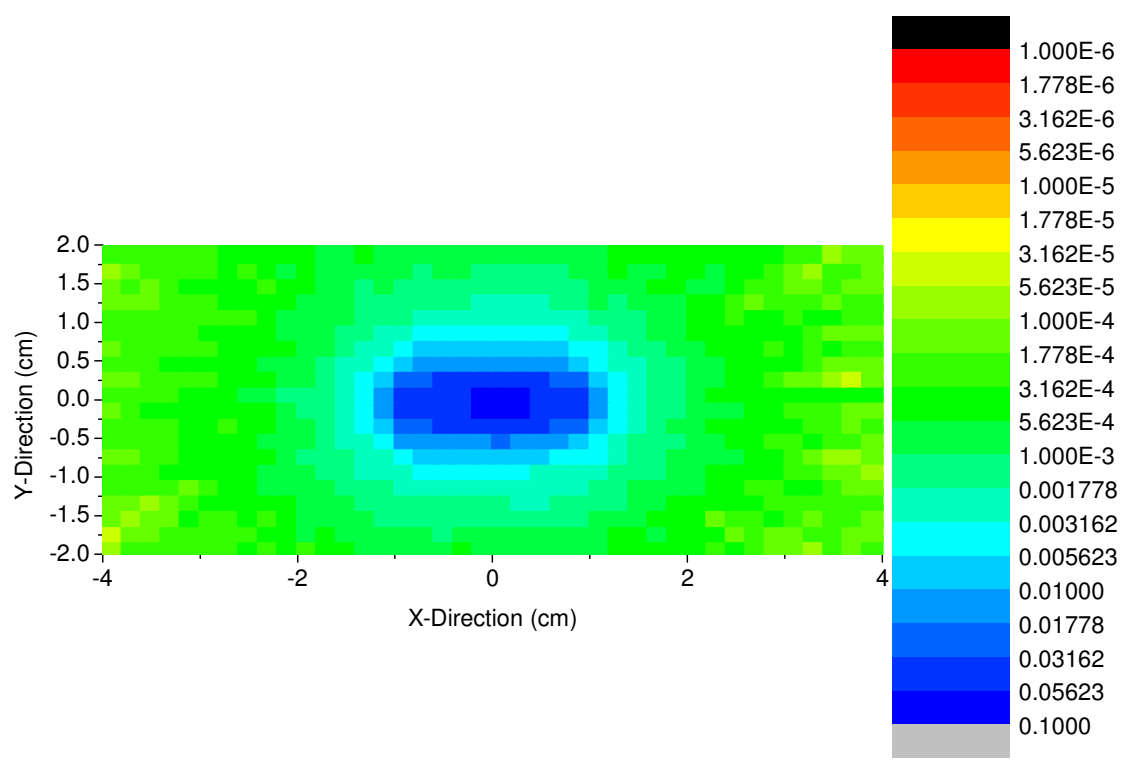

Figure 8. Pion_+ flux spatial distribution in a layer at the exit of the target region. The units are pions $/ \mathrm{cm}^{2}$-sec normalized for a proton beam intensity of $1.0 \mathrm{proton} / \mathrm{sec}$.

Table 4 presents the numeric values of the pions_+ current through the entrance and exit surfaces of the target and at a surface at the entrance of the beam stop tunnel for several angular intervals (see a description of the surfaces and angles at the beginning of this section). As it can be seen, for each proton that enters the target 5.6e-03 pions_+ go into the accelerator hall, this represents, for a beam intensity of $1.32 \mathrm{e}+11$ protons/ second, $7.4 \mathrm{e}+08$ pions/second going into the accelerator hall. Assuming that these pions are nearly isotropic this represents a pion flux of $1.17 \mathrm{e}+04 \mathrm{pion} / \mathrm{cm}^{2}-\mathrm{sec}$ at 1 meter from the target and $4.7 \mathrm{e}+02$ pion $/ \mathrm{cm}^{2}$-sec at 5 meters from the target. Also, from the table, one can see that the pions_+ entering the accelerator hall through the surface at the entrance of the beam stop tunnel, when the target is present, is only about 2.91e-03 pions_+ per proton beam and this value compares with $2.79 \mathrm{e}-03$ pions_+ when the there is no thorium target. Table 4 also shows that the pions going forward are about $7.9 \mathrm{e}-02$ per proton beam and that the large majority will hit positions deep in the beam stop "tunnel" and will not activate the surface of the concrete. Based on that, one can say that there will be a small addition of pions_+ directed to the accelerator hall but the absolute number (about 5.6e-03 pions_+ per proton beam) of this addition is much smaller than the neutron flux into the accelerator hall as such resulting in a small additional activation.

Table 4. Pion current angular distribution in the entrance, exit surface of the target and entrance of the beam stop tunnel for the cases with and without target material in the target region. The units are number of pions per second and normalized for a proton beam intensity of 1.0 proton/sec.

\begin{tabular}{|c|c|c|c|c|c|c|}
\hline \multicolumn{8}{|c|}{ With the Target Present } \\
\hline Surface & $180^{\circ}$ to $150^{\circ}$ & $150^{\circ}$ to $120^{\circ}$ & $120^{\circ}$ to $90^{\circ}$ & $90^{\circ}$ to $60^{\circ}$ & $60^{\circ}$ to $30^{\circ}$ & $30^{\circ}$ to $0^{\circ}$ \\
\hline Entrance Target & $1.52 \mathrm{E}-03$ & $2.78 \mathrm{E}-03$ & $1.23 \mathrm{E}-03$ & 0.0 & 0.0 & 0.0 \\
\hline
\end{tabular}




\begin{tabular}{|c|c|c|c|c|c|c|}
\hline Exit Target & $2.55 \mathrm{E}-04$ & $1.25 \mathrm{E}-05$ & $4.50 \mathrm{E}-06$ & $7.64 \mathrm{E}-03$ & $2.39 \mathrm{E}-02$ & $4.73 \mathrm{E}-02$ \\
\hline Tunnel Entrance & $2.72 \mathrm{E}-03$ & $1.41 \mathrm{E}-04$ & $5.20 \mathrm{E}-05$ & $9.73 \mathrm{E}-03$ & $2.39 \mathrm{E}-02$ & $4.73 \mathrm{E}-02$ \\
\hline \multicolumn{7}{|c|}{ Without the Presence of any Target Material } \\
\hline Entrance Target & $1.40 \mathrm{e}-05$ & 0.0 & 0.0 & 0.0 & 0.0 & 0.0 \\
\hline Exit Target & $2.40 \mathrm{E}-04$ & $3.50 \mathrm{E}-06$ & $5.00 \mathrm{E}-07$ & 0.0 & 0.0 & 0.0 \\
\hline Tunnel Entrance & $2.74 \mathrm{E}-03$ & $3.70 \mathrm{E}-05$ & $8.00 \mathrm{E}-06$ & 0.0 & 0.0 & 0.0 \\
\hline
\end{tabular}

\subsection{Alphas}

Figures 9 and 10 present the alpha flux distribution in a thin slice at the entrance and exit of the target, respectively. As it can be seen the alpha flux in the layer on the back of the target is much focused in the central region, indicating a very forward peaked distribution, while in the backward direction is much diffused with a much lower intensity.

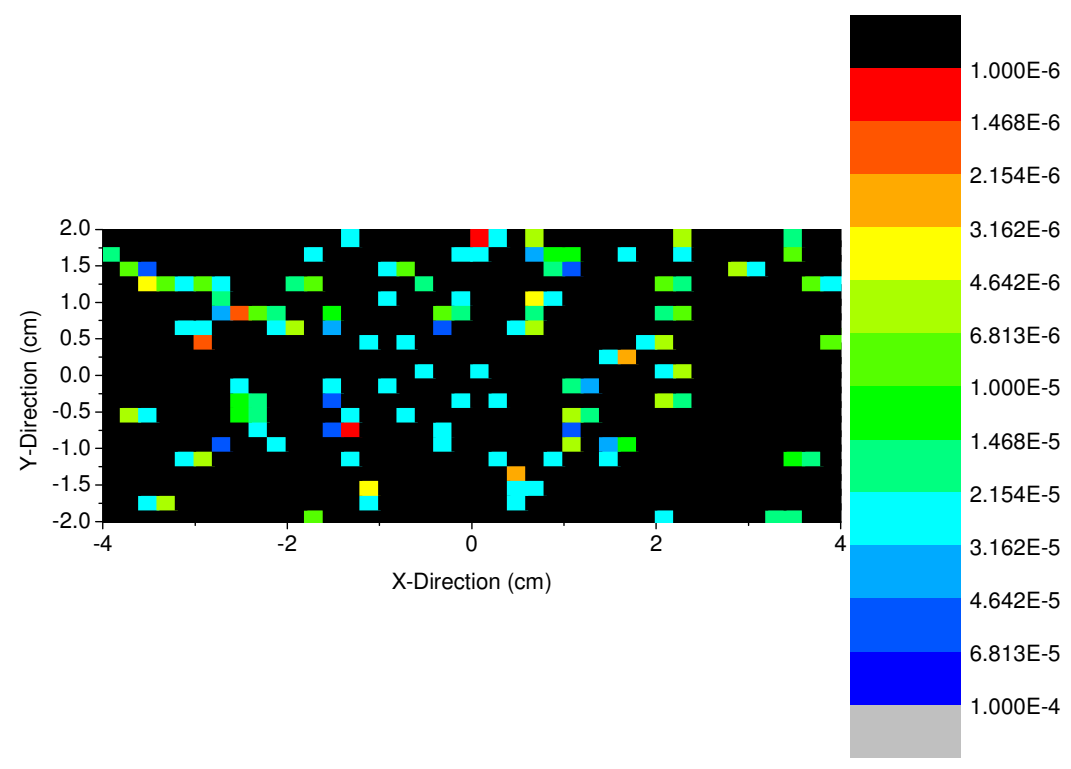

Figure 9. Alpha flux spatial distribution in a layer at the entrance of the target region. The units are alphas $/ \mathrm{cm}^{2}$-sec normalized for a proton beam intensity of 1.0 proton/sec. 


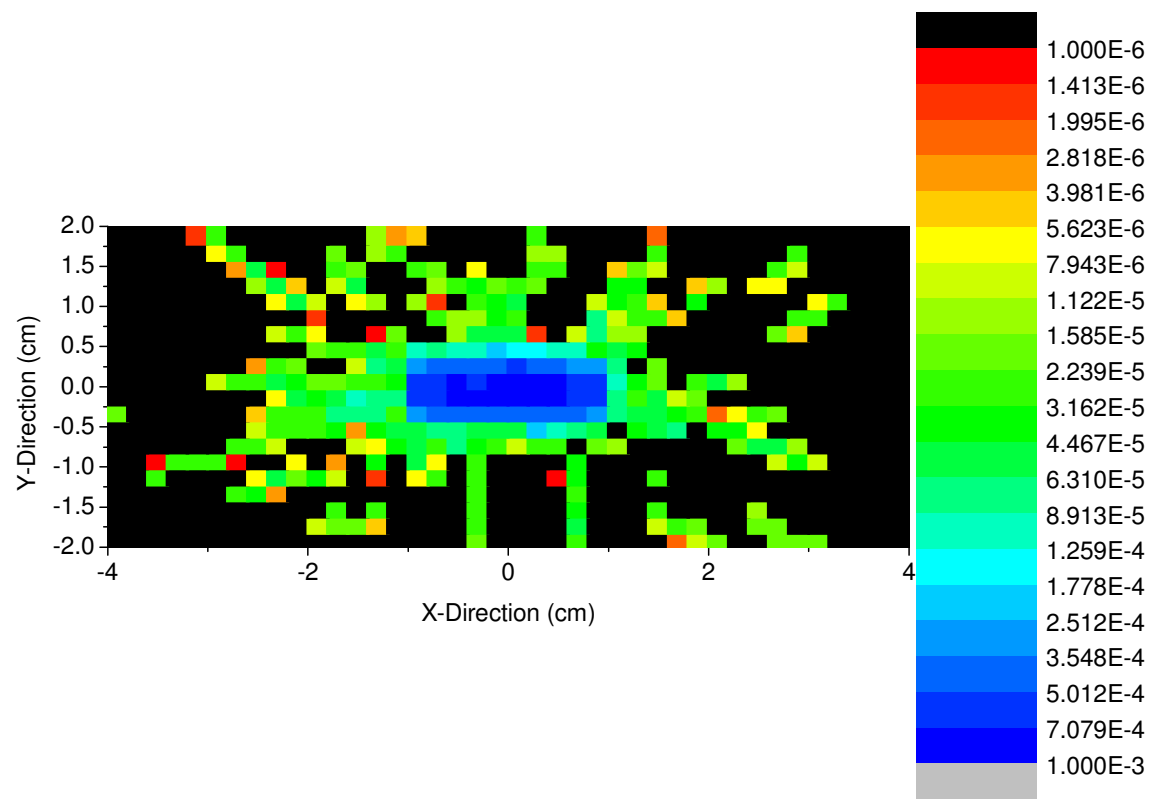

Figure 10. Alpha flux spatial distribution in a layer at the exit of the target region. The units are alphas $/ \mathrm{cm}^{2}$-sec normalized for a proton beam intensity of 1.0 proton/sec.

Table 5 presents the numeric values of the alphas current through the entrance and exit surfaces of the target and at a surface at the entrance of the beam stop tunnel for several angular intervals (see a description of the surfaces and angles at the beginning of this section). As it can be seen, for each proton that enters the target 2.1e-04 alphas go into the accelerator hall, this represents, for a beam intensity of $1.32 \mathrm{e}+11$ protons/ second, $2.77 \mathrm{e}+07$ alphas/second going into the accelerator hall. Assuming that these alphas are nearly isotropic this represents an alpha flux of $4.41 \mathrm{e}+02$ alphas $/ \mathrm{cm}^{2}-\mathrm{sec}$ at 1 meter from the target and 17.6 alphas $/ \mathrm{cm}^{2}-\mathrm{sec}$ at 5 meters from the target. Also, from the table, one can see that the alphas entering the accelerator hall through the surface at the entrance of the beam stop tunnel, when the target is present, is only about 3.41e-06 alphas per proton beam and this value compares with 2.91e-06 alphas when the there is no thorium target. Table 4 also shows that the alphas going forward are about 3.99e-04 alphas per proton beam and that the large majority will hit positions deep in the beam stop "tunnel" and will not activate the surface of the concrete. Based on that, one can say that there will be a small addition of alphas directed to the accelerator hall but the absolute number (about 2.1e-04 alphas per proton beam) of this addition is much smaller than the neutron flux into the accelerator hall as such resulting in a small additional activation.

Table 5. Alpha current angular distribution in the entrance, exit surface of the target and entrance of the beam stop tunnel for the cases with and without target material in the target region. The units are number of alphas per second and normalized for a proton beam intensity of 1.0 proton/sec. 


\begin{tabular}{|c|c|c|c|c|c|c|}
\hline \multicolumn{7}{|c|}{ With the Target Present } \\
\hline Surface & $180^{\circ}$ to $150^{\circ}$ & $150^{\circ}$ to $120^{\circ}$ & $120^{\circ}$ to $90^{\circ}$ & $90^{\circ}$ to $60^{\circ}$ & $60^{\circ}$ to $30^{\circ}$ & $30^{\circ}$ to $0^{\circ}$ \\
\hline Entrance Target & $5.60 \mathrm{E}-05$ & $9.50 \mathrm{E}-05$ & $4.90 \mathrm{E}-05$ & 0.0 & 0.0 & 0.0 \\
\hline Exit Target & $5.00 \mathrm{E}-07$ & $5.00 \mathrm{E}-07$ & 0.0 & $1.20 \mathrm{E}-04$ & $1.88 \mathrm{E}-04$ & $9.10 \mathrm{E}-05$ \\
\hline Tunnel Entrance & $2.41 \mathrm{E}-06$ & $1.00 \mathrm{E}-06$ & 0.0 & $1.41 \mathrm{E}-04$ & $1.88 \mathrm{E}-04$ & $9.10 \mathrm{E}-05$ \\
\hline \multicolumn{7}{|c|}{ Without the Presence of any Target Material } \\
\hline Entrance Target & 0.0 & 0.0 & 0.0 & 0.0 & 0.0 & 0.0 \\
\hline Exit Target & 0.0 & $5.00 \mathrm{E}-07$ & 0.0 & 0.0 & 0.0 & 0.0 \\
\hline Tunnel Entrance & $1.41 \mathrm{E}-06$ & $1.5 \mathrm{e}-06$ & 0.0 & 0.0 & 0.0 & 0.0 \\
\hline
\end{tabular}

\section{Heating}

The beam stop structure and surroundings will receive heat deposited by beam particles and all types of particles emanating from the beam stop and target. Figure 11 displays the spatial heating distribution on a horizontal plane leveled with the beam centerline. The unit of the heating plotted is $\mathrm{MeV} / \mathrm{gram}$ per proton beam. The incident energy of the proton beam is $8 \mathrm{GeV}$; then the total energy available in the beam for the intensity of $1.32 \mathrm{e}+11$ protons/second is 168 Watts. The calculated energy deposited in the target is 1.0 Watt and in the steel beam stop is 125.6 Watts, indicating the steel beam stop is the largest radiation producing element of the irradiation set-up what justifies its dominance in the activation of the accelerator hall through neutrons that stream through the beam stop tunnel.

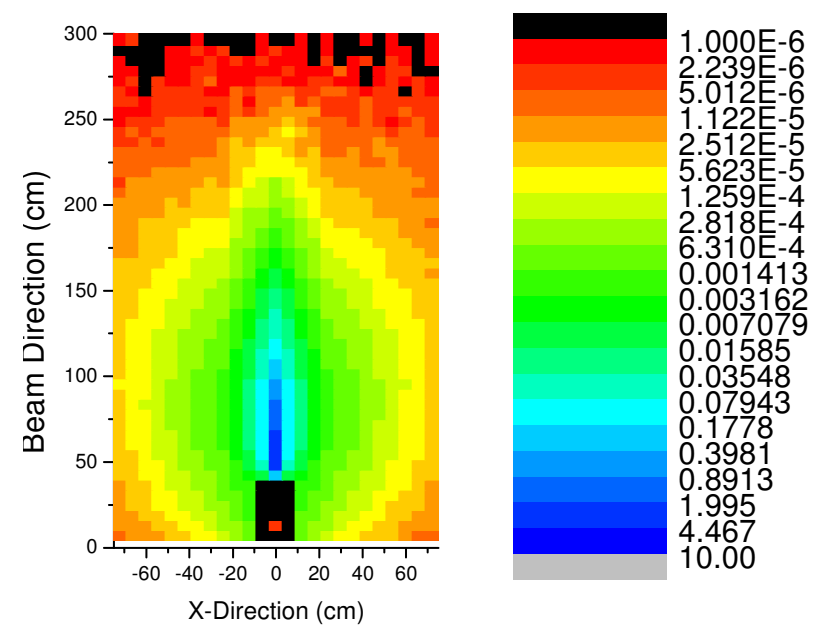

Figure 11. Total heating deposition on the horizontal plane leveled with the beam centerline. The unit is MeV/gram per proton beam. 


\section{Conclusions}

Based on the analysis performed, the conclusion is that the major and principal contributor for the activation of the accelerator hall is neutrons scattered back from the steel beam stop. The neutrons produced in the target in the backward direction will increase the neutron population, during irradiation, in the accelerator hall by roughly $50 \%$ what should not be a major impact in terms of activation of the accelerator hall. Furthermore, the irradiation campaign proposed will have $1.32 \mathrm{e}+11$ protons/second during 1 week; then representing a total number of protons $8.0 \mathrm{e}+16$ protons for the whole campaign. The MI- 8 absorber can take $6.8 \mathrm{e}+18$ protons per year, based on FNAL guidelines, which represents the ADESH limit due to ground water contamination. Then, this irradiation will take about $1.17 \%$ of the full year limit and even if fully charged for the additional $50 \%$ of neutrons in the accelerator hall due to the presence of the thorium target it would represent $1.76 \%$ of the year limit of the MI-8 absorber. However, the additional neutrons in the accelerator hall are mainly low energy neutrons when compared with the neutrons produced in the beam stop or in the forward direction at the target. This is due to the fact that the neutrons going into the accelerator hall are mainly produced in the backward direction and the momentum balance at the collision site, where they are produced, predicts a very low energy for such neutrons when compared with the forward ones. Then, as a conclusion those neutrons should not have a significant contribution for the ground water activation. Regarding the forward peaked component of the neutron and other particles production at the target, they will be more than one hundred times lower than the ones produced in the steel beam stop (based on the heat deposition on the target and on the steel beam stop), and as such should not add much to the ground water activation.

Regarding the other particles produced in the thorium target, the calculations estimate that none will have a significant impact on the activation of materials present in the accelerator hall.

Finally, it is safe to say that the irradiation of the thorium target will not add significant activation to the MI- 8 absorber structure and surroundings. 


\section{PART III - Heating Issues}

\section{Introduction}

The same assumptions as the previous sections was adopted for this set of calculation, namely, $1.32 \times 10^{11} \mathrm{p} / \mathrm{s}, 8 \mathrm{GeV}$ protons, $2 \times 1 \times 1 \mathrm{~cm}^{3}$ thorium full density target.

\section{General Assumptions}

The sample is irradiated for the full time during one week with an average beam intensity of $1.32 \times 10^{11}$ protons/second and processed 10 days after irradiation ends.

The geometry configuration used to simulate the thorium target was a block with external dimensions of $2 \times 1 \times 1 \mathrm{~cm}^{3}$.

The third dimension of the block is the direction of the beam; then the beam crosses, in the model, $1 \mathrm{~cm}$ of thorium target. The range of an $8 \mathrm{GeV}$ proton in thorium is about $5.72 \mathrm{~m}$, indicating that only a very small amount of the beam energy will be deposited in the thorium target.

The beam stop is represented in the geometry despite having relatively small influence on the results, increasing computer time, and worsening statistics but it was used anyway in the MCNPX simulations because the code can handle this type of calculation easily.

\section{Results}

The transport calculation was performed with the MCNPX code. The FLUKA code was also used to validate the results; several cases were run and the MCNPX/CINDER results compared with the FLUKA results. The comparison of the results was presented in the Preliminary Report I.

The calculated heating deposition due the interaction of the beam and all secondaries particles produced by the beam interaction with the target is calculated to be 1.0 watt. It is assumed that the target will have no other form of heat transfer but radiation. This is a conservative approach because the air convection around the sample is another heat transfer mechanism that is relevant beside conduction to the target holder and even enlargement of the radiation heat transfer area that the target holder may represent. To calculate the operating temperature to remove the calculated heating by radiation the following formula is used:

$$
\mathrm{R}=\mathrm{P} / \mathrm{A}=\varepsilon \sigma\left[\left(\mathrm{T}_{1}\right)^{4}-\left(\mathrm{T}_{2}\right)^{4}\right]
$$

Where:

$\mathrm{R}$ is the emitted heating by radiation; $\mathrm{P}$ is the power emitted; $\mathrm{A}$ is the area of the free surface for radiation heat transfer; $\varepsilon$ is the emissivity of the material; $\sigma$ is the Stefan-Boltzmann constant $\left(\sigma=5.67 \times 10^{-8} \mathrm{~W} /\left[\mathrm{m}^{2} \cdot \mathrm{K}^{4}\right]\right) ; \mathrm{T}_{1}$ is the temperature of the material; and $\mathrm{T}_{2}$ is the temperature of the environment.

In the thorium target irradiated at the booster line of the FNAL, the variables of equation (1) have the following values: 
$\mathrm{P}=1.0 \mathrm{~W}$

$\mathrm{A}=1 . \times 10^{-3}$ (the target has 4 surfaces with $2 \mathrm{~cm}^{2}$ and 2 with $1 \mathrm{~cm}^{2}$ ).

$\varepsilon$ is for thorium between 0.35 and $0.4^{9}$

$\mathrm{T}_{2}$ is assumed $300^{\circ} \mathrm{K}$

$\mathrm{T}_{1}$ is the unknown.

Then solving for $\mathrm{T}_{1}$, we have:

$1.0 / 1 . \times 10^{-3}=0.35 * 5.67 \times 10^{-8} *\left[\left(\mathrm{~T}_{1}\right)^{4}-8.1 \times 10^{9}\right]$;

Then;

$\mathrm{T}_{1}=\left[1.79 \times 10^{11}+8.1 \times 10^{9}\right]^{0.25}=491.78^{\circ} \mathrm{K}$

This indicates that the stead state temperature of the target to radiate $1.0 \mathrm{~W}$ is $\sim 219^{\circ} \mathrm{C}$ while the melting temperature of the thorium is $1750^{\circ} \mathrm{C}$. This calculated temperature is only for radiation heat transfer and it is an upper limit that will be reduced by free air convection and other potential heat transfer mechanisms to/by the sample holder. This temperature is showing that there is plenty of room to operate the target before it reaches near the melting point. Situations such as the beam collapsing to a small spot would not be enough to melt the target if corrective action is taken in seconds/minutes time, as shown below. Also, it is important to point out that the target can be covered with a thin foil of a metal with higher emissivity, or painted with carbon (AquaDag) what would reduce the operating temperature of the target (by example, an emissivity of 0.9 would result in an operating temperature of $407^{\circ} \mathrm{K}$ ). In any case, the temperature of the target is going to be low enough to prevent a high release rate of the radioactivity generated in the target, what is of importance to minimize the impact of the experiment on adding radioactivity to the irradiation position.

Another point if the pulse structure of the beam can have an important influence on the temperature. A simple way to check this is to calculate the time that will take to the target to hit the operating temperature and the temperature that the target had to rise to assimilate one pulse. The heat capacity of the thorium metal is equated as:

$$
\mathrm{C}_{\mathrm{p}}=24.905+4.049 \times 10^{-3} \mathrm{~T}+5.591 \times 10^{-6} \mathrm{~T}^{2} \mathrm{~J} / \mathrm{mol} . \mathrm{K}^{10}
$$

To find the time that $1.0 \mathrm{~W}$ would bring a $2 \mathrm{~cm}^{3}$ thorium block from $300^{\circ} \mathrm{K}$ to $491.59^{\circ} \mathrm{K}$ we use:

$\mathrm{Q}=\mathrm{m} \mathrm{C}_{\mathrm{p}} \Delta \mathrm{T}=(23 / 232.0381) * 28.14 * 192 .=610.85 \mathrm{~J}$

Where:

$\mathrm{m}=$ number of moles, the mass of the target is $23 \mathrm{~g}, 1 \mathrm{~mol}$ is 232.0381

$\mathrm{C}_{\mathrm{p}}$ is given above and assessed at $480^{\circ} \mathrm{K}$

$\Delta \mathrm{T}=(491.78-300)^{\mathrm{o}} \mathrm{K}$

To calculate the time, we use:

$\mathrm{t}=\mathrm{Q} / \mathrm{P}=610.85 / 1.0=610.85$ sec. $=10.18$ minutes.

\footnotetext{
${ }^{9}$ Use of Energy, Minerals and Changing Techniques by Kaulir Kisor Chatterjee

${ }^{10}$ Heat Capacity of Well-Characterized Thorium Metal from $298^{\circ} \mathrm{K}$ to $700^{\circ} \mathrm{K}$; Franklin L. Oetting and David T. Peterson
} 
This is the lowest time because it does not account for any heat transfer and all the energy is used to increase the target temperature. The result indicates that the target will reach operating temperature $\left(\sim 492^{\circ} \mathrm{K}\right)$ in more than 10 minutes.

Now, the temperature increase in one pulse would be:

$1.0=(23 / 232.0381) * 28.14 * \Delta \mathrm{T} \Rightarrow \Delta \mathrm{T}=0.36{ }^{\circ} \mathrm{K}$

This indicates that the ramp up of the temperature is slow.

Another topic of importance is the level of radiation stored in the target. Table 1 presents the fraction of DOE STD-1027-92 CAT-3 threshold after one week of irradiation of the thorium $\left(2 \times 1 \times 1 \mathrm{~cm}^{3}\right)$ target. This table shows how far from the DOE CAT-3 threshold is the hazard of the collective radioisotopes produced during irradiation at the time that vault is open. The results indicate that the CAT-3 fraction is very small and that there is plenty of room to have a much higher beam power and still having only to follow CAT-3 safety guidelines to transport and process the target. Attachment 4 contains a listing of radioisotopes attributed to the target, aluminum target stand, and copper target holder with their individual fraction of the CAT-3 limit.

Table 1. Fraction of DOE STD-1027-92 CAT-3 threshold for a $2 \times 1 \times 1 \mathrm{~cm}^{3}$ irradiated.

\begin{tabular}{|c|c|c|c|}
\hline & After 7 days of Irradiation & 10 days after the EOI & 30 days after the EOI \\
\hline $2 \times 1 \times 1 \mathrm{~cm}^{3}$ Target & $1.43 \times 10^{-03}$ & $5.43 \times 10^{-04}$ & $2.11 \times 10^{-04}$ \\
\hline
\end{tabular}

\section{Conclusions}

The irradiation of thorium targets in the booster beam line of the FNAL seems to be highly feasible. The results presented were based on MCNPX/CINDER calculations with validation of the FLUKA code and results agreed within a $20 \%$ range.

The operating temperature of the target is expected to be $219^{\circ} \mathrm{C}$ during the irradiation not causing any problem of melting the target.

The activity calculated indicates that a much more powerful proton beam can be used without making the target to reach the CAT-3 limits. The beam power can be about 700 times higher for the small target $2 \times 1 \times 1 \mathrm{~cm}^{3}$ without reaching the CAT-3 limits, what represents a promising future for this production technique. 


\section{Attachment 4}

\section{Radioisotope Inventory as a Fraction of DOT CAT 3 Limits $^{11}$}

${ }^{11}$ LA-12981-MS, "Table of DOE-STD-1027-92 Hazard Category 3", Threshold Quantities for ICRP-30 List of 757 Radionuclides" August 1995 


\section{Radioisotopes attributed to the Thorium target:}

Note these isotopes represent $93.7 \%$ at shutdown and $95.8 \%$ at 10 days after shutdown of the total fraction to the DOE CAT-3 limit, and the remaining are dispersed in hundreds of isotopes with very small fractions. Following is the list of the 20 most hazard isotopes attributed to the target:

$\begin{array}{lrr} & \text { EOI } & \text { 10 days } \\ \text { I-131 } & 6.21 \mathrm{E}-04 & 2.69 \mathrm{E}-04 \\ \text { Rn-220 } & 3.01 \mathrm{E}-04 & 6.18 \mathrm{E}-05 \\ \text { I } 133 & 9.39 \mathrm{E}-05 & 3.21 \mathrm{E}-08 \\ \mathrm{I}-126 & 7.72 \mathrm{E}-05 & 4.53 \mathrm{E}-05 \\ \mathrm{I}-124 & 4.69 \mathrm{E}-05 & 8.94 \mathrm{E}-06 \\ \mathrm{I}-125 & 4.28 \mathrm{E}-05 & 4.05 \mathrm{E}-05 \\ \text { Th-228 } & 3.33 \mathrm{E}-05 & 3.35 \mathrm{E}-05 \\ \text { Th-232 } & 2.47 \mathrm{E}-05 & 2.47 \mathrm{E}-05 \\ \text { Ac-227 } & 1.69 \mathrm{E}-05 & 1.69 \mathrm{E}-05 \\ \text { Lu170 } & 1.19 \mathrm{E}-05 & 5.11 \mathrm{E}-07 \\ \text { Lu169 } & 1.18 \mathrm{E}-05 & 8.95 \mathrm{E}-08 \\ \text { Yb166 } & 1.07 \mathrm{E}-05 & 5.71 \mathrm{E}-07 \\ \text { Th227 } & 1.04 \mathrm{E}-05 & 7.21 \mathrm{E}-06 \\ \text { Ac225 } & 1.03 \mathrm{E}-05 & 5.86 \mathrm{E}-06 \\ \text { Tm166 } & 1.01 \mathrm{E}-05 & 6.03 \mathrm{E}-07 \\ \text { Br 82 } & 4.60 \mathrm{E}-06 & 4.13 \mathrm{E}-08 \\ \text { Kr 88 } & 4.46 \mathrm{E}-06 & 7.61 \mathrm{E}-25 \\ \text { Po210 } & 3.92 \mathrm{E}-06 & 4.52 \mathrm{E}-06 \\ \text { I 135 } & 3.35 \mathrm{E}-06 & 3.38 \mathrm{E}-17 \\ \text { Tc 96 } & 3.25 \mathrm{E}-06 & 6.43 \mathrm{E}-07\end{array}$

Radioisotopes attributed to the aluminum ${ }^{12}$ stand at shutdown and 10 days post EOI:

\begin{tabular}{|c|c|c|}
\hline & EOI & 10 days \\
\hline $7 \mathrm{Be}$ & $7.95 \mathrm{E}-10$ & $6.98 \mathrm{E}-10$ \\
\hline $11 \mathrm{C}$ & 2.26E-09 & $2.14 \mathrm{E}-224$ \\
\hline $13 \mathrm{~N}$ & $4.71 \mathrm{E}-10$ & $0.00 \mathrm{E}+00$ \\
\hline 150 & 1.40E-09 & $0.00 \mathrm{E}+00$ \\
\hline $18 \mathrm{~F}$ & 1.44E-09 & $3.54 \mathrm{E}-49$ \\
\hline $22 \mathrm{Na}$ & 3.59E-09 & 3.57E-09 \\
\hline $24 \mathrm{Na}$ & 4.77E-07 & $7.28 \mathrm{E}-12$ \\
\hline $24 \mathrm{Ne}$ & $2.40 \mathrm{E}-10$ & $0.00 \mathrm{E}+00$ \\
\hline $27 \mathrm{Mg}$ & $2.68 \mathrm{E}-11$ & $0.00 \mathrm{E}+00$ \\
\hline
\end{tabular}

${ }^{12}$ J.B. Cumming, G. Friedlander, J. Hudis, and A.M. Poskanzer, Spallation of Aluminum by 28 GeV Protons, Phys. Rev. Vol. 127, No. 3, August 1, 1962, pp 950-954 
Radioisotopes attributed to the $\mathrm{Cu}^{13}$ target holder at shutdown and 10 days post EOI:

$\begin{array}{ccc} & & \text { EOI } \\ & & 10 \text { days } \\ 24 \mathrm{Na} & 8.61 \mathrm{E}-07 & 1.43 \mathrm{E}-11 \\ 28 \mathrm{Mg} & 9.01 \mathrm{E}-08 & 3.12 \mathrm{E}-11 \\ 42 \mathrm{~K} & 5.05 \mathrm{E}-08 & 7.21 \mathrm{E}-14 \\ 43 \mathrm{~K} & 1.29 \mathrm{E}-07 & 7.45 \mathrm{E}-11 \\ 43 \mathrm{Sc} & 5.12 \mathrm{E}-09 & 7.85 \mathrm{E}-28 \\ 44 \mathrm{Sc} & 1.17 \mathrm{E}-07 & 1.80 \mathrm{E}-26 \\ 44 \mathrm{mSc} & 1.90 \mathrm{E}-07 & 1.11 \mathrm{E}-08 \\ 46 \mathrm{Sc} & 7.48 \mathrm{E}-08 & 6.88 \mathrm{E}-08 \\ 47 \mathrm{Sc} & 2.08 \mathrm{E}-08 & 2.74 \mathrm{E}-09 \\ 48 \mathrm{Sc} & 1.65 \mathrm{E}-07 & 3.66 \mathrm{E}-09 \\ 48 \mathrm{~V} & 4.13 \mathrm{E}-07 & 2.68 \mathrm{E}-07 \\ 48 \mathrm{Cr} & 9.70 \mathrm{E}-09 & 7.10 \mathrm{E}-12 \\ 51 \mathrm{Cr} & 1.01 \mathrm{E}-08 & 7.88 \mathrm{E}-09 \\ 52 \mathrm{Mn} & 7.59 \mathrm{E}-07 & 2.20 \mathrm{E}-07 \\ 54 \mathrm{Mn} & 1.80 \mathrm{E}-08 & 1.76 \mathrm{E}-08 \\ 56 \mathrm{Mn} & 8.38 \mathrm{E}-08 & 3.60 \mathrm{E}-35 \\ 52 \mathrm{Fe} & 1.23 \mathrm{E}-08 & 1.72 \mathrm{E}-17 \\ 59 \mathrm{Fe} & 1.62 \mathrm{E}-08 & 1.39 \mathrm{E}-08 \\ 55 \mathrm{Co} & 5.88 \mathrm{E}-08 & 4.42 \mathrm{E}-12 \\ 56 \mathrm{Co} & 1.49 \mathrm{E}-07 & 1.36 \mathrm{E}-07 \\ 57 \mathrm{Co} & 4.02 \mathrm{E}-09 & 3.92 \mathrm{E}-09 \\ 58 \mathrm{Co} & 1.33 \mathrm{E}-07 & 1.21 \mathrm{E}-07 \\ 60 \mathrm{Co} & 7.00 \mathrm{E}-09 & 6.98 \mathrm{E}-09 \\ 56 \mathrm{Ni} & 1.19 \mathrm{E}-08 & 3.83 \mathrm{E}-09 \\ 57 \mathrm{Ni} & 7.51 \mathrm{E}-08 & 7.40 \mathrm{E}-10\end{array}$

${ }^{13}$ P. Kozma and J. Kliman, SPALLATION OF COPPER BY 9 GeV/c PROTONS AND DEUTERONS, Czech. J. Phys. B 38 (1988) 